\title{
Forest Regeneration: Perceptions of Natural Resource Professionals in West Virginia
}

\author{
Ellen Lee Voss \\ West Virginia University
}

Follow this and additional works at: https://researchrepository.wvu.edu/etd

\section{Recommended Citation}

Voss, Ellen Lee, "Forest Regeneration: Perceptions of Natural Resource Professionals in West Virginia" (2012). Graduate Theses, Dissertations, and Problem Reports. 4933.

https://researchrepository.wvu.edu/etd/4933

This Thesis is protected by copyright and/or related rights. It has been brought to you by the The Research Repository @ WVU with permission from the rights-holder(s). You are free to use this Thesis in any way that is permitted by the copyright and related rights legislation that applies to your use. For other uses you must obtain permission from the rights-holder(s) directly, unless additional rights are indicated by a Creative Commons license in the record and/ or on the work itself. This Thesis has been accepted for inclusion in WVU Graduate Theses, Dissertations, and Problem Reports collection by an authorized administrator of The Research Repository @ WVU. For more information, please contact researchrepository@mail.wvu.edu. 


\title{
Forest Regeneration:
}

\section{Perceptions of Natural Resource Professionals in West Virginia}

\author{
Ellen Lee Voss
}

\begin{abstract}
Thesis submitted to the
Davis College of Agriculture, Natural Resources, and Design

at West Virginia University

in partial fulfillment of the requirements for the degree of

Master of Science

in

Forestry
\end{abstract}
David W. McGill, Ph.D., Chair
Kathryn G. Arano, Ph.D.
Michael P. Strager, Ph.D.

Division of Forestry

Morgantown, West Virginia

2012

Keywords: natural hardwood regeneration, central Appalachians 


\section{ABSTRACT \\ Forest Regeneration: \\ Perceptions of Natural Resource Professionals in West Virginia}

Ellen Lee Voss

It has generally been assumed that natural hardwood regeneration in West Virginia after a timber harvest or other disturbance will be abundant and successful. However, changes that are being observed in the seedling and sapling components of forest stands suggest that problems may exist with regeneration of desirable species. Factors affecting regeneration have been the topic of conversation among foresters and other natural resource professionals for years. To address the need for more information about this issue, we conducted a mail survey of natural resource professionals (NRPs) in West Virginia. The objectives of the survey were to determine how they perceive the quality of regeneration, their level of satisfaction with regeneration, the types of concerns they have, and the locations and spatial variability of their regeneration concerns. Almost half (49\%) of 261 respondents reported they were dissatisfied with the regeneration they had observed. Eighty-nine percent had at least one concern, while $40 \%$ had three concerns. For two-thirds (66\%) of NRPs, the trees they would like to see regenerate did not correspond to the trees they observed to actually regenerate most abundantly. In general, satisfaction with regeneration was highest in the southwestern, southern, and southeastern parts of the state. 


\section{DEDICATION}

For Trixie, my bright spirit 


\section{ACKNOWLEDGEMENTS}

Thanks to my advisor, Dr. Dave McGill, and to committee members Dr. Kathryn Arano and Dr. Michael Strager.

Thanks to Steve Harouff for assistance with mapping, and to Dr. Harry Boone for assistance with issues of nonresponse bias.

Thanks to Meg McCuen, my officemate, for lending her presence to the questionnaire cover and for being such a good sport in general.

Thanks to AHC suitemate, Dan Magill, for cheering me on.

Thanks to the Pilot Survey participants: Juergen Wildman, Bill Gillespie, Stuart Moss,

John Bell, Bob Radspinner, Barbara Breshock, Chris Ryan, Mike Strager, and Gary Foster.

Thanks to my parents and friends for their encouragement and support. 


\section{TABLE OF CONTENTS}

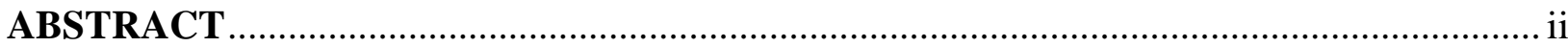

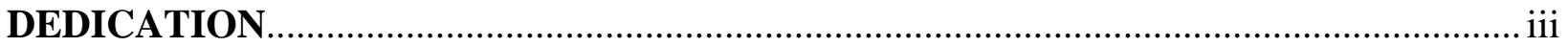

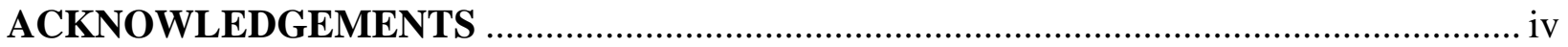

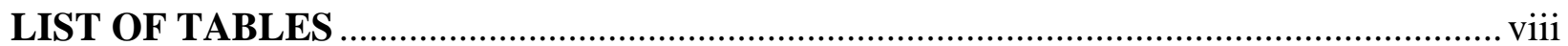

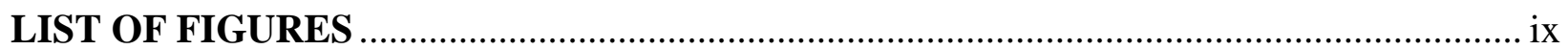

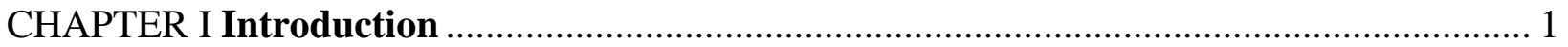

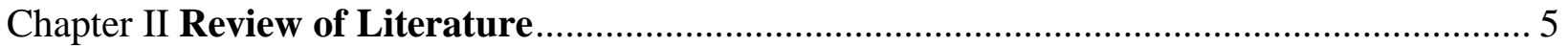

Nature of regeneration in West Virginia.................................................................... 5

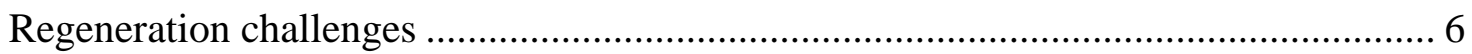

Changing species composition and oak regeneration ................................................. 6

Timber harvesting practices ............................................................................... 9

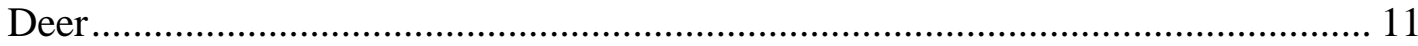

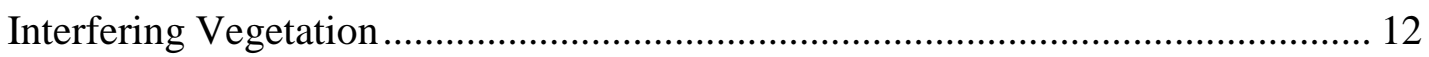

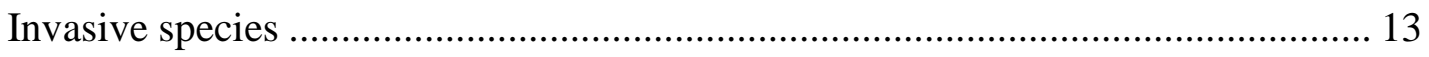

Tools for assessing regeneration ............................................................................ 14

Policies to ensure adequate regeneration ..................................................................... 17

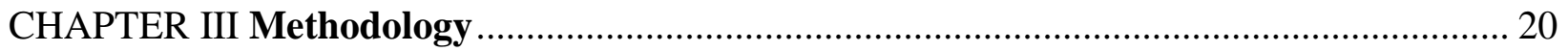

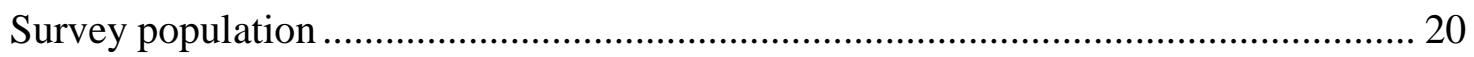

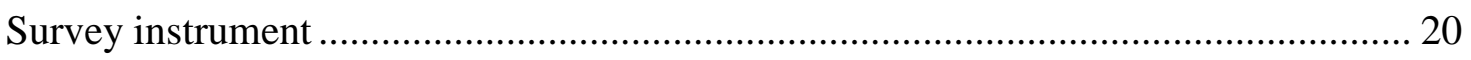


Survey delivery

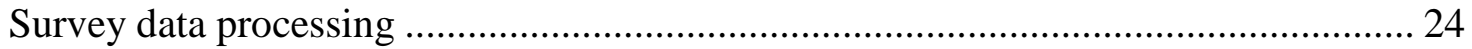

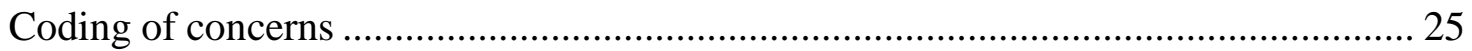

Relative importance of concerns..................................................................... 27

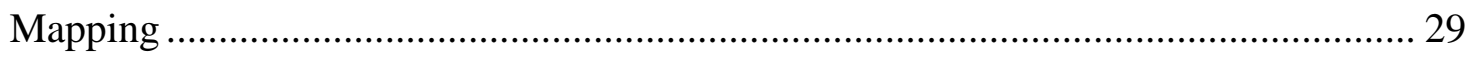

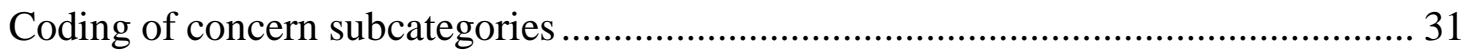

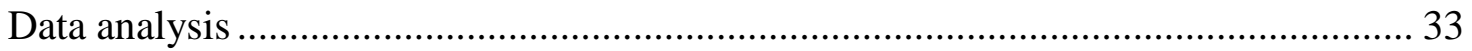

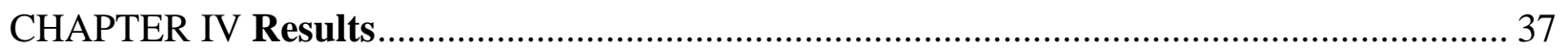

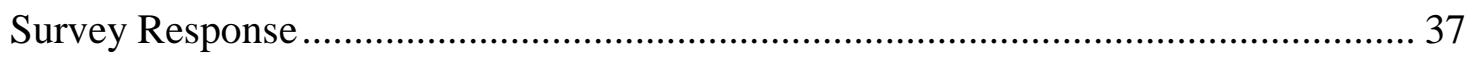

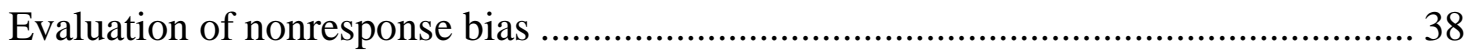

Experience and background of natural resource professionals .................................. 39

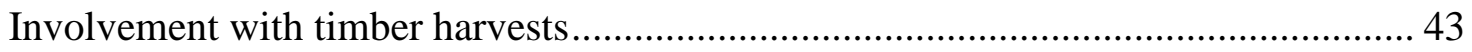

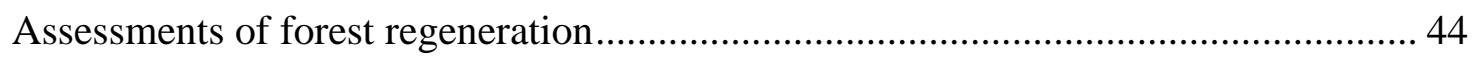

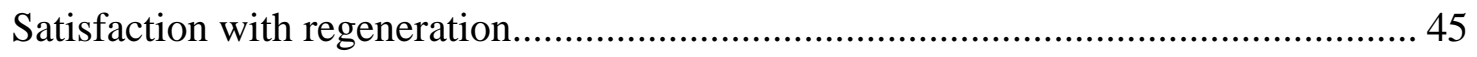

Factors affecting satisfaction with regeneration ............................................... 48

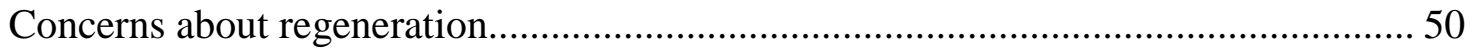

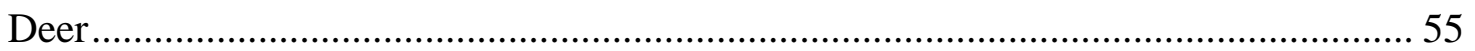

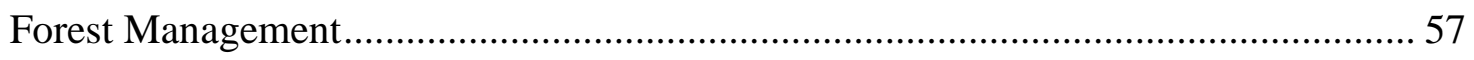

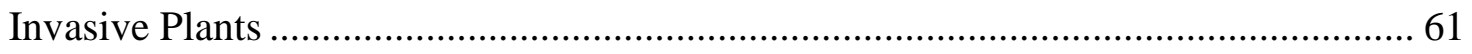

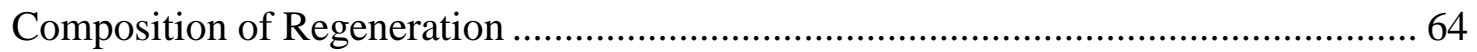




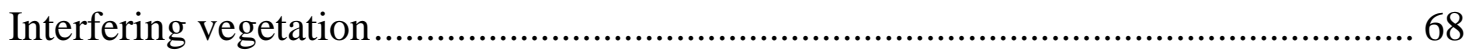

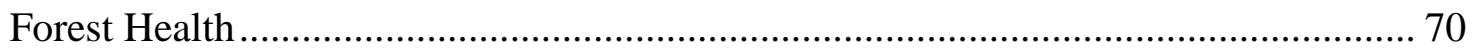

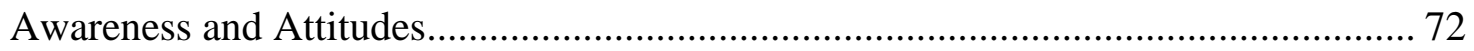

Mining and Mineral Development..................................................................... 74

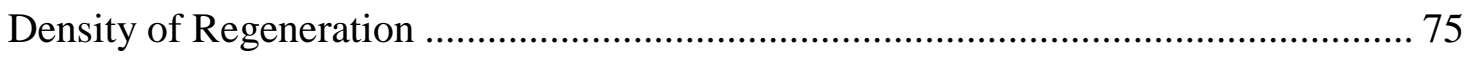

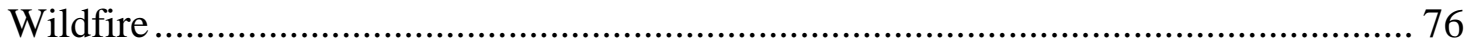

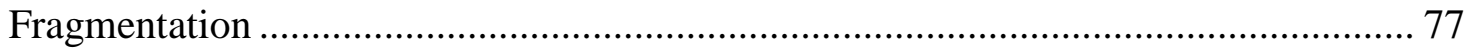

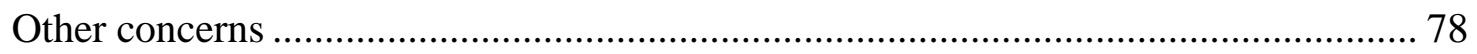

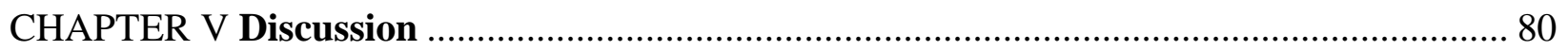

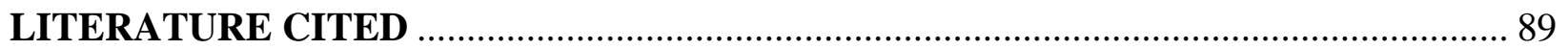

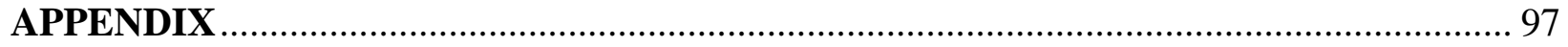

Survey Notifications and Questionnaire ....................................................... 97 


\section{LIST OF TABLES}

Table 1. Eleven independent variables used to explore factors associated with a respondent's

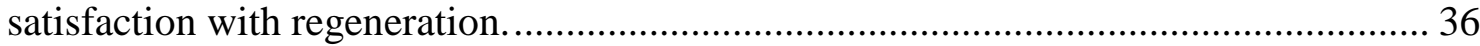

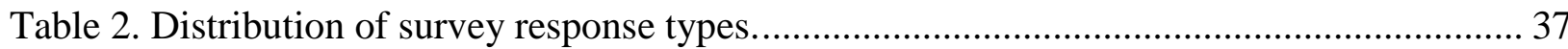

Table 3. Distribution of specialty, employment category, and employment sector. .................. 40

Table 4. Number of respondents by employment category and natural resource specialty. ........ 41

Table 5. Involvement of survey respondents with forestry-related activities.......................... 43

Table 6. Types of regeneration assessments done by survey respondents. ............................. 45

Table 7. Independent variables used in logistic regression to explore their association with a

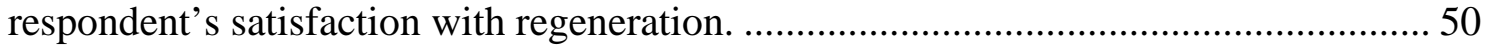

Table 8. Twelve main categories of concerns about forest regeneration.................................. 54

Table 9. Distribution of respondents' concerns related to impacts of deer on regeneration. ....... 55

Table 10. Distribution of respondents’ concerns related to forest management......................... 59

Table 11. Distribution of respondents’ concerns related to invasive plants. ............................ 62

Table 12. Distribution of respondents’ concerns related to composition of regeneration............ 66

Table 13. Distribution of respondents’ concerns related to interfering vegetation..................... 69

Table 14. Distribution of concerns related to forest health................................................... 71 


\section{LIST OF FIGURES}

Figure 1. Distribution of the number of observations about forest regeneration made by survey respondents in each county.

Figure 2. Distribution of the number of observations about forest regeneration made by survey respondents in each county.

Figure 3. Distribution of timber harvest involvement among survey respondents....

Figure 4: Distribution of respondents' satisfaction with regeneration on a scale ranging from "completely dissatisfied" to "completely satisfied."

Figure 5. Number of natural resource professionals observing successful regeneration in each county.

Figure 6. Average level of satisfaction for respondents making observations within each county, based on a Likert scale of 1 to 4 ...... 47

Figure 7. Distribution of the number of concerns per survey respondent. ............................... 51

Figure 8. Number of regeneration concerns per county. The mean was 22 concerns................. 52

Figure 9. Ratio of concerns to observations for each county................................................. 53

Figure 10. Ranking of twelve categories of concerns about forest regeneration....................... 54

Figure 11. Relative importance of regeneration concerns related to deer. ................................ 56

Figure 12. Relative importance of deer concerns mapped using an interpolation tool to emphasize

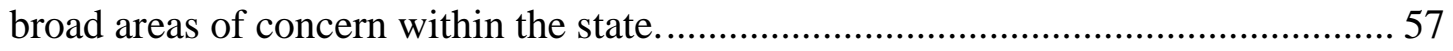

Figure 13. Relative importance of forest management concerns.......................................... 60

Figure 14. Forest management concerns mapped using an interpolation tool to emphasize broad

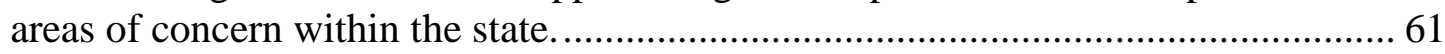

Figure 15. Relative importance of invasive plants............................................................ 63

Figure 16. Invasive plant concerns mapped using an interpolation tool to emphasize broad areas of concern within the state. 64

Figure 17. Relative importance of concerns about composition of regeneration.

Figure 18. Concerns about composition of regeneration mapped using an interpolation tool to emphasize broad areas of concern within the state.

Figure 19. Relative importance of concerns about interfering vegetation. 70 
Figure 20. Relative importance of concerns about forest health.

Figure 21. Relative importance of concerns about attitudes.............................................. 73

Figure 22. Relative importance of concerns about mineral development. ................................ 74

Figure 23. Relative importance of concerns about regeneration density................................. 75

Figure 24. Relative importance of concerns about wildfire............................................... 76

Figure 25. Relative importance of concerns about fragmentation......................................... 77

Figure 26. Relative importance of other concerns about regeneration. .................................... 79

Figure 27: Percent of public and private employees who were dissatisfied and satisfied with

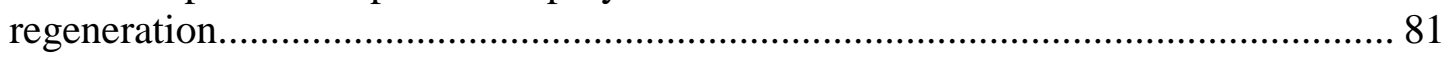




\section{CHAPTER I}

\section{Introduction}

Most forest land in West Virginia is either moderately or fully stocked with commercially important tree species. In fact, the latest Forest Service inventory found the volume of growing stock to be the highest in recorded history, and tree growth exceeded tree removal by a nearly two-to-one ratio (Widmann et al. 2012). In the 2001 statewide forest inventory, West Virginia had the second-highest volume of hardwood growing stock in the United States (Widmann et al. 2007). The amount of forest land has remained stable over the last ten years.

However, changes in species composition and age structure are occurring that could dramatically alter the quality of future forests. Summarizing Forest Inventory and Analysis data from the 2008 inventory cycle, Research Scientist Rich Widmann pointed out the following:

The sapling/seedling size class has decreased significantly since 1961, which could have some implications for future forest management and regeneration activities (Widmann et al. 2012).

Regeneration is one of the most fundamental components of forest management, because it allows us to define forests as a renewable resource. It has generally been assumed that natural hardwood regeneration after a timber harvest or other disturbance will be abundant and successful (WV Forest Practice Standards 1972). How do we know whether or not we have adequate regeneration in West Virginia?

Over 60 years ago, the United States Forest Service Inventory and Analysis program (FIA) established permanent inventory plots and conducted the first statewide inventory of forests in West Virginia (Widmann et al. 2012). The FIA program cooperates with the West Virginia Division of Forestry and landowners to conduct a complete inventory of plots every 5 to 
7 years. Each plot represents about 6,000 acres. Regeneration data is obtained by counting live seedlings and saplings within a 6.8-foot radius microplot nested within each of four 24-foot radius subplots. Hardwood seedlings over one foot tall and up to one inch in diameter are tallied, as well as saplings between one and 5 inches in diameter (USDA Forest Service 2010).

Changes that are being observed in the seedling and sapling components of forest stands suggest that problems may exist with regeneration of desirable species. Overall, there has been a decline in the number of seedlings and saplings; sapling/seedling stands now represent 7 percent of timberland. When compared to its five surrounding states, West Virginia has the lowest percentage of timberland in the sapling/seedling stand-size class (Widmann et al. 2012).

Species composition of small-diameter trees is much different than that of large-diameter trees. There have been large increases in the numbers of red maple, beech, and other low-value saplings, and large decreases in the numbers of saplings of oak and other species important for their commercial or wildlife value. Red maple is now the most numerous sapling, followed by sugar maple, beech, and blackgum.

In 2001, because of concerns in Pennsylvania, the Pennsylvania Bureau of Forestry cooperated with the Forest Service's FIA program to begin an intensive landscape-scale study of regeneration. The Pennsylvania Regeneration Study added measurements of all tree seedlings up to one inch in diameter as well as related understory vegetation to standard FIA inventory plot measurements. The range of results for successful regeneration of commercial species was from 50 percent to 64 percent (McWilliams et al. 2004).

In New York, The Nature Conservancy analyzed FIA plot data from the 2002-2006 inventory cycle to calculate a Forest Regeneration Index for each plot. They found that 57 
percent of FIA plots in New York had poor or fair regeneration of timber species, and 32 percent of plots had poor or fair regeneration of native canopy trees (Shirer and Zimmerman 2010).

In 2008 the West Virginia Forest Management Review Commission, an advisory committee created by the state legislature, directed the WV Division of Forestry (DOF) to complete a new strategic plan for forestry in West Virginia and requested that the agency address the topic of forest regeneration. In conducting the statewide forest resources assessment that formed the basis for planning, information about the causes and locations of forest regeneration problems was found to be a significant data gap (West Virginia Division of Forestry 2010). The strategic plan established forest regeneration as Sub-Issue 3.4 and mandated that the DOF work to "identify, understand, and resolve the forest regeneration issues in the state," with the goal of achieving adequate regeneration of desirable species.

The strategic plan states that most of the knowledge about forest regeneration problems in West Virginia is anecdotal in nature. Foresters and other natural resource professionals are working in the field, making observations and formulating opinions. For years, they have been commenting on changes they are observing in the quality of regeneration. This topic is brought up frequently at professional meetings as well as informal walks in the woods. Factors affecting regeneration—including over-browsing by deer, repeated wildfires, cutting practices, and competition from non-native invasive plants and interfering vegetation—have been the topic of conversation among professionals for years. To address the need for more information about this issue, we conducted a mail survey of natural resource professionals in West Virginia. The objectives of the survey were to determine how natural resource professionals perceive the quality of regeneration, their level of satisfaction with regeneration, the types of concerns they have, and the locations and spatial variability of their regeneration concerns. As stated in the WV 
Statewide Forest Resource Strategy, "all sectors of the forestry, wildlife, and natural resource communities are stakeholders in this effort. It will require the full range of expertise and funding to fully understand and resolve this issue” (West Virginia Division of Forestry 2010). 
Chapter II

\section{Review of Literature}

\section{Nature of regeneration in West Virginia}

West Virginia's forests are diverse, growing at a range in elevation of over 4,600 feet and spanning five ecoregions (Bailey 1995). The 2008 forest inventory identified 109 tree species, 46 forest types, and 13 forest-type groups in West Virginia (Widmann et al. 2012). Oak/hickory forests are most important, comprising 73 percent of forest land, while maple/beech/birch forests comprise 17.5 percent. Less prevalent forest-type groups include oak/pine, Virginia/pitch pine, elm/ash/cottonwood, white pine/hemlock, and spruce/fir (Widmann et al. 2012).

Silviculture in West Virginia and the Central Appalachians relies for the most part on natural hardwood regeneration, which is usually abundant and well-distributed after both clearcutting and partial cutting (Hicks 1998, Miller et al. 2001). Regeneration occurs from advance seedlings that were established before the harvest, new seedlings that develop from seeds stored in the forest floor, and sprouts from the stumps of cut trees or wounded roots (Beck 1988). For oak stand replacement, advanced regeneration and sprouting are most important (Loftis 1993).

In West Virginia, research has focused on artificial regeneration to establish valuable hardwood species such as northern red oak following timber harvests (Smith 1993, Kochenderfer et al. 2006, Schuler and Miller 1996) and to restore disturbed areas such as surface mines (Emerson et al. 2009). However, the cost-effectiveness and cultural challenges of regenerating slow-growing species such as oaks can be obstacles to artificial regeneration (Davidson 1988). Most research has focused on the use of various silvicultural manipulations in order to obtain 
desirable natural hardwood regeneration (Smith and Miller 1987). Partial cutting practices favor the reproduction of a few shade-tolerant species, while clearcutting favors the reproduction of numerous species that differ in shade tolerance (Schuler 2004, Miller and Kochenderfer 1998). Composition of regeneration will also depend on the abundance of advance reproduction, site quality, and the influence of factors such as deer, insects, disease, and interfering vegetation (Marquis and Brenneman 1981).

\section{Regeneration challenges}

A common sentiment expressed in regard to natural hardwood regeneration in West Virginia is that "Given a chance to grow, trees re-establish themselves fairly quickly in most areas of the state," (Widmann et al. 2007) and "New trees of some commercial species almost always naturally follow the harvest cut,” (WV Forest Practice Standards Committee 1972). Abundant regeneration of hardwood trees that are desirable for timber or wildlife is less certain.

\section{Changing species composition and oak regeneration}

The latest forest inventory data show that oaks represent more than 45 percent of trees 20 inches and above in diameter, but only eight percent of trees less than ten inches in diameter. A lack of oaks in the small-diameter classes means that as large oaks are harvested or die, they are being replaced by species such as red maple and sugar maple (Widmann et al. 2012).

Concerns about adequate oak regeneration in West Virginia have existed since at least the mid-1950s (Clark 1992). Regeneration of oaks, especially northern red oak, on moderate to highquality sites in the central Appalachians has been recognized as a problem for many years (Carvell and Tryon 1961, Loftis 2004, Schuler 2004, Schuler and Miller 1995). On the best sites, oak regeneration has more competition from herbaceous vegetation, ferns, and faster-growing shade-intolerant seedlings (Carvell and Tryon 1961). In studies of mixed-oak stands in West 
Virginia and western Maryland, Weitzman and Trimble (1957) found a strong correlation between site index and abundance of northern red oak regeneration; regeneration on mesic sites was not as abundant as on poorer sites. Carvell and Tryon (1961) found that stand history and degree of disturbance was found to be very closely correlated with the amount of oak regeneration. Stands that had been thinned, grazed, or lightly burned during the past 20 years generally possessed a greater reservoir of oak regeneration than undisturbed stands. The authors attributed this increase in advanced regeneration to a continuous supply of light that reached the forest floor due to repeated disturbances. Most oak species are adapted to survive on nutrientpoor sites and to survive periodic fire and drought. However, one type of ecological stress for which oaks are not well-adapted is low light (Abrams 1992).

Under conditions that include periodic fires, succession in oak forests is kept in check, because later successional species such as red maple and sugar maple have low resistance to fire (Abrams 1992). Under conditions where large-scale disturbances from fire or logging are minimal, oak species are expected to decline in importance. McEwan et al. (2011) found an association between regeneration failure in oaks and changing populations of wildlife species such as deer and turkey. "These wildlife species were uncommon during the early 1900s when oak forests were initiating across much of the region. The absence of these seedling browsers and seed predators could have facilitated oak regeneration.” In the mid-to-late 1900s, when oak regeneration problems began, population numbers of deer, turkey, and other seed predators were rapidly increasing (McEwan et al. 2011). Acorn weevils and acorn moths are also important acorn predators, and have been shown to affect oak regeneration in central Pennsylvania oak stands (Galford et al. 1991). 
Long-term silvicultural trials in mixed mesophytic stands at the Fernow Experimental Forest showed that in unmanaged control stands, the diversity of trees declined over 50 years as shade-tolerant species increased in density (Schuler 2004). Northern red oak and chestnut oak were initially the most abundant species, while sugar maple and red maple were most abundant at the end of the study period. These shifts in species composition corroborate local and regional forest trends.

Collins and Carson (2004) observed 21 forest stands in the Monongahela National Forest and hypothesized that forest stands dominated by mature oaks today may be artifacts of site conditions that favored saplings 100 years ago. Adult oaks may be abundant in some areas due to logging and burning during the stand initiation stage, and not because of favorable site characteristics. According to Nowacki and Abrams (1992), disturbance of the overstory can accelerate the conversion to mesophytic hardwoods on any landscape where a mesophytic understory is present. Tift and Fajvan (1999) observed Appalachian hardwood stands in the West Virginia University Forest and concluded that red maple dominance may be accelerated by harvesting practices that focus only on the removal of mature overstory trees.

Miller et al. (2001) studied regeneration in 26 clearcuts on the Monongahela National Forest and found that in general, species composition of young clearcuts was similar to overstory species in adjacent mature stands. However, there were some exceptions. In some cases, although red oak and black cherry dominated the overstory of a mature stand, regeneration in the adjacent clearcut was dominated by sugar maple and red maple. In other clearcuts, the expected proportion of red oak and chestnut oak regeneration was reduced and partially displaced by black cherry and yellow poplar (Miller et al. 2001). 


\section{Timber harvesting practices}

Timber harvest practices such as diameter-limit and single tree-selection harvests have favored the decline of oaks and have decreased the diversity of forest stands in West Virginia (Schuler 2004). Diameter-limit cutting is the practice of removing all trees larger than a selected size, usually the minimum sawlog diameter (Kenefic and Nyland 2005).

Diameter-limit harvests leave stands that contain mostly saplings, poles, and other trees of low value; new trees usually regenerate, but they are not always of desirable species or in sufficient numbers to adequately occupy the stand (Kenefic and Nyland 2005). The practice of diameter-limit cutting is a widespread problem, and has been characterized as "the second great exploitation of the eastern hardwood forest,” (Nyland 1992).

Current FIA inventory data (2010) shows that the percentage of poorly-stocked stands in West Virginia has increased nearly 30 percent since 1989; 17 percent of timberland is now poorly stocked with commercially important species. Because of their age and stand size, it can be assumed that many poorly stocked stands have originated from poor harvesting practices (Widmann et al. 2012). Diameter-limit harvesting is the most common form of timber harvesting in West Virginia (Fajvan et al. 1998). From a study of 99 harvested stands on nonindustrial private forest land across the state, Fajvan et al. (1998) found that more than 80 percent of harvests were some form of diameter-limit cut. They concluded that the focus of timber harvests in West Virginia during 1993-94 was on the extraction of sawtimber-sized trees of the most commercially desirable species. They observed concentrated harvesting of valuable species, especially oaks and yellow poplar. The use of silvicultural treatments was rare (Fajvan et al. 1998). 
Perkey and Powell (1988) commented on the lack of landowner education regarding forest regeneration practices. In a 1978 woodland owner survey, 76 percent of landowners in West Virginia responded “True” or “Don’t Know” when shown the statement "Selective cutting is always good forestry." When shown a related statement, "Clearcutting is always bad forestry," 63 percent of landowners agreed or did not know (Birch and Kingsley 1978). A survey of Tree Farmers in West Virginia found that even among a group of landowners who are predisposed to forest management, 55\% responded that clearcutting should be banned (Egan et al. 1997). If landowners believe a cutting practice is bad, they are less likely to use it (Perkey and Powell 1988).

However, the use of even-aged harvest methods such as clearcuts and shelterwood treatments may not be sufficient to regenerate oaks on mesic sites. A ten-year of study of various shelterwood treatments on the Fernow Experimental Forest in north-central West Virginia showed that overstory treatments stimulated abundant black birch regeneration, reducing the chances of establishing oak (Schuler and Miller 1995). In a study of regeneration in 20 stands on the Monongahela National Forest that had received a shelterwood cut 2 to 5 growing seasons prior to measurement, Johnson et al. (1998) concluded that regeneration stocking of desirable species was relatively low for beech-cherry-maple and Appalachian hardwood stands, and lowest in mixed oak stands.

An FIA landowner survey conducted in 2006 found that only 2 percent of non-industrial private forest landowners in West Virginia had a written management plan; only 5 percent had sought forest management advice; and timber production ranked low in importance as a reason for owning forest land (Butler 2008). However, the relatively high number of landowners who 
harvest timber indicates that most timber harvests are not part of a long-term management plan (Widmann et al. 2007).

Deer

The Forest Service acknowledges that white-tail deer overabundance has become a serious forest health issue (USDA Forest Service 2003). Over-browsing by deer in areas of West Virginia with high deer populations can be a serious hindrance to natural hardwood regeneration (WV Division of Forestry 2010). In Allegheny hardwood stands in northwestern Pennsylvania, deer populations in excess of 20 deer per square mile are likely to have negative impacts on regeneration and overbrowsing has been shown to be a major cause of regeneration failures (Horsley et al. 2003). Marquis and Brenneman (1981) found that 62 percent of clearcuts on the Allegheny National Forest were not stocked adequately with preferred species. At least 87 percent of inadequately stocked clearcuts had failed to regenerate because of deer browsing, since regeneration was satisfactory inside deer exclosures. Regeneration failures caused by deer on 35,000 acres of industrial forest in Michigan and Wisconsin has placed International Paper Company’s certification under the Sustainable Forestry Initiative Standard at risk (Donovan 2005).

The extent of damage to forest regeneration by deer in West Virginia has been and continues to be a widely debated issue (Office of Legislative Auditor 1995, West Virginia Legislative Auditor 2011). In regenerating clearcuts in Allegheny hardwood forests on private industrial property in West Virginia, deer density was estimated at between 5 and 6 deer/sq mi. Overall summer deer use of woody twigs was greater than $15 \%$ (Campbell et al. 2006). Future stands may include more beech, yellow-poplar, and red maple because of their high relative abundance and light browsing pressure. There was moderate-to-high relative browsing pressure 
on black cherry, which is traditionally considered low-preference deer forage. Researchers consider deer densities of between 2.3 to 3.1 deer/sq mi. to be a reasonable guideline for timber industry land in the central Appalachians of West Virginia (Campbell et al. 2006).

While deer can reduce the success of regeneration after a harvest, heavy browsing can make it difficult to obtain advanced regeneration of desirable species before harvesting. This may be of even greater importance to regeneration success (Michael 1988). Heavily browsed stands may have no desirable advance regeneration, or the understory may be dominated by undesirable plants such as ferns, grass, striped maple, or beech (Marquis and Brenneman 1981). Most oak species, including northern red oak, have seedlings with very slow juvenile growth rates (Lorimer 1993, Smith 1993); this increases their susceptibility to browsing damage over several growing seasons. In mixed-oak stands in central Pennsylvania, Yuska et al. (2008) have observed that the habitat for advance regeneration of oak has changed; they see the widespread emergence of a substantial mid-story population of red maple, which is less preferred as browse than oak. In fact, the mid-canopy and understory shade in the stands they studied arose almost entirely from species that are generally avoided by deer.

\section{Interfering Vegetation}

A variety of plants can interfere with natural hardwood regeneration, including ferns, grasses, beech and striped maple, rhododendron and mountain laurel, grapevines, and a shadetolerant understory composed of species such as sourwood, red maple, and blackgum (Horsley 1988). A dense understory of shade-tolerant species on mesic sites is a major limiting factor to oak seedlings and prevents adequate development of advanced oak regeneration by casting such a heavy shade that oak seedlings may die or not fully develop (Lorimer 1993). When tall understory saplings of competing shade-tolerant species were removed experimentally, there 
were 10 to 140 times as many oak seedlings on experimental plots as on undisturbed plots after five years (Lorimer et al. 1984).

Hayscented and New York ferns are avoided by deer and have become abundant in many areas in the northern mountains of West Virginia, where they form a dense ground cover that suppresses seedling establishment due to competition for light (Horsley 1993). Herbaceous species that form tall, dense populations (such as wood nettle and many nonnative invasive plant species) can inhibit desirable tree seedlings through competition for light or for soil nutrients (Gilliam 2007, Lyon and Sharpe 2003).

\section{Invasive species}

Natural regeneration is known to be affected by invading plant species that utilize various mechanisms to dominate understory environments and outcompete desired species for available resources (Stinson and others 2006). Many invasive plants appear to be resistant to deer herbivory, including Japanese stiltgrass, garlic mustard, Japanese barberry, multiflora rose, and tree-of-heaven (Rawinski 2008). Japanese stiltgrass is potentially the most problematic invasive plant in West Virginia because of its seed longevity, ease of dispersal, resistance to deer herbivory, and its ability to form monocultures under closed canopies (WV Division of Forestry 2010). After application of a grass-specific post-emergent herbicide to eliminate stiltgrass, Flory (2010) observed a two-fold increase in the number of tree seedlings that colonized experimental plots, which suggests that invasions of stiltgrass can suppress natural regeneration.

Whenever an opening is created by fire, timber harvesting, coal mining, oil and gas drilling, or road construction, invasive plants have a greater opportunity to become established (WV Division of Forestry 2010). Huebner and Tobin (2006) compared the occurrence of invasive plants on mature forest sites and on recent clearcuts in Tucker County, West Virginia 
and found that clearcuts contained more invasive species. Sites that were northeast-facing and the most mesic were most likely to be invaded. Forest clearcuts may temporarily reduce the abundance of dominant species that would normally competitively exclude other species, releasing niche space and increasing colonization rates of early-successional species and possibly exotics (Huebner and Tobin 2006). Oswalt et al. (2007) observed a dramatic increase in stiltgrass after overstory removal in a hardwood forest in Tennessee. Both the density and diversity of regeneration of native woody species declined with increasing stiltgrass cover (Oswalt et al. 2007).

In West Virginia, stocking levels have decreased since 2000 as acreage has shifted from fully stocked and overstocked stands to moderately and poorly stocked stands. Stands that are poorly stocked with trees are probably more susceptible to invasion by non-native species than fully stocked stands because of their more open growing conditions (Widmann et al. 2012).

\section{Tools for assessing regeneration}

A number of models and decision tools have been developed for use in predicting the success of natural hardwood regeneration after a timber harvest. These tools can be used by natural resource professionals to evaluate alternative management prescriptions before actual harvest and to increase the likelihood of getting adequate regeneration after a harvest. Regeneration predictions are based on an assessment of advance reproduction, overstory trees, and site factors.

Marquis et al. (1992) developed a decision tool called SILVAH based on the premise that species composition of advance regeneration largely determines the species composition of the next stand. The user inventories seedling advance reproduction, sprouting potential, sapling and pole advance regeneration, interfering understory plants, site limitations, and intensity of deer 
browsing; SILVAH uses this data to make predictions of regeneration success and to select appropriate silvicultural prescriptions for Allegheny and northern hardwood stands. Generally, if the SILVAH model predicts that 70 percent of inventory plots are stocked with desirable reproduction, successful regeneration is expected to occur. The SILVAH system has been widely used in northern hardwood stands in Pennsylvania to prescribe successful treatments in areas where deer browsing and other factors had previously prevented regeneration (Marquis et al. 1993).

In oak-dominated forests, the goal is generally to regenerate new stands with a large oak component. However, regeneration of oaks is not assured unless a high potential for oak regeneration is already in place (Sander et al. 1984). Many oak stands in the central Appalachians have low oak regeneration potentials (Steiner et al. 2008). Tools have been developed to help forest managers determine whether the current oak regeneration potential of a stand is adequate and to provide prescriptions to improve oak regeneration potential if it is insufficient. For mixed-oak stands, these tools generally use the size of advanced reproduction to predict the amount of oak that is expected in the next stand (Loftis 1993).

Sander et al. (1984) developed a regeneration model and guidelines for stands in the Missouri Ozarks where oak site index is 70 and below, using pre-harvest inventories of the overstory and advance reproduction as predictors. Using his model, only advance oak reproduction over $4.5 \mathrm{ft}$. in height will be competitive in the new stand, and a height of 6 to 8 feet is recommended before cutting (Sander 1972). In West Virginia, Carvell (1988) developed guidelines for making pre-harvest assessments that stress the importance of not only the size of advance oak regeneration, but also its vigor (Carvell 1988). 
Loftis (1990) used an approach similar to Sander to develop a regeneration model called REGEN for mixed hardwood forests in Southern Appalachia; the model predicts the likelihood of successfully regenerating red oak based on pre-harvest inventories of advance reproduction and site quality. Vickers et al. (2011) are working to extend the REGEN model to the Central Appalachians of Virginia and West Virginia. Their model can be used to predict the future species composition of stands regenerated using clearcuts on four site classes ranging from xeric to mesic.

In 2000, a group of collaborators from the US Forest Service, Pennsylvania Bureau of Forestry, Penn State University, and private industry began work on extending the SILVAH decision tool that had been applied successfully for Allegheny and northern hardwoods to mixedoak forests in the Mid-Atlantic region, including West Virginia (Brose et al. 2008). The SILVAH tool for oaks (SILVAH-OAK) uses inventory data from three nested plots that focus on tree regeneration, obstacles to successful regeneration, and overstory conditions. The decision criteria are similar to those of the original SILVAH tool; however, the goal of the oak prescriptions is to create new even-aged hardwood stands with oak comprising at least 50 percent of the dominant and co-dominant trees at canopy closure. The timing and sequence of treatments mimic the historical disturbance regime that perpetuated oak forests (Brose et al. 2008).

Steiner et al. (2008) have developed guidelines explicitly for regenerating oaks in the Central Appalachians under even-aged silvicultural systems. Long-term research on oak regeneration in 90 mixed-oak stands in central Pennsylvania that were regenerated by clearcutting, with site index values between 60 and 75, form the basis for the guidelines. They predict expected stocking by oak 30 years after harvest, expressed as a percentage of full stocking. What differentiates these guidelines from some others developed specifically for 
regenerating oak (Sander et al. 1984) is that they assume that small advance regeneration (less than $1 \mathrm{ft}$. in height) can make a significant contribution to future stand development (Gould et al. 2006). The Central Appalachian oak regeneration guidelines may not be as useful for stands on high-quality sites and those that contain a significant component of yellow-poplar, which can compete vigorously with oak (Steiner et al. 2008). As part of the 1989 FIA statewide forest inventory, mixed-oak stands that had undergone recent disturbance due to heavy cutting or gypsy moth mortality were sampled. Most stands had regenerated, but composition of regeneration typically consisted of light-seeded intolerant species such as black cherry, sweet birch, and red maple. These "invader" species were likely not part of the advance seedling component of the sampled stands, and raise questions about how well advanced regeneration stocking guides can predict future stand stocking (McWilliams et al. 1995b).

\section{Policies to ensure adequate regeneration}

West Virginia does not have a state Forest Practices Act that governs forest management activities or that addresses forest regeneration. The West Virginia Division of Forestry has no regulations pertaining to regeneration on state lands such as state forests and wildlife management areas. However, regeneration assessments, as described in SILVAH and SILVAHOAK, are used when preparing a prescription for a silvicultural treatment or regeneration cut on state lands. After cutting, follow-up assessment of post-harvest regeneration consists of a walkthrough and use of visual observation in order to determine its adequacy (Breshock, personal communication).

The Logging and Sediment Control Act of 1992 (WV Code Chapter 19, Section 1B, Article 1B) establishes mandatory guidelines for logging operations that include licensing, notification, logger certification and training, and enforcement of Best Management Practices to 
reduce or limit erosion and sedimentation. However, there are no requirements for pre-or postharvest regeneration assessments or regeneration stocking levels. Other laws that are pertinent to forest land are the Forest Insect and Disease Control Act (WV Code Chapter 20, Section 3, Article 19) Ginseng Regulation (WV Code Chapter 19, Section 1A, Article 3a) and the Noxious Weed Act (WV Code Chapter 19, Article 12D). Noxious Weed Act pertains to several nonnative invasive plant species that are prevalent in forests, including Japanese stiltgrass, tree-ofheaven, autumn olive, tartarian honeysuckle, Morrow’s honeysuckle, and kudzu. However, none of these laws address forest regeneration.

Most states in the western U.S. and many in the East have adopted state forest practice acts. The most commonly regulated category of forestry practices is roads and trails, followed by practices involving chemicals, while the least commonly regulated are cultural practices and reforestation activities, including natural regeneration (Ellefson et al. 2004). Most regulations related to natural regeneration have the objective of ensuring adequate regeneration of desirable commercial tree species and often include regeneration standards, requirements for management plans before harvest, and provisions for seed trees (Cubbage 1991). In a 2004 assessment of state forest practice regulatory programs that address regeneration, it was found that eight states had monitoring programs for pre-harvest inspection of proposed timber harvests and seven states had monitoring programs that included inspections of regeneration and stand condition several years after harvest (Ellefson et al. 2004).

Most regeneration regulations do not control post-harvest activity directly, but instead mandate only that the site have a certain number of seedlings per acre in years subsequent to the harvest. The Maine Forest Practices Act requires adequate regeneration of commercial tree species on a site within 5 years of completion of any timber harvest. (Maine Revised Statutes, 
Title 12, Part 11, Chapter 805, Subchapter 3-A: Forest Practices). Regeneration standards apply to clearcuts larger than five acres and specify minimum acceptable stocking levels in terms of trees per acre of acceptable growing stock species. Attainment of the regeneration standard must be certified by a Licensed Professional Forester using sample plots. If the site fails to meet regeneration standards, landowner is required to submit a mitigation plan certified by a Licensed Professional Forester that may include tree planting or other regeneration activities.

The California Forest Practices Act regulations also require that a minimum acceptable stocking level be attained by advanced regeneration, direct seeding, planting, sprouting, or natural seedfall within five years after harvest. Minimum acceptable stocking is determined using a system that assigns increasing points to larger trees and varies by site class, but the average stocking is 300 seedlings per acre. The regulations also specify the types of tree species that must be regenerated on a harvested site; the percentage of "desirable" species cannot diminish compared to that in the pre-harvest stand. (California Code of Regulations, Title 14, Division 1.5, Chapter 4, Subchapter 14). Oregon's Forest Practice Act is even more stringent; it requires reforestation when a stand's stocking level five years post-harvest is below the regeneration standards, regardless of what the stand's stocking was like before harvesting. Regeneration laws in some eastern states cover only conifers. The Virginia Forest Practices Act has a "seed tree” provision that requires that a certain number of cone-bearing larger trees must be left after harvesting loblolly or white pine. (Virginia Code of Regulations, Title 10.1, Chapter 11, Sections 64 and 71). Maryland has a similar law that applies to harvests on lands occupied by loblolly, shortleaf, or pond pine. 


\section{CHAPTER III}

\section{Methodology}

A mail-based survey was used to achieve the project objectives. The objectives were to determine how natural resource professionals perceive the quality of regeneration, their level of satisfaction with regeneration, the types of concerns they have, and the locations and spatial variability of their regeneration concerns.

\section{Survey population}

The population under study consisted of all natural resource professionals (NRPs) working in West Virginia. The researchers attempted to survey the entire population of NRPs. The survey mailing list consisted of 578 individuals. The majority were professional foresters or forestry technicians who were registered with the WV Board of Registration for Foresters during the 2009-2010 and 2010-2011 registration years. In addition, the mailing list of current members was obtained through the cooperation of the WV Division of the Society of American Foresters. The survey population also included wildlife biologists, ecologists, and other natural resource professionals employed by state and federal government and nonprofit organizations. We surveyed NRPs in order to gain the perspective and professional opinion of those with extensive training and experience with forest ecosystems.

\section{Survey instrument}

The survey instrument was a mailed questionnaire. The questionnaire was formulated to provide respondents the opportunity to express their level of satisfaction with the regeneration they have observed over the past ten years, any concerns they have related to these observations, 
and to elaborate on their challenges and successes related to regeneration. The survey was crafted using the assumption that natural regeneration in West Virginia is generally abundant and successful; there was no discussion or suggestion within the questionnaire of any specific regeneration concerns or issues that might exist. The project investigators took this approach in order to avoid any suggestions that might influence survey responses.

A pilot survey was developed and sent to a review team comprised of two consulting foresters, a state service forester, two assistant state foresters, two state wildlife biologists, a WVU forestry professor/forestry consultant, and a WVU professor/GIS analyst. Reviewers were asked to provide feedback to improve the clarity and the ability of the survey to gather the desired information.

The survey contained 44 questions organized into three sections. The first section was designed to gather information about the respondent's professional experience: his specialty, types of forestry-related activities, employment sector, length of experience, frequency with which he observed forest regeneration, and involvement with timber harvests. Respondents were asked to specify their employment category. For the purposes of this analysis it was decided to assign only one employment code per respondent. Therefore, if a respondent chose "retired" plus an active employment category, he was placed into the active employment category. If a respondent chose two active employment categories, he was placed into the employment category that was full-time as opposed to part-time.

Respondents were asked to list up to four counties in which most of their observations related to regeneration occurred; if they were involved in timber harvesting they were asked to list up to four counties in which most of their timber harvests have occurred. 
The second section gathered information about the extent to which the respondent made assessments of forest regeneration, both in the context of timber harvests and otherwise. Questions were related to the types of assessments they made (casual observations vs. plot-based measurements), timing of their assessments (pre-harvest, post-harvest), and the intensity of their assessments (number of plots or points per acre). In addition, NRPs were asked about their general satisfaction with regeneration they had observed over the past 10 years and those counties where they saw the most successful regeneration. This was asked using a four-level Likert scale, ranging from completely satisfied to completely dissatisfied. This question was designed to serve as a key indicator of general satisfaction with regeneration and is referred to as SATISFACTION.

The third and final section was designed to gather information about the types of concerns respondents had related to regeneration and the general locations and spatial variability of regeneration issues. The use of open-ended questions, as opposed to the use of predetermined categories, was an important part of the design of this final section of the survey. The openended questions were intended to provide a blank slate so that respondents could describe their observations and opinions without any bias or guidance from the survey. In fact, when designing the survey the assumption was that regeneration following timber harvesting is generally abundant and successful.

In the third section of the survey, respondents were asked how they defined successful regeneration and to describe some of the indicators which they use to judge successful regeneration. They were asked to rate their general level of satisfaction with the regeneration they have observed and to list up to four counties where they have observed the most successful 
regeneration. They were then asked to list the tree species they would like to see regenerate most abundantly, as well as those that actually do regenerate most abundantly.

Questions in this section are key to our research goal of investigating the condition of regeneration in West Virginia. Respondents had the opportunity to answer three iterations of a series of questions about their concerns. They were first asked whether they had any concerns related to forest regeneration and if so, to describe their top concern (using an open-ended question), the severity of that concern (using a Likert scale), indicators or factors that form the basis of their concern (open-ended), and the number of years their concern has existed. Respondents were then asked to list up to four counties in which their concern about regeneration was the greatest. This series of questions was then repeated two more times, using the technique of probing to elicit as much information as possible. The first iteration of the series asked for a "top concern," and the second and third rounds asked for "another concern."

Finally, the survey concluded by giving respondents the opportunity to describe specific examples of regeneration successes or concerns they have observed as well as to share any other comments they may have related to forest regeneration.

\section{Survey delivery}

The mail survey was conducted following methodology recommended by Dillman (2000). On February 23, 2011 a postcard was mailed to the survey population that announced the upcoming survey, provided some information about it, and requested the cooperation of survey recipients. On March 1, a package containing a cover letter, the survey, and a postage-paid return envelope was mailed to the survey population. Two weeks later on March 16, a reminder postcard was mailed to those who had not yet returned the survey. Finally, on April 1 a second mailing of the cover letter, survey, and return envelope was sent to those who had not yet 
responded. April 24, 2011 was set as the cut-off date for receiving surveys; at that point it was assumed that all survey recipients who intended to respond had done so and no surveys were received after that date.

\section{Survey data processing}

Returned surveys were sorted into three groups corresponding to their arrival date: whether they arrived after the first survey mailing, after the reminder postcard, or after the second survey mailing. Survey responses were entered into an Excel spreadsheet. Responses were associated only with a four-digit ID number and not with any name or address, in order to maintain the level of confidentiality required under the research exemption granted by the West Virginia University Office of Research Compliance (IRB Protocol \#H-23006)

Returned surveys were categorized as one of several response types. A “Complete” response had all or most questions completed through Question \#21: “In general, how satisfied have you been with the regeneration you have seen in West Virginia during the past 10 years?” This essentially included all but the section on concerns. If a survey was returned and most questions were not completed through Question \#21, it was coded as a “Partial response.” Surveys were coded as "Refusals" if they were returned blank, or the respondent indicated they would prefer not to participate in the study. NRPs who did not fill out the survey, but stated that they were not experienced enough or had not worked in West Virginia during the last 10 years were considered "Not eligible.” Surveys that were returned due to bad addresses or the fact that a respondent was deceased were classified as such. Surveys that apparently reached the respondent but were not returned were classified as “Unknown: Not returned” (AAPOR 2008). Unless explicitly stated, only complete responses were used in this study. 


\section{Coding of concerns}

Concerns related to forest regeneration were categorized into primary issues using three rounds of coding. Working independently, the two primary researchers completed a first round of coding that resulted in 21 categories of concerns related to forest regeneration. The researchers then collaborated and following discussions, these 21 categories were consolidated into 13 categories. The two researchers then worked independently and coded all concerns again using the revised categories. This second round of coding was tested for intercoder reliability and this resulted in a correspondence of 88 percent between the two coders. The researchers again collaborated to discuss and refine the coding categories, which were then pared down to 12 categories. The researchers again recoded all of the concerns using this third round of categories, to yield the final database of concern codes. All respondents' concerns were placed into the twelve categories below:

1. Deer-Any mention of deer, deer browse.

2. Composition of regeneration-Specific reference to the species composition of regenerating stands as undesirable; concern for absence or diminution of a particular species (e.g. red oak, black cherry, walnut, etc.) or species group such as oaks.

3. Invasive plants-Any mention of “invasives;" reference to any of the non-native invasive plant species (e.g. tree-of-heaven, Japanese stiltgrass, autumn olive, etc.)

4. Density of regeneration-References to the quantity of regenerating stems, including “none.”

5. Fragmentation - Includes references to residential and commercial development, exurban sprawl, fragmentation of forest land.

6. Forest health-Insects, diseases, and other factors that negatively affect forest tree and shrub species. 
7. Wildfires - Includes concern about the impacts of man-made or natural wildfires on regeneration. The issue of prescribed fire or controlled burns is classified under the category of "forest management".

8. Forest management and silviculture - Includes references to forest planning, silvicultural practices, regeneration methods (e.g. clearcutting, selection system, group selection, etc.), best management practices, intermediate stand treatments, timber stand improvement, prescribed fire, and thinning. Includes references to timber harvest practices such as diameter-limit cutting and high-grading; and impacts from timber harvests such as soil compaction or damage from harvesting or logging equipment.

9. Mineral development-Mention of surface or strip mines, gas wells, Marcellus shale wells.

10. Attitudes and perceptions - Attitude or perceptions of landowners or the public related to the forestry profession or forest management activities.

11. Interfering vegetation-Includes references to native plant species that are undesirable competitors of regenerating commercial species. Some examples of interfering vegetation are beech, striped maple, ferns, and grasses. Note: Concerns related to less merchantable or "undesirable” species such as birch, red maple, fire cherry, etc. are placed in the category of “composition of regeneration.” Also, references to non-native invasive plant species are classified under the category of "invasive plants."

12. Other concerns - any concerns not included in the categories listed above.

Because the questions that asked respondents to describe their concerns about regeneration were open-ended, it was possible for a respondent's answer to be associated with more than one of the concern categories listed above. For example, a response such as "We are getting no oak regeneration because of the deer" would be coded in the "Deer" category and also in the "Composition of regeneration” category. Cases such as this were treated as two separate concerns. Respondents were given three opportunities to describe their concerns about 
regeneration (Questions 26, 31, and 37). The answers to each of these questions could be coded with up to three different concern codes, although the majority of answers were coded with only one concern code. Therefore each respondent could potentially be associated with up to nine concerns.

When respondents were asked to describe their concerns related to regeneration, they were also asked to list up to four counties where this concern was the greatest; in other words, each respondent had the opportunity to associate a concern with up to four counties. However, duplicates were not retained; for example, one respondent could not express a concern about deer in Monongalia County more than once; if this occurred, the concern “deer” for "Monongalia County” was counted only once.

\section{Relative importance of concerns}

In the first section of the survey, respondents were asked to list up to four counties in which most of their observations of regeneration took place. The numbers of respondents making observations were not evenly distributed across all 55 counties. There was a wide range of respondents per county with a minimum of two, a maximum of 67, and an average of 17 (see Figure 1). Due to the uneven distribution of respondents across counties, a metric of "relative importance” was developed for use in mapping the importance of concerns. This metric was used to map concerns rather than the actual number of times a particular concern was expressed for a county, in an effort to normalize the number of concerns. 


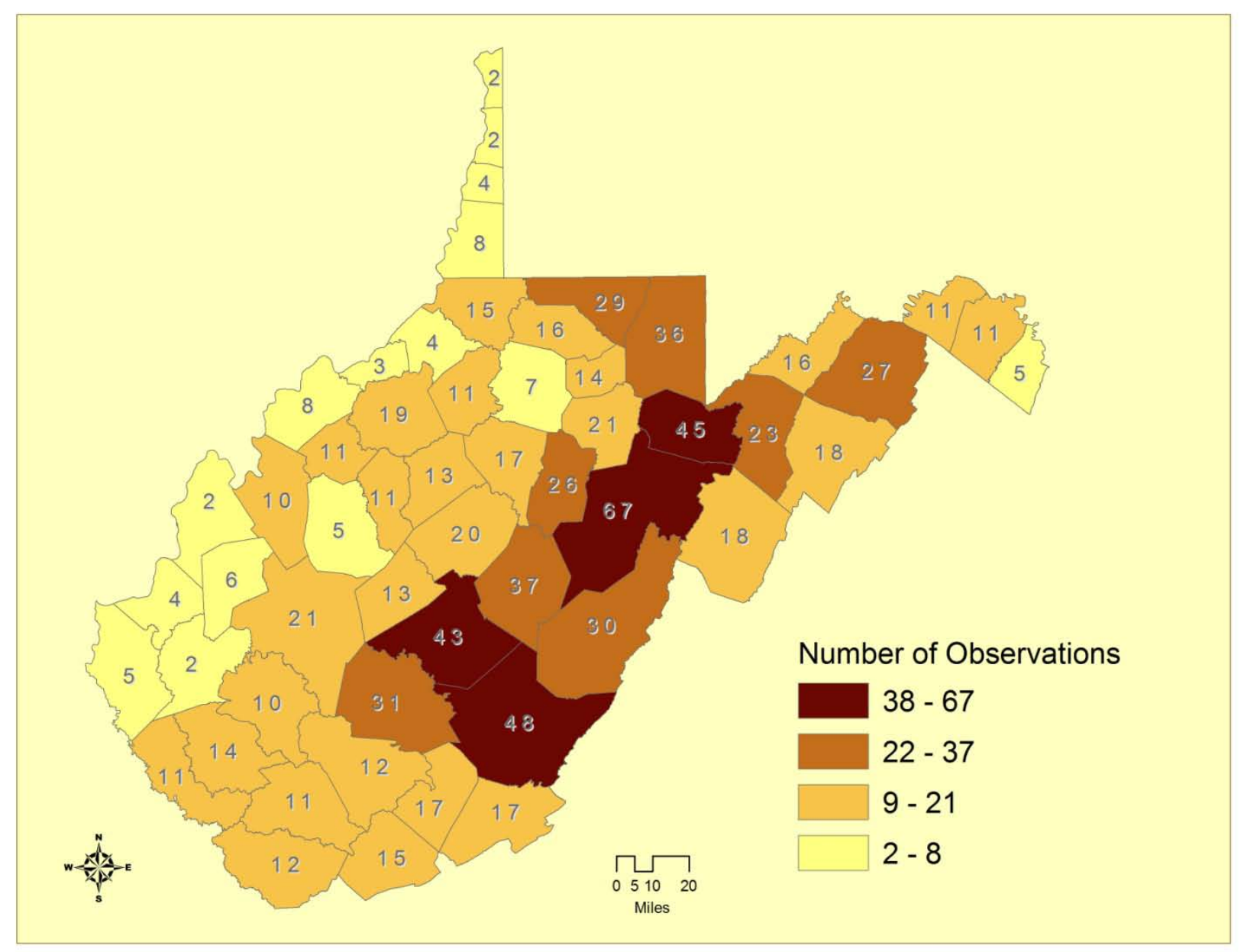

Figure 1. Distribution of the number of observations about forest regeneration made by survey respondents in each county.

To determine the relative importance of a concern for a given county, the number of concerns for one of the 12 categories of concerns (described above) was used as the numerator and the total number of all concerns reported for the county was used as the denominator, multiplied by 100 to generate a proportion. These were calculated for each concern category in each county. Relative importance values convey the relative levels of concern in each county for each issue related to forest regeneration. For example, a relative importance of 75 percent for “deer” in Barbour County means that 75 percent of the concerns about forest regeneration in Barbour County were related to deer. 


\section{Mapping}

For all 12 categories of regeneration concerns, a series of maps was created in ArcGIS 9.3.1 that depicts the relative importance of each concern in each county. The same class breaks were used on all maps in the series to allow for comparison among maps and to convey the importance of each concern relative to other concerns. Manual breaks were applied to each map; therefore some maps in the series did not include classes from the entire data range. Zero values were separated into their own class and the number of classes was limited to four to assist map reading by a general audience (Brewer 2006).

Four classes were used:

$\begin{array}{ll}51-100 & \text { (High importance) } \\ 26-50 & \text { (Moderate importance) } \\ 1-25 & \text { (Low importance) } \\ 0 & \text { (No importance) }\end{array}$

In addition, in order to create a graphical representation and visual aid to call attention to areas around the state where concerns are concentrated, maps were created in ArcGIS 9.3.1 using an interpolation tool known as Inverse Distance Weighted. This is a Spatial Analyst tool that creates a raster grid by interpolating between known point values. It relies both on point locations and on values associated with each point location. Basically, contour maps of our regeneration observations were created.

However, our data was collected on a county basis; each observation or concern was associated with one of 55 counties (which function as polygons in ArcGIS) and not with a specific geographic point. The 55 county polygons first had to be converted into 55 points. We used the Data Management tool in ArcGIS 10.0 to convert the county polygon shapefile into a shapefile that contained the centroid of each of the 55 counties, which are point features. We 
then joined the relative importance values for each county with the county centroid shapefile. This gave us the appropriate input type with which to map our concerns.

The Inverse Distance Weighted interpolation took three factors into account: 1) the relative importance of each concern within a county; 2) the geographic center of the county, or the centroid; and 3) the observations surrounding each county. Interpolation adds another dimension by taking into account the values for each county, as well as the values for counties that surround it. One limitation of this method is that it contains the assumption that the majority of the concern in a county is located at the geographical center of the county (its centroid).

The following settings for the Inverse Distance Weighted interpolation tool were used in ArcGIS 9.3.1:

1. The Relative Importance for a concern in each county (expressed as a percent) was used for the z-value.

2. The input point features was a shapefile containing the centroid for each county.

3. The following settings were used: Power=4; Search radius type=Variable; Search radius settings: Points $=24$ and maximum distance $=67,000 \mathrm{~m}$ (furthest distance between two centroids); Output cell size was 1 mile=1609.344 meters.

4. All values were rounded to the nearest whole number. No decimal places were used.

The same consistent manual classification method used for the county-level concern maps was used for concern maps created using Inverse Distance Weighted interpolation. This allowed for comparisons among all maps in the series. The same four classes were used:

$\begin{array}{ll}51-100 & \text { (High importance) } \\ 26-50 & \text { (Moderate importance) } \\ 1-25 & \text { (Low importance) } \\ 0 & \text { (No importance) }\end{array}$

All maps that depict other data use a classification method known as the Jenks Natural Breaks algorithm. This is a method for classifying data presented in a choropleth map that uses 
an algorithm to calculate a series of break values so that variance within classes is minimized and variance between classes is maximized (Jenks 1977). This method of classification has been incorporated into ArcGIS, where it is known as the Natural Breaks method. Maps were created in ArcGIS 9.3.1. using the Natural Breaks method with four classes specified.

\section{Coding of concern subcategories}

After the twelve main categories of concerns were created and validated, subcategory codes were created for seven of these in order to obtain more information. The two primary researchers then used the same process by which they generated the main concern categories to test and further refine the subcategories. They first coded subcategories independently, tested for intercoder reliability to achieve a rate of over $88 \%$, then collaborated to discuss and refine the coding subcategories. As a final step, the subcategories were tested using a West Virginia University research assistant and a graduate research assistant. A random sample of $20 \%$ of response was chosen for each concern with subcategories. Intercoder reliability of $90 \%$ or greater was achieved.

The following subcategories were created within broad categories:

\section{Deer}

a. Impacts of deer on regeneration of forests in general-No mention of any particular species or groups of species

b. Impacts of deer on specific tree species-Mention of one or more tree species that are being negatively impacted by deer

\section{Composition of Regeneration}

a. Lack of desirable regeneration

b. Less desirable species are increasing in importance

c. Species diversity-Species diversity of regeneration is changing

d. Changing species composition-- no mention of desirable vs. less desirable species

\section{Invasive Plants}



a. Impacts of invasive plants in general
b. Impacts of specific invasive plants

\section{Density of Regeneration}

No subcategories were created.

\section{Fragmentation}

No subcategories were created.

\section{Forest Health}
a. One or more specific insects are mentioned
b. One or more specific diseases are mentioned
c. Insects and/or disease are mentioned in general
d. Other forest health issues are mentioned

\section{Wildfire}

No subcategories were created.

\section{Forest management and silviculture}

a. Environmental impacts of harvesting

b. Cutting practices_-Includes high-grading, diameter-limit cutting, selective or partial cutting, or cutting practices in general

c. Silvicultural practices-Includes mention of one or more specific types of silvicultural practices, e.g. thinning, timber stand improvement, or prescribed burning. Includes mention of clearcuts, shelterwood, and other regeneration harvest techniques. Also includes mention of silviculture (or lack thereof) in general

d. Other-Other forest management concerns

\section{Mineral development}

No subcategories were created.

\section{Attitudes and perceptions}

a. Public perception of forestry practices-Includes public opinions about timber harvesting or management

b. Landowner awareness and attitudes - Includes lack of awareness or attitudes toward forest management

\section{Interfering vegetation}
a. Impacts of interfering vegetation on regeneration in general 
b. Impacts of specific types of interfering vegetation

\section{Other concerns}

No subcategories were created.

\section{Data analysis}

SPSS was used to summarize descriptive statistics that described the respondents' professional natural resources experience, the extent to which they observed and assessed regeneration, and their concerns about regeneration. Three respondents selected multiple employment specialties (two chose 'forestry' plus 'other environmental or natural resource specialty,' and one chose 'forestry’ plus 'wildlife'); however, all three were placed into the 'forestry' category, since their names originated from the WV Society of American Foresters and the WV Board of Registered Foresters rosters.

When asked for their employment category, thirty-one respondents chose more than one. Researchers assigned only one employment category per respondent. If a respondent chose "retired" plus an active employment category, he was placed into the active employment category. If a respondent chose two active employment categories, he was placed into the employment category that was full-time as opposed to part-time. Employment types that were difficult to categorize were placed into the "other" category (for example, one respondent commented that he worked for the Board of Education; this was hard to place into one of the standard employment categories).

Next, using the employment categories as a guide, each respondent was placed into one of three employment sectors. Those whose employment category was state government, nonprofit, federal government, or college/university were placed into the "Public/Nonprofit" employment sector. Those whose employment category was corporation/TIMO, other private 
company, or self employed/consulting were placed into the "Private" employment sector. Those whose employment category was retired or other were placed into the "Retired/Other" sector. In order to accomplish project objectives, univariate logistic regression (Hosmer and Lemeshow 2000) was used to investigate respondents’ satisfaction levels and associated attributes. The indicator variable (SATISFACTION; see above) was recoded from a four-level Likert scale to a binary form representing respondents who were either satisfied or dissatisfied in general with regeneration they had observed ( $1=$ satisfied, $0=$ not satisfied). This variable was recoded because the two extreme categories, completely satisfied and completely dissatisfied, contained only $6 \%$ and $7 \%$ of the total distribution, respectively. Not only did these extreme categories contain a relatively low number of cases, the distinction between "completely" and "somewhat" is difficult to interpret. The resulting distribution of respondents into two satisfaction classes was nearly symmetric with $49 \%$ either completely or somewhat dissatisfied and 51\% either completely or somewhat satisfied. Hence, SATISFACTION was converted into a dichotomous variable to represent either a satisfied or dissatisfied state.

PROC LOGISTIC in SAS (SAS Institute 2004) was used to model the binary state of whether or not a respondent was satisfied with regeneration. Univariate logistic regression was used since the analysis was exploratory and this allowed researchers to retain all cases. SATISFACTION (responses to Question \#21 that asked how satisfied the respondent was with the regeneration he had seen) served as the binary dependent variable, and several independent variables were derived from respondents' attributes and perceptions (Table 1). Eleven variables were explored to determine their relationship with the level of satisfaction expressed by NRPs. Independent variable types included binary, categorical, and continuous. 
As part of the logistic regression, an odds ratio is calculated (the slope or beta coefficient is a transformed odds ratio). The odds ratio is a measure of the strength of the association between a dependent variable and an independent variable (Allison 1999). It estimates the likelihood of a dependent variable outcome (yes/no; high/low; satisfied/dissatisfied) given a particular level of the independent variable. In this study, odds ratios represent the magnitude of association of independent variables with SATISFACTION. The odds ratio compares the odds of a respondent in one class of the independent variable being satisfied with the odds of a respondent in another class being satisfied. If the odds ratio is one, there is no difference in the odds between groups. For the result to be statistically significant, the confidence interval should not overlap one. Confidence levels were deemed statistically significant if the 90 percent confidence interval (alpha $=0.10$ ) did not contain one. 
Table 1. Eleven independent variables used to explore factors associated with a respondent's satisfaction with regeneration.

\begin{tabular}{|c|c|c|}
\hline Independent variable & $\mathbf{n}$ & Variable Type \\
\hline Years of forestry-related work in WV & 230 & Continuous \\
\hline Natural resource specialty & 237 & Categorical \\
\hline \multicolumn{3}{|l|}{ Other environmental vs. Forestry } \\
\hline \multicolumn{3}{|l|}{ Wildlife vs. Forestry } \\
\hline Employment sector & 237 & Categorical \\
\hline \\
\hline \multicolumn{3}{|l|}{ Private vs. Public } \\
\hline Number of forestry-related activities & 237 & Continuous \\
\hline Frequency of observing regeneration & 236 & Categorical \\
\hline \multicolumn{3}{|l|}{ High vs. Low } \\
\hline \multicolumn{3}{|l|}{ Medium vs. Low } \\
\hline Respondent does regeneration assessments & 235 & Binary \\
\hline Respondent does assessments in harvested areas & 178 & Binary \\
\hline Respondent is involved with timber harvests & 229 & Binary \\
\hline Percent of harvests revisited & 196 & Continuous \\
\hline Respondent’s desired trees are regenerating & 236 & Binary \\
\hline Respondent has concerns about regeneration & 237 & Binary \\
\hline
\end{tabular}




\section{CHAPTER IV}

\section{Results}

\section{Survey Response}

Out of a survey population of 578 natural resource professionals, 341 (59\%) returned questionnaires. Out of these, 261 questionnaires (45.2\% of total) were classified as “complete” responses and used in data analysis. Two-hundred and thirty-seven questionnaires (41\%) were never returned due to unknown reasons. The response rate and cooperation rate were calculated using the following methods: (AAPOR 2008)

$$
\begin{aligned}
& \text { Response rate }=(\text { Complete }+ \text { Partials }) /(\text { Complete }+ \text { Partials }+ \text { Refusals }+ \text { Not Returned }) \\
& \text { Cooperation rate }=(\text { Complete }+ \text { Partials }) /(\text { Complete }+ \text { Partials + Refusals }) \text {. }
\end{aligned}
$$

The response rate for the survey was 50.4 percent and the cooperation rate was 90.6 percent. Table 2 shows the distribution of response types.

Table 2. Distribution of survey response types.

\begin{tabular}{lcc}
\hline Response Type & Number & Percent \\
\hline Complete & 261 & 45.2 \\
Unknown: Survey not returned & 237 & 41.0 \\
Not eligible & 39 & 6.7 \\
Refusal & 28 & 4.8 \\
Partial & 8 & 1.4 \\
Deceased & 4 & 0.7 \\
Bad address & 1 & 0.2 \\
\hline Total & 578 & 100.0 \\
\hline
\end{tabular}




\section{Evaluation of nonresponse bias}

Survey research should consider the possibility of nonresponse bias; this type of error exists when those included in the survey population who did not respond (nonrespondents) are different from those who did respond (Dillman 2000). Since some research has shown that nonrespondents are similar to late responders, it may be possible to estimate nonresponse bias by substituting the population of late responders for nonrespondents.

A recommended procedure for handling potential nonresponse bias is to compare early to late responders to see if there are significant differences in their responses; if so, then nonresponse bias may be present. In this case, survey findings cannot be generalized to the entire survey population but must be limited to the actual survey respondents. Lindner et al. (2001) outline a protocol for conducting this comparison; their recommendations were followed for this research.

Of the 261 "complete" responses, 53\% of questionnaires were returned following the first mailing; 23\% were returned following the reminder postcard; and 24\% following the second mailing. The first group, composed of 139 respondents, was characterized as early responders; the second and third groups, composed of a total of 122 respondents, were characterized as late responders.

In order to test for nonresponse bias, the group of 139 early responders was compared to the group of 122 late responders. The two groups were compared on three characteristics: their natural resource specialty, the number of years they have practiced forestry-related work in West Virginia, and the number of forestry-related activities they perform. There were no significant differences between early and late responders. Chi square analysis found that a respondent's natural resource specialty was independent of a respondent's status as an early or late responder 
$\left(\chi^{2}=.913, \mathrm{df}=4, \mathrm{p}=.923\right)$. The $\mathrm{t}$ test for independent samples found no association found between a respondent's status as an early or late responder and the number of years he has practiced forestry-related work in West Virginia $(\mathrm{p}=.252)$ or the number of forestry-related activities he performs $(\mathrm{p}=.779)$. In addition, chi square analysis found that the number of concerns related to forest regeneration (a possible response variable) was found to be independent of a respondent's status as an early or late responder $\left(\chi^{2}=2.077, \mathrm{df}=3, \mathrm{p}=.557\right)$. Because no potential nonresponse bias was found, the results of the survey can be generalized to the entire survey population.

\section{Experience and background of natural resource professionals}

Most respondents’ natural resource specialty was forestry-related (89.3\%); respondents with a wildlife specialty made up 7.3 percent of respondents and 3.4 percent had an environmental or other natural resource specialty. The leading employment categories were state government (22\%), consulting (21\%), and corporate (18\%). Fifty-four percent of respondents worked in the private sector, 39 percent worked in the public/nonprofit sector, and seven percent worked in the retired/other sector. See Table 3 for distribution of employment types. 
Table 3. Distribution of specialty, employment category, and employment sector.

\begin{tabular}{lc}
\hline & Percent of All Respondents \\
Natural Resource Specialty & \\
\hline Forestry & 89.3 \\
Wildlife & 7.3 \\
Environmental & 3.4 \\
Employment Category & \\
\hline State government & 22 \\
Consulting & 21 \\
Corporate & 18 \\
Other private company & 15 \\
Federal government & 12 \\
Retired & 6 \\
College/University & 3 \\
Nonprofit & 2 \\
Other & 1 \\
Employment Sector & 54 \\
\hline Private & 39 \\
Public & 7 \\
Retired/Other &
\end{tabular}

Respondents whose natural resource specialty was forestry were fairly evenly distributed over four employment categories: consulting (23\%), corporate (20\%), state government (20\%), and other private company (17\%). Those whose natural resource specialty was wildlife worked mostly for state government (63\%). For the nine respondents whose natural resource specialty was ‘environmental or other natural resource specialty,’ most worked for federal government or a nonprofit organization (See Table 4). 
Table 4. Number of respondents by employment category and natural resource specialty.

\begin{tabular}{lcccc}
\hline \multirow{2}{*}{$\begin{array}{l}\text { Employment } \\
\text { Category }\end{array}$} & \multicolumn{4}{c}{ Natural Resource Specialty } \\
\cline { 2 - 5 } & Forestry & Wildlife & Environmental & Total \\
\hline Consulting & 54 & 0 & 0 & 54 \\
Corporate & 47 & 0 & 1 & 48 \\
State government & 45 & 12 & 0 & 57 \\
Other private company & 39 & 0 & 0 & 39 \\
Federal government & 21 & 5 & 4 & 30 \\
Retired & 15 & 1 & 0 & 16 \\
College/University & 8 & 1 & 0 & 9 \\
Nonprofit & 2 & 0 & 3 & 5 \\
Other & 2 & 0 & 1 & 3 \\
\hline Total & 233 & 19 & 9 & 261 \\
\hline
\end{tabular}

Respondents have an average of 25 years of forest-related work, with a range of from two to 54 years. The average length of time that respondents have been practicing forest-related work in West Virginia is 21 years, with a minimum of 1 year and a maximum of 52 years.

Based on a scale of 1 to 4, ranging from "never" to "frequently," the majority of respondents (72\%) observe forest regeneration "frequently" and 23 percent observe regeneration “occasionally.” Only one respondent reported that he observed regeneration with a frequency of 1 or "never;" this response was included in the survey analysis. Survey respondents as a whole observe forest regeneration with an average frequency of 3.67. Those with a forestry specialty averaged 3.68, while those with a wildlife specialty averaged 3.63 and those with an “environmental or other specialty” averaged of 3.56.

Respondents were asked to list up to four counties where most of their observations of regeneration took place. On average, each respondent observed regeneration in 3.5 counties. Observations were made in all 55 counties in West Virginia. Counties with the most observations were Randolph (67 observations), Greenbrier (48), and Tucker (45). Counties with the fewest 
observations were Hancock, Mason, Brooke, and Lincoln (two observations each). See Figure 2 for the distribution of the number of observations per county.

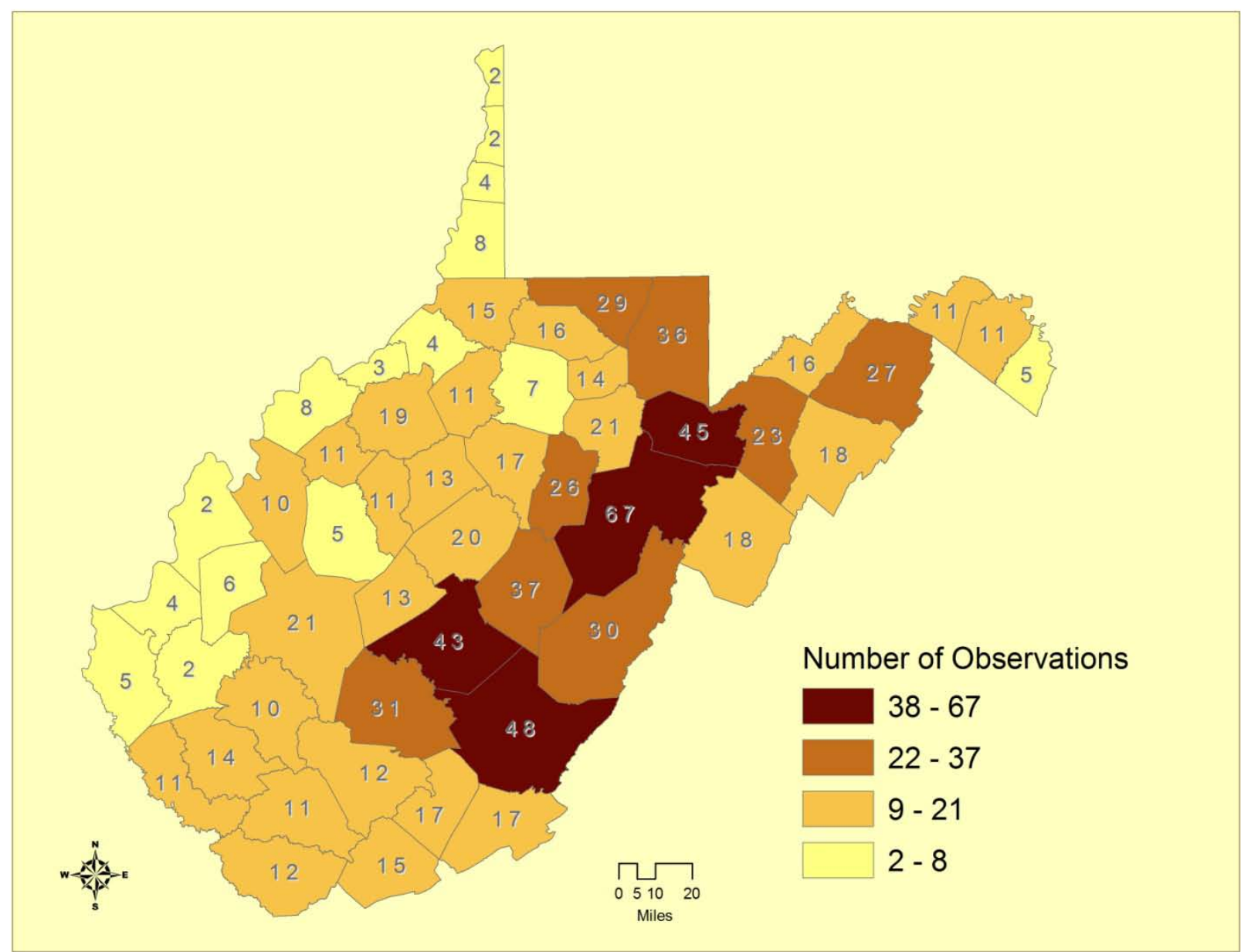

Figure 2. Distribution of the number of observations about forest regeneration made by survey respondents in each county.

Respondents were asked about the types of forest-related work they did and were provided with a list from which to choose. Activities were clustered into three groups: forest management, timber, and other. Of the forest management-related activities, most respondents chose Timber Stand Improvement (60\%), forest management plan writing (55\%), and thinning (53\%). Of the timber-related activities, the most frequently chosen were timber inventory/cruising (73\% of respondents), timber sale administration (55\%), and logging 
compliance (49\%). Of the other activities, the most frequently chosen were wildlife management (32\% of respondents), education/outreach (31\%), and wildfire control (28\%). See Table 5 for percent of respondents involved with various forestry-related activities.

Table 5. Involvement of survey respondents with forestry-related activities.

Forest Management Activities

Percent of All Respondents

Timber stand improvement 60

Forest management plans 55

Thinning 53

Invasive species control 42

Grapevine control 37

Tree planting 33

Other regeneration activities 28

Other activities

Timber-related Activities

Timber inventory/cruising

Timber sale administration

Logging compliance

Timber harvesting/logging

Timber procurement

Certification/auditing

\section{3}

55

49

35

23

17

\section{Other activities}

Wildlife management 32

Education/outreach 31

Wildfire control 28

Wildlife management plans 13

Other 12

\section{Involvement with timber harvests}

Respondents have been involved with an average of 87 timber harvests in West Virginia over the past ten years, with a range of from 0 to 1000 harvests and a standard deviation of 148 . Nineteen percent of respondents have not been involved with timber harvests, while a similar 
number (19 percent) have been involved with 100 or more harvests. See Figure 3 for the distribution of timber harvest involvement among survey respondents.

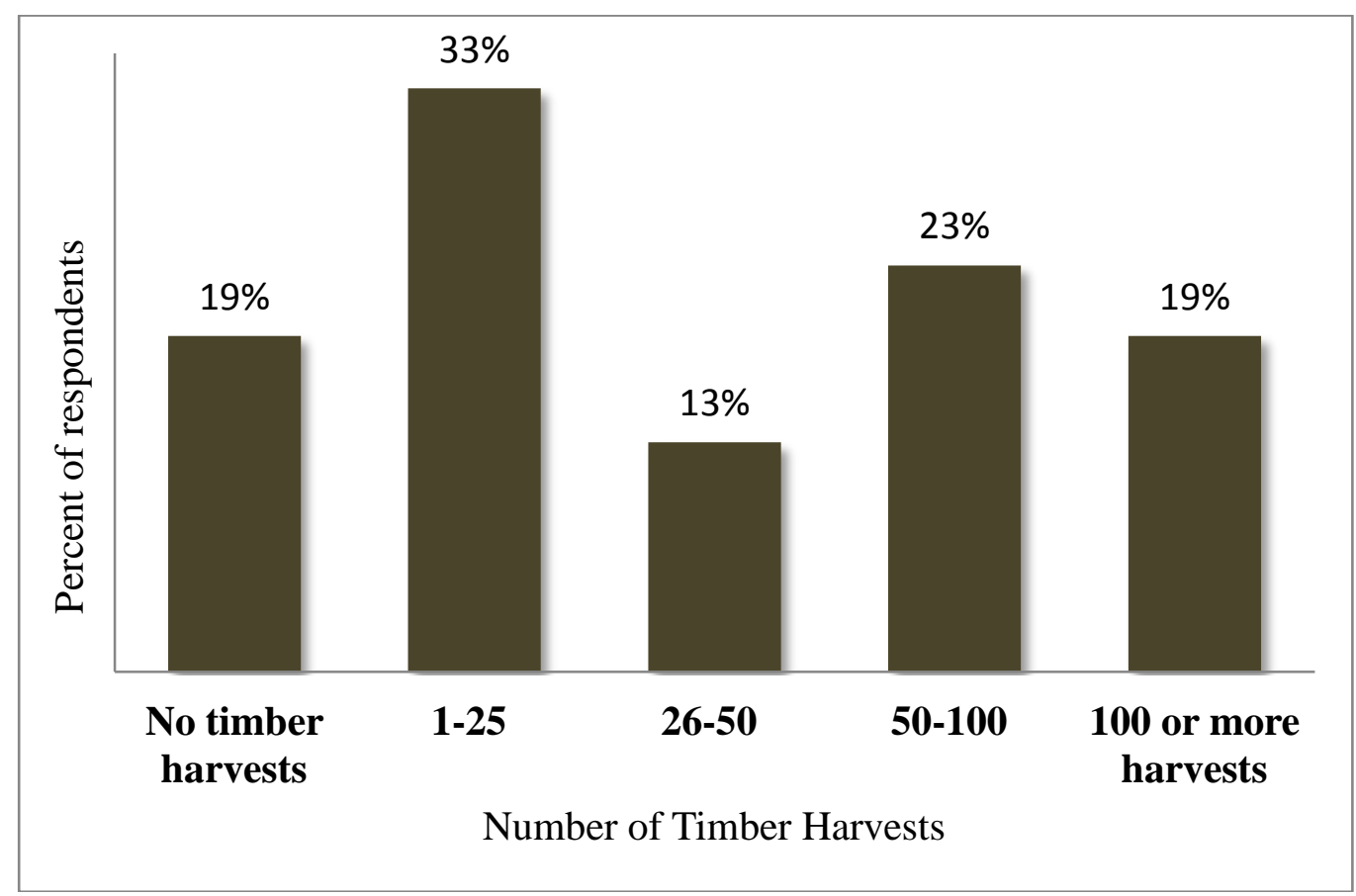

Figure 3. Distribution of timber harvest involvement among survey respondents.

The average acreage of timber harvests was 74 acres, with a range of 0 to 800 acres.

Respondents were asked to list up to four counties in West Virginia where most of their timber harvests over the past ten years had occurred. The largest number of timber harvests occurred in Randolph (6.4\% of total), Greenbrier (5.5\%), and Nicholas (5.5\%). Brooke and Hancock counties had the fewest harvests, with $0.1 \%$ of the total each.

\section{Assessments of forest regeneration}

Most respondents (71\%) reported that they did regeneration assessments of some kind. Of those who did assessments, 93\% did assessments in areas where timber had been or will be 
harvested. On average, respondents revisited $45 \%$ of timber harvests to assess regeneration. The average time to revisit a site was 2.9 years following harvest.

Table 6. Types of regeneration assessments done by survey respondents. Percentages represent the proportion of respondents who conducted pre-harvest, post-harvest, and non-timber related surveys respectively.

\begin{tabular}{cc}
\hline Pre-harvest assessment & Percent \\
\hline Visual observation & 91 \\
Plot-based survey & 41 \\
Other type of assessment & 13 \\
Post-harvest assessment & \\
\hline Visual observation & 93 \\
Plot-based survey & 30 \\
Other type of assessment & 7 \\
Assessment unrelated to timber harvest & \\
\hline Visual observation & 73 \\
Plot-based survey & 19 \\
Other type of assessment & 8 \\
\hline
\end{tabular}

Most regeneration assessments were done by visual observation. If a plot-based survey was done, it was most likely done as part of a pre-harvest assessment. See Table 6 for distribution of assessment types. Of those who record their assessments of regeneration; $49 \%$ of respondents reported they used handwritten notes; 36\% used paper data sheets; and $14 \%$ used electronic data recorders.

\section{Satisfaction with regeneration}

Respondents were asked to report how satisfied they were with the regeneration they have seen in West Virginia during the past 10 years. They were presented with a scale containing four values: completely satisfied $=4$, mostly satisfied $=3$, mostly dissatisfied $=2$, and completely dissatisfied $=1$. For all respondents, $51 \%$ were either mostly satisfied or completely satisfied with 
the regeneration they have observed, while $49 \%$ were either mostly dissatisfied or completely dissatisfied. See Figure 4 for the distribution of satisfaction levels among respondents.

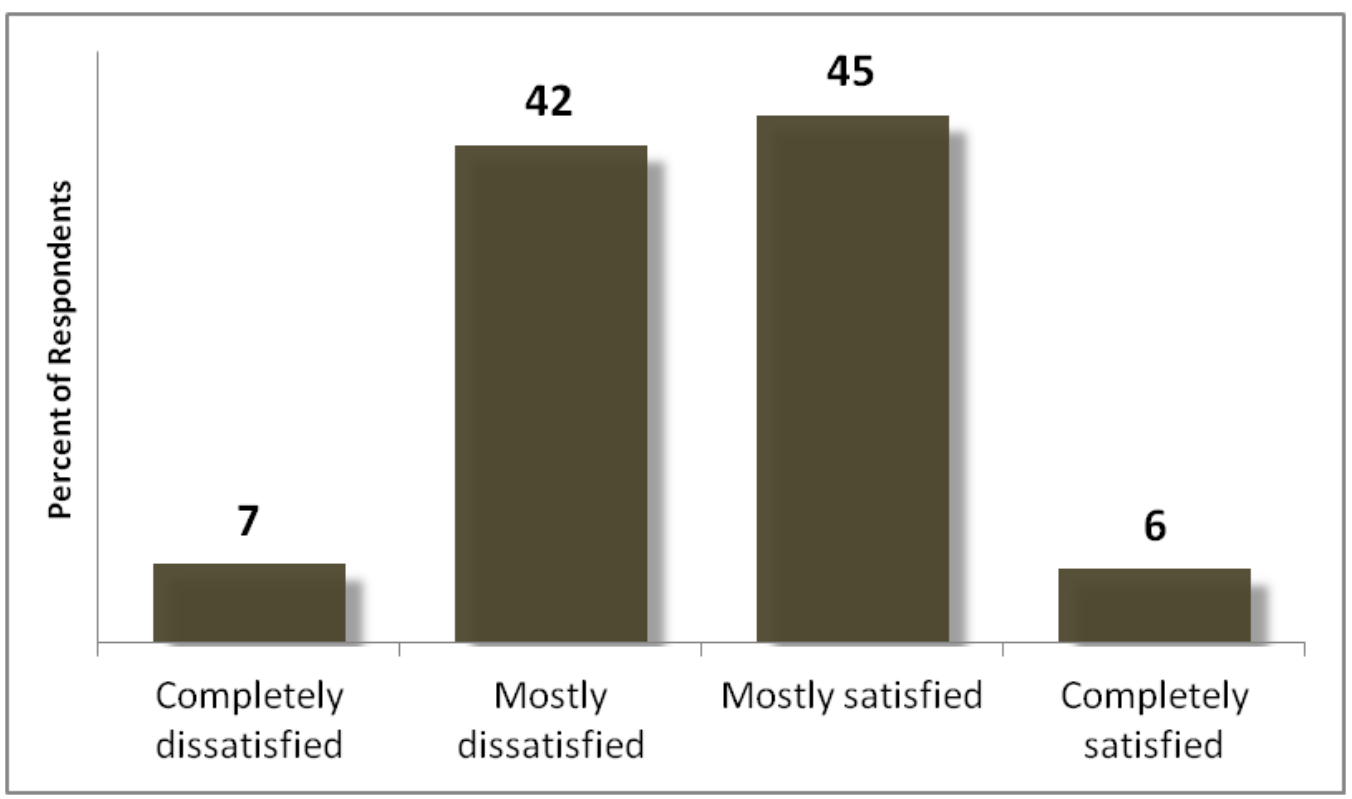

Figure 4: Distribution of respondents' satisfaction with regeneration on a scale ranging from "completely dissatisfied" to "completely satisfied."

Respondents were asked to list up to four counties where they had seen the most successful regeneration. Randolph, Nicholas, and Greenbrier counties were mentioned most frequently, by $10 \%, 8 \%$, and $8 \%$ of respondents respectively. The counties mentioned least often were Harrison, Putnam, and Tyler, each mentioned by $0.2 \%$ of respondents. See Figure 5 for the distribution of observations of successful regeneration. The average level of satisfaction for respondents making observations within each county, based on a Likert scale of 1 to 4 , is represented in Figure 6. 


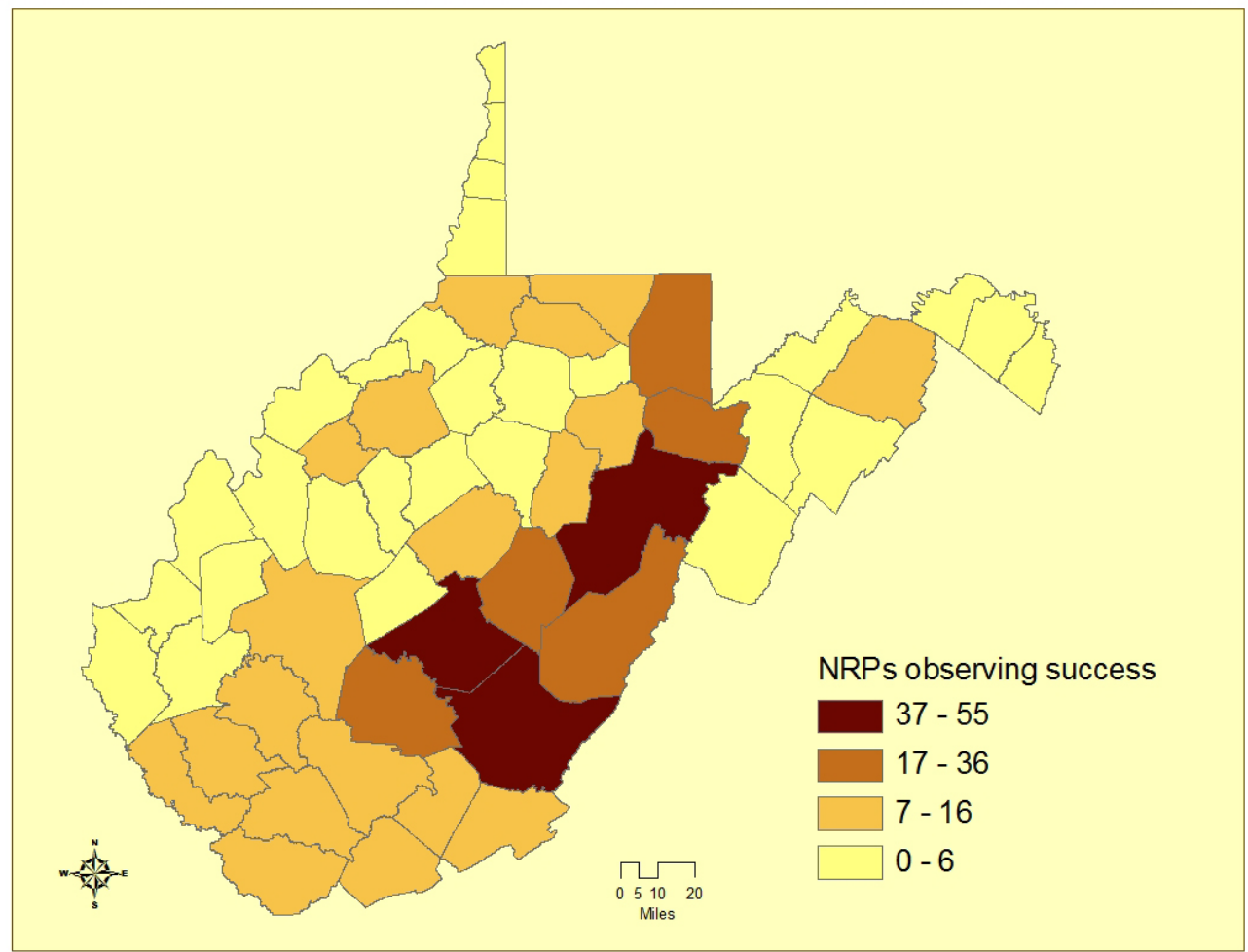

Figure 5. Number of natural resource professionals observing successful regeneration in each county.

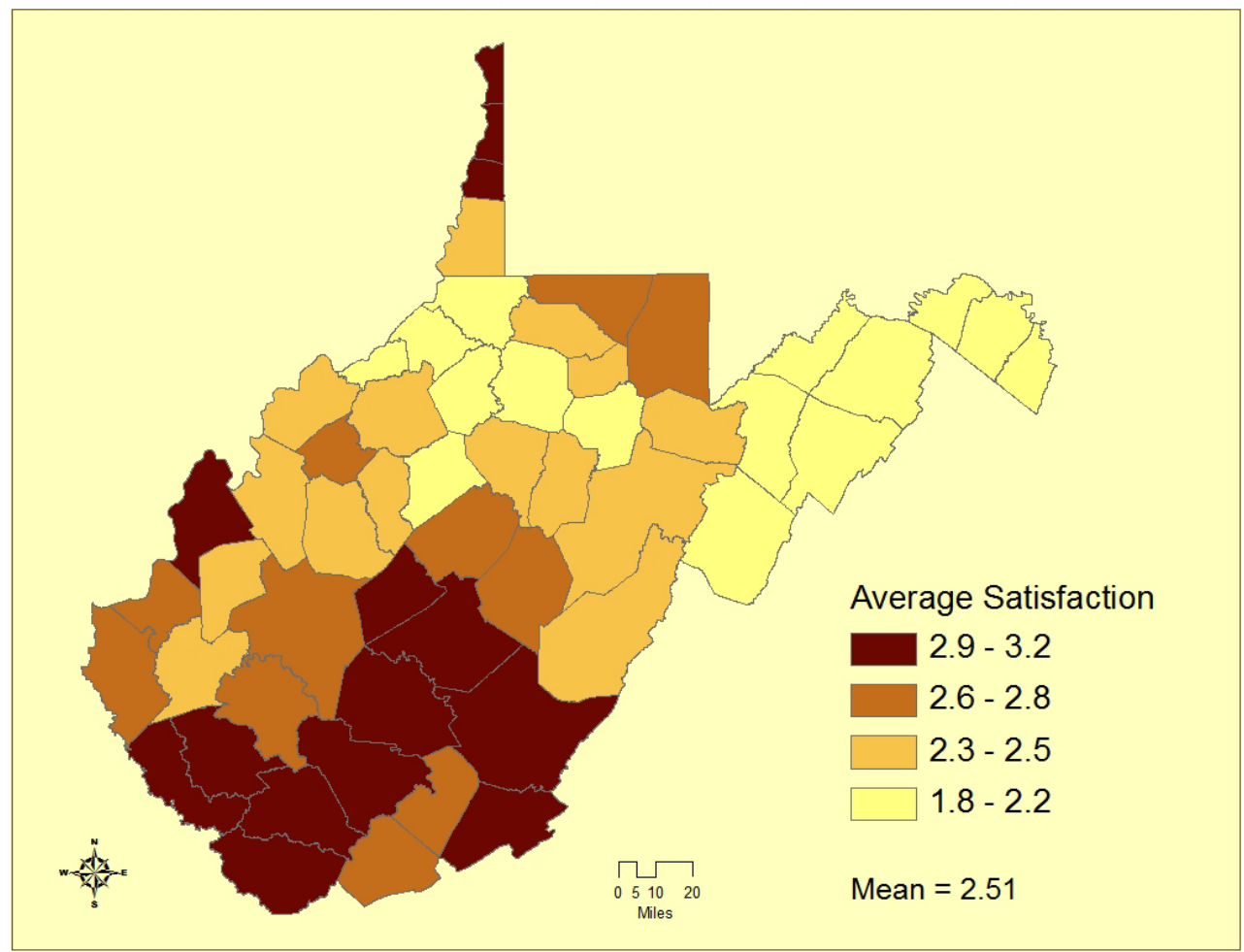

Figure 6. Average level of satisfaction for respondents making observations within each county, based on a Likert scale of 1 to 4 . 
The tree species that NRPs would like to see regenerate most abundantly were red oak (25\%), black cherry (18\%), white oak (14\%), yellow poplar (12\%), and sugar maple (10\%). The tree species that NRPs observed to actually regenerate most abundantly were red maple (25\%), yellow poplar (21\%), beech (8\%), and black cherry (7\%).

Respondents' desired trees were matched against the trees they observed to actually regenerate; for 34\% of respondents, at least one of their desired tree species matched one of the tree species they observed to regenerate most abundantly. The most frequent match between desired species and observed species was yellow poplar, which accounted for $37 \%$ of all matches; all oaks as a group accounted for $26 \%$; and black cherry accounted for $23 \%$ of matches.

\section{Factors affecting satisfaction with regeneration}

Fifty-one percent of respondents were satisfied with regeneration. The factors affecting satisfaction were explored using logistic regression to evaluate the relationship between whether or not respondents were satisfied and eleven independent variables (Table 7). The indicator variable (SATISFACTION; see above) was recoded from a four-level Likert scale to a binary form representing respondents who were either satisfied or dissatisfied in general with regeneration they had observed ( $1=$ satisfied, $0=$ not satisfied). This variable was recoded because the two extreme categories, completely satisfied and completely dissatisfied, contained only 6\% and $7 \%$ of the total distribution, respectively. Not only did these extreme categories contain a relatively low number of cases, the distinction between "completely" and "somewhat" is difficult to interpret. The resulting distribution of respondents into two satisfaction classes was nearly symmetric with $49 \%$ either completely or somewhat dissatisfied and 51\% either completely or 
somewhat satisfied. Hence, SATISFACTION was converted into a dichotomous variable to represent either a satisfied or dissatisfied state.

Three independent variables showed a significant association with satisfaction $(\mathrm{p}<.10)$. First, whether or not a respondent had been involved with timber harvests affected their satisfaction. Respondents who had been involved with at least one timber harvest had about twice the odds of being satisfied with regeneration (odds ratio=2.026) than those who had not been involved with any timber harvests. Second, whether or not respondents saw their desired tree species regenerating affected their satisfaction level. Respondents who observed at least one of their desired species regenerating abundantly had more than 3.5 times the odds of being satisfied (odds ratio $=3.562$ ) than those who did not observe at least one of their desired species regenerating abundantly. Third, whether or not a respondent had concerns about regeneration was strongly associated with his satisfaction level. Respondents with no concerns about regeneration had almost 30 times the odds of being satisfied (odds ratio-29.947) than those who had one or more concerns about regeneration. 
Table 7. Independent variables used in logistic regression to explore their association with a respondent's satisfaction with regeneration. Odds ratios (OR) are presented with $90 \%$ confidence intervals (CI).

\begin{tabular}{|c|c|c|c|}
\hline Independent variable & OR & $90 \% \mathrm{CI}$ & $\mathbf{P}>\chi^{2}$ \\
\hline Years of forestry-related work in WV & 0.999 & $0.981-1.017$ & 0.926 \\
\hline \multicolumn{4}{|l|}{ Natural resource specialty } \\
\hline Other environmental vs. Forestry & 0.292 & $0.075-1.140$ & 0.315 \\
\hline Wildlife vs. Forestry & 0.478 & $0.201-1.135$ & 0.851 \\
\hline \multicolumn{4}{|l|}{ Employment sector } \\
\hline Retired/Other vs. Public & 1.736 & $0.723-4.165$ & 0.756 \\
\hline Private vs. Public & 2.200 & $1.387-3.489$ & 0.109 \\
\hline Number of forestry-related activities & 1.007 & $0.949-1.069$ & 0.847 \\
\hline \multicolumn{4}{|l|}{ Frequency of observing regeneration } \\
\hline High vs. Low & 0.405 & $0.077-2.142$ & 0.338 \\
\hline Medium vs. Low & 0.400 & $0.071-2.252$ & 0.361 \\
\hline Respondent does regeneration assessments & 1.397 & $0.857-2.276$ & 0.260 \\
\hline Respondent does assessments in harvested areas & 2.764 & $0.709-10.782$ & 0.143 \\
\hline Respondent is involved with timber harvests & 2.026 & $1.113-3.688$ & $0.052 *$ \\
\hline Percent of harvests revisited & 1.005 & $0.999-1.102$ & 0.189 \\
\hline Respondent's desired trees are regenerating & 3.562 & $2.910-5.795$ & $<0.001^{*}$ \\
\hline Respondent has no concerns about regeneration & 29.947 & $5.511-162.749$ & $0.001 *$ \\
\hline
\end{tabular}

* Significant at $\mathrm{p}<.10$

\section{Concerns about regeneration}

In the third section of the survey respondents are taken through three iterations of a series of questions. Respondents are first asked for a "top concern,” then for "another concern” and again for "another concern.” Researchers then coded the concerns expressed by respondents into 12 broad categories. Of the 261 respondents, 28 respondents (11\%) did not have any concerns about forest regeneration. Sixty-nine respondents (26\%) had one concern. Eighty-five respondents (33\%) had two concerns. Seventy-nine respondents (30\%) had three concerns. Each 
concern could be coded and placed in up to three concern categories. When given the series of three opportunities to express a concern about forest regeneration, on average each respondent used 1.82 of their opportunities. Figure 7 shows the number of concerns per respondent.

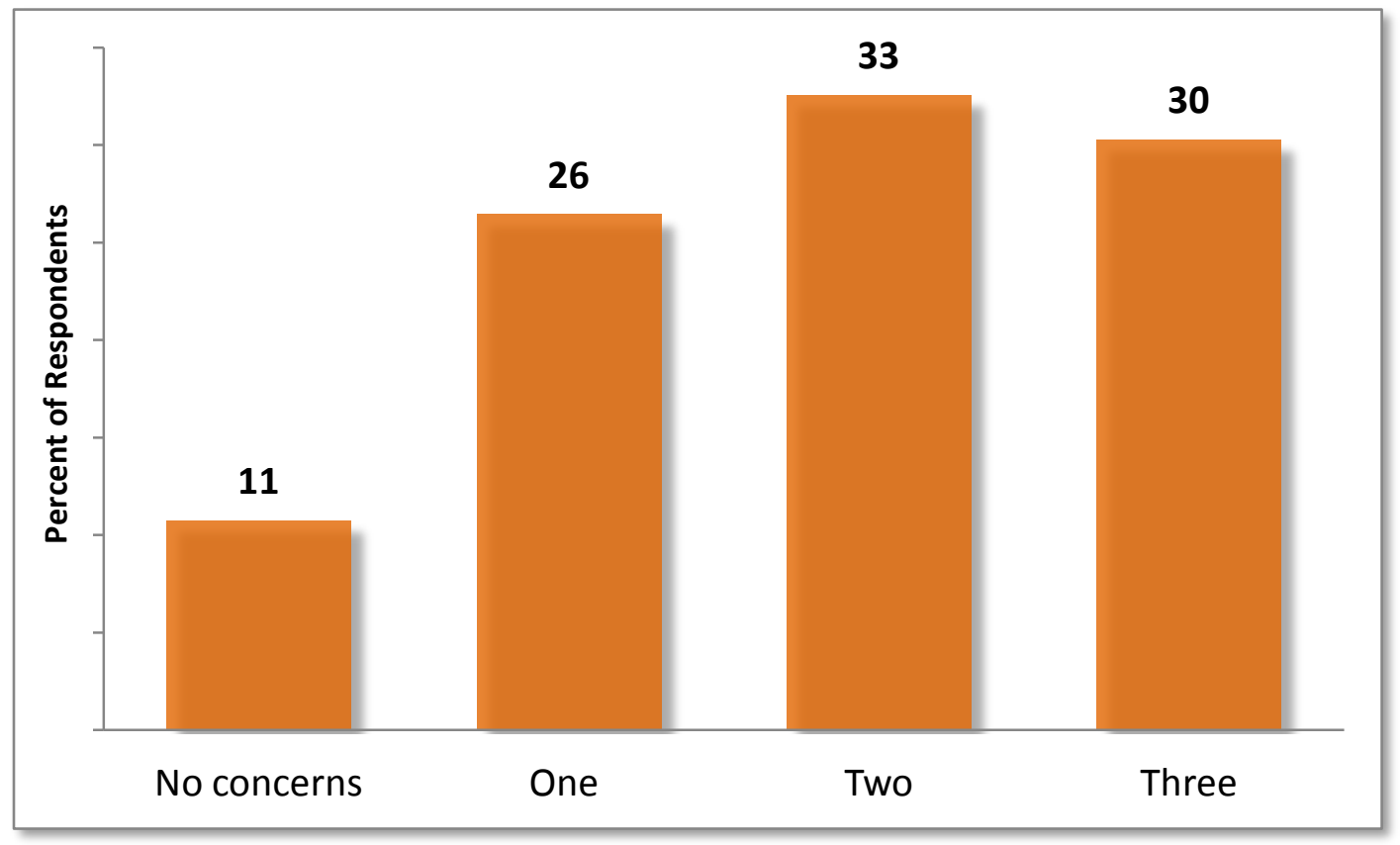

Figure 7. Distribution of the number of concerns per survey respondent.

A respondent could associate each concern with up to four counties. The total number of concerns for all counties was 1,213. Randolph County had the largest number of concerns (82), followed by Hampshire (53), Monongalia (51), Greenbrier (50), and Preston (46). Lincoln County had the fewest number of concerns, with one concern. The average number of concerns per county was 22. Figure 8 depicts the number of concerns per county. 


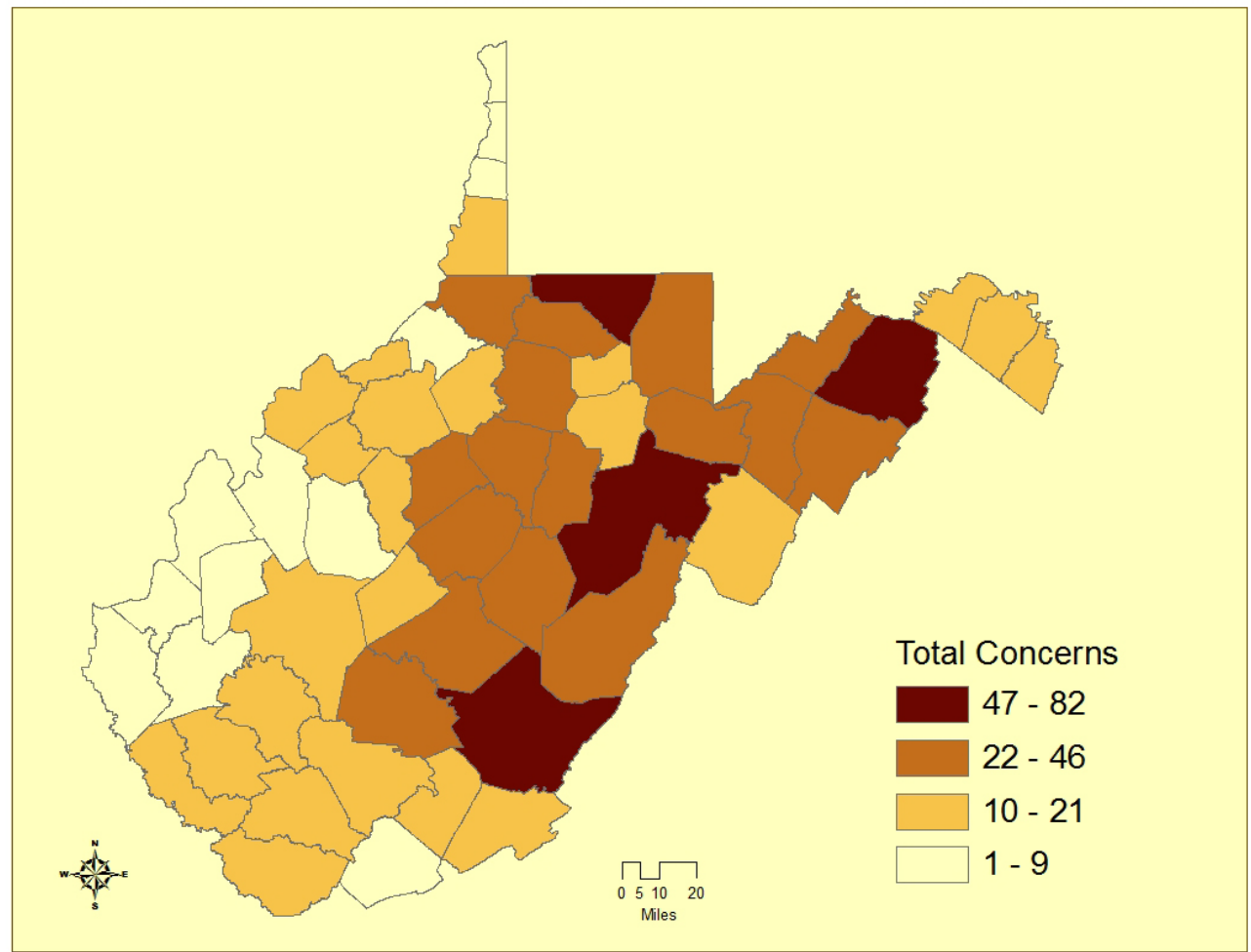

Figure 8. Number of regeneration concerns per county. The mean was 22 concerns.

In general, counties with the greatest numbers of observations also had the greatest numbers of regeneration concerns associated with them. The correlation was 0.877 . However, in order to determine which counties had higher numbers of concerns relative to the number of observations, a ratio of the number of concerns to the number of observations was computed for each county. Harrison County had the highest number of concerns per observation (4.14) followed by Pleasants (3.67), Lewis (2.65), Gilmer (2.54), and Jefferson (2.2). Lincoln and Mercer county had the lowest ratios (.50 and .60 respectively). See Figure 9 for the ratio of concerns to observations for each county. 


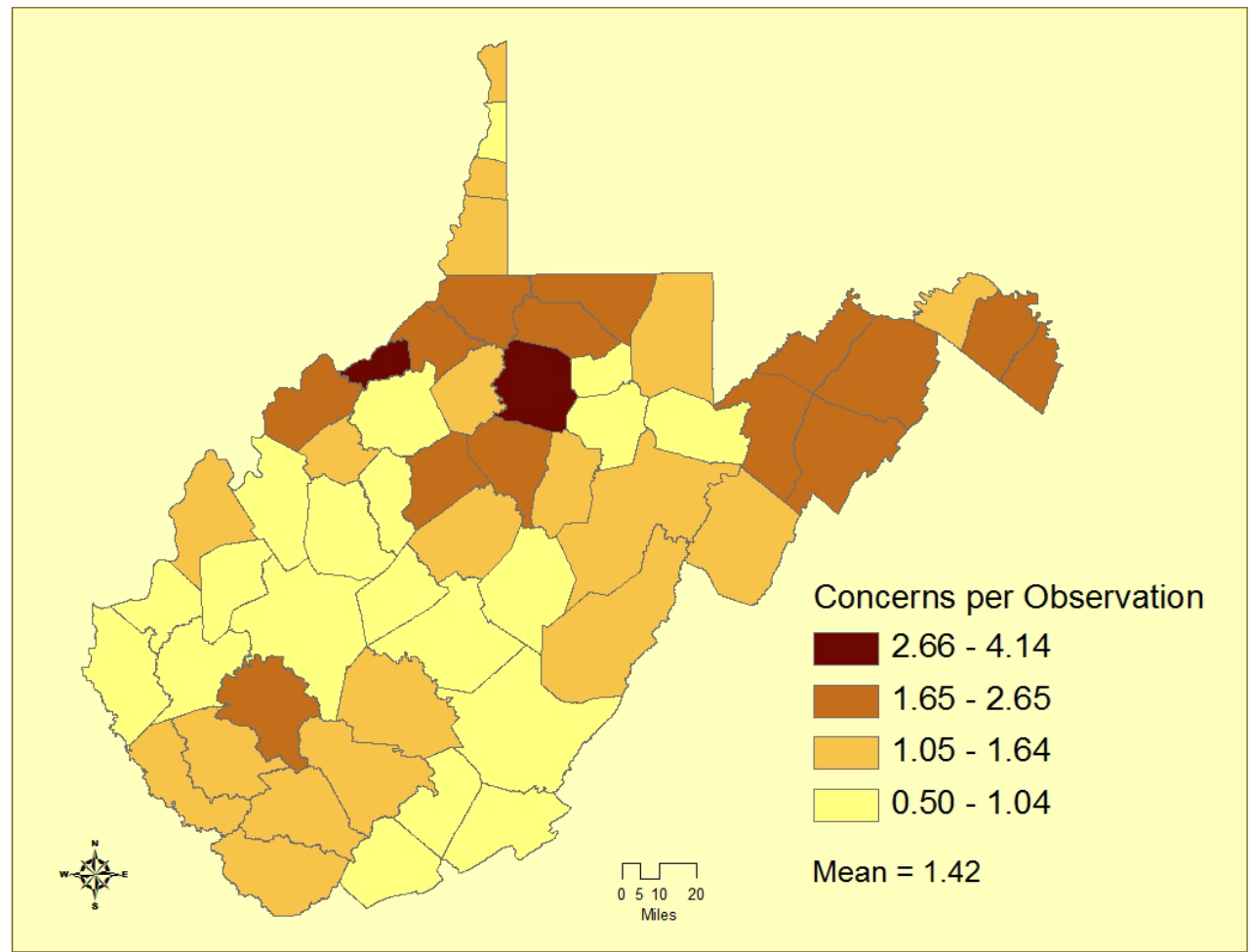

Figure 9. Ratio of concerns to observations for each county.

Concerns about regeneration in West Virginia were placed into 12 main categories. Table 8 lists these categories and the number of respondents who had concerns in each category. The categories of deer, forest management, invasive plants, and composition of regeneration contained the majority of concerns expressed by respondents. Figure 10 displays the relative ranking of these 12 categories of concerns. 
Table 8. Twelve main categories of concerns about forest regeneration.

\begin{tabular}{lcc}
\hline Concern & $\begin{array}{c}\text { Number of } \\
\text { respondents }\end{array}$ & $\begin{array}{c}\text { Percent of all } \\
\text { respondents }\end{array}$ \\
\hline Deer & 124 & 48 \\
Forest Management & 97 & 37 \\
Invasive Plants & 86 & 33 \\
Composition of Regeneration & 73 & 28 \\
Interfering Vegetation & 32 & 12 \\
Health & 22 & 8 \\
Attitudes & 19 & 7 \\
Mineral Development & 15 & 6 \\
Other & 12 & 5 \\
Density of Regeneration & 10 & 4 \\
Wildfire & 10 & 4 \\
Fragmentation & 10 & 4 \\
\hline
\end{tabular}

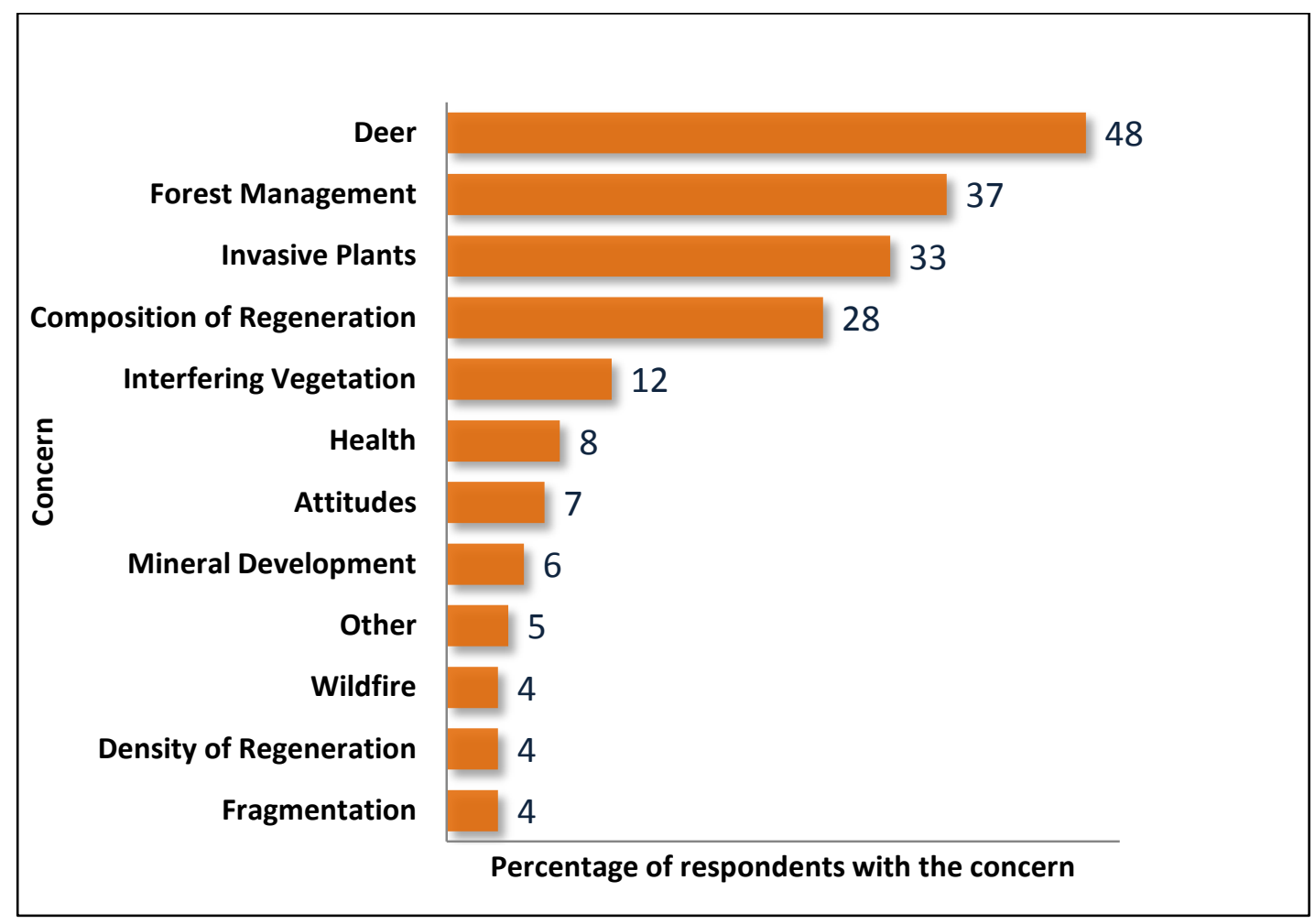

Figure 10. Ranking of twelve categories of concerns about forest regeneration. 


\section{Deer}

The leading concern for natural resource professionals is deer; $48 \%$ of all respondents expressed at least one concern about the impact of deer on forest regeneration. Concerns about deer were coded and placed into two subcategories. Eighty percent (80\%) of respondents who expressed concerns related to deer were concerned about the negative impacts of deer on regeneration in general. This subcategory incorporates several concepts: deer browse is excessive; deer densities are too high; and excessive deer browse is damaging desirable regeneration. There is no mention of any particular species or groups of species.

The other $20 \%$ of respondents had concerns related to the negative impacts of deer on specific tree species or groups of species. Most were concerned with regeneration of oaks: $60 \%$ with oaks in general, and 32\% with regeneration of red oaks in particular; $12 \%$ were concerned about regeneration of conifer species (white pine, loblolly, and balsam fir); and 4\% each were concerned about white oak and black cherry (see Table 9).

Table 9. Distribution of respondents’ concerns related to impacts of deer on regeneration.

$\begin{array}{lc}\text { Deer concern } & \text { Percent of respondents } \\ (n=124,48 \% \text { of respondents) } & \text { within main category }\end{array}$

Concerned about negative impacts of deer in general

Concerned about negative impacts of deer on specific tree species

Tree species of concern

Oaks

Red oaks

Conifers

White oak

Black cherry
80

20

\section{Percent within subcategory}

60

32

12

4

4 
Each respondent could associate a concern about deer with up to four counties. The total number of coded concerns related to deer was 308 . This comprised $25.4 \%$ of all concerns. Roane County had the largest proportion of concerns related to deer (75\%) followed by Doddridge (66.7\%), Mason (66.7\%), Putnam (50\%), and Ritchie (46.7\%). The importance of this concern was not evenly distributed across all counties; it was higher in a broad band of counties stretching across the northern half of the state (see Figure 11). Figure 12 displays the same information about deer concerns using the Inverse Distance Weighted interpolation tool to emphasize broad areas of concern within the state.

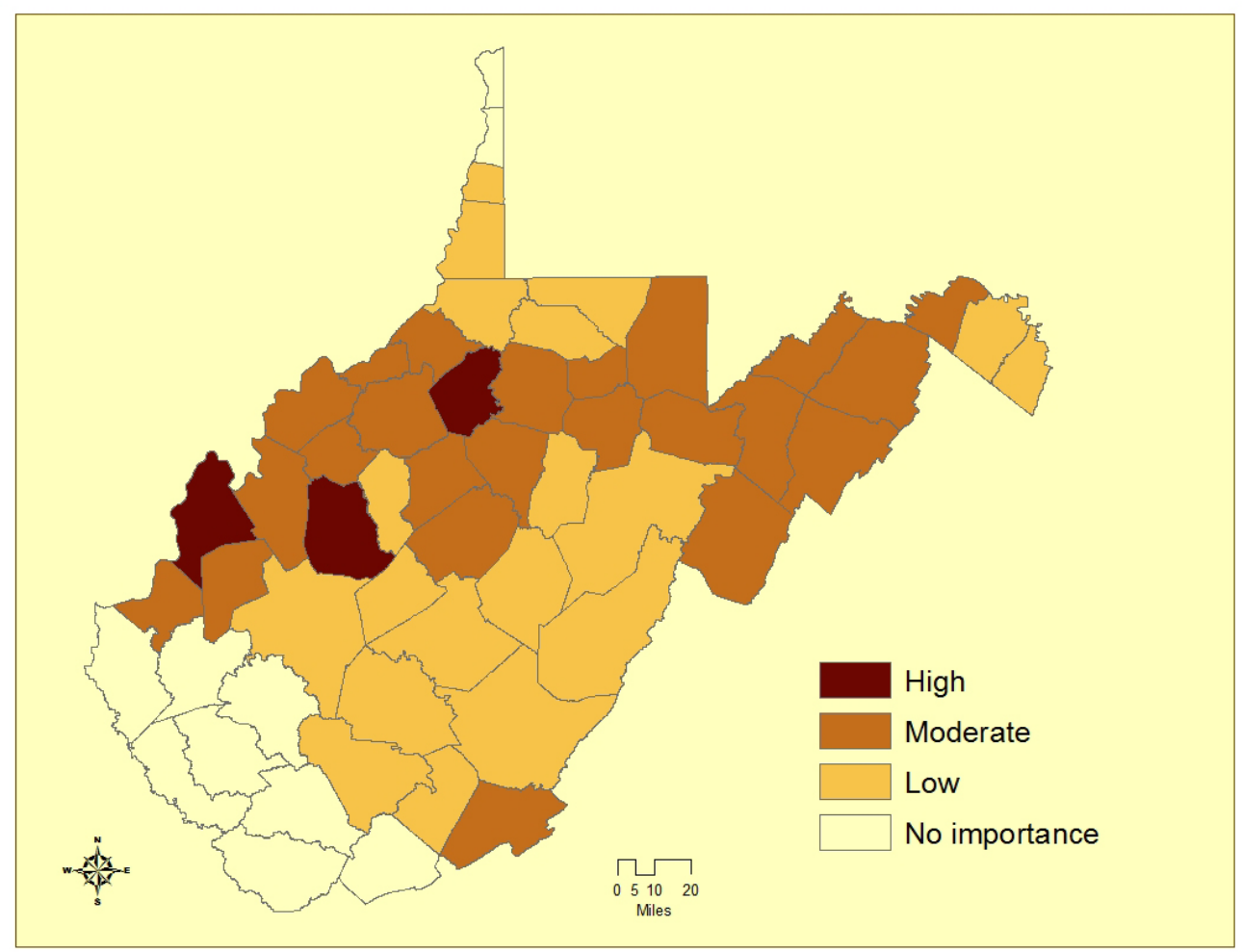

Figure 11. Relative importance of regeneration concerns related to deer. 


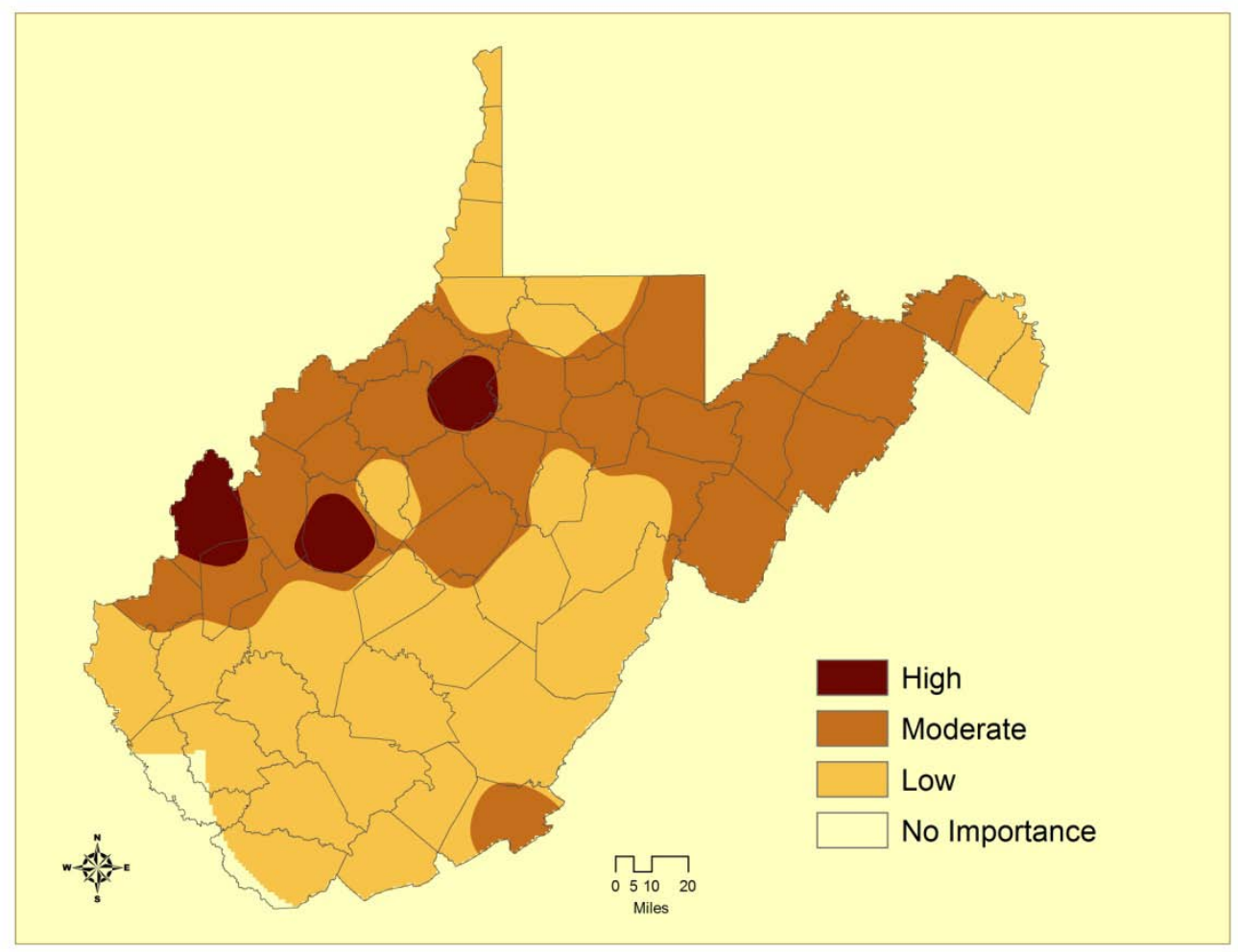

Figure 12. Relative importance of deer concerns mapped using an interpolation tool to emphasize broad areas of concern within the state.

\section{Forest Management}

Thirty-seven percent (37\%) of all respondents expressed concerns related to forest management and regeneration. This was the second most prevalent concern expressed by survey respondents. Survey responses were analyzed and placed into four subcategories in order to obtain more information. It was possible for a response to be coded with more than one subcategory code. Ninety-seven respondents’ concerns were coded into four subcategories to yield 123 subcategory codes. See Table 10 for the distribution of respondents' concerns related to forest management. The following subcategories were included within the forest management category: 


\section{Cutting practices}

Sixty percent (60\%) of respondents who had concerns about forest management had concerns about cutting practices. The majority of these respondents (93\%) specified that their concerns were about the prevalence of high-grading and diameter limit cutting in West Virginia (high-grading 53\%, diameter limits 40\%). Other concerns include poor cutting practices (16\%), partial cuts (7\%), “selective cutting” (5\%), and logging that was driven only by economic interests (3\%).

\section{Silvicultural practices}

Fifty-two percent (52\%) of respondents who had concerns about forest management had concerns about silvicultural practices. Thirty-eight percent of these respondents expressed the general concern that appropriate silvicultural practices are not being applied and that there is a lack of active management. Fifty-eight of these respondents expressed concerns related to this, but more narrowly focused. These concerns include the lack of regeneration harvests, the lack of Timber Stand Improvement, and harvesting without sufficient advanced regeneration. Twelve percent of these respondents were concerned that there is a lack of prescribed fire to help regeneration. Other concerns were a lack of early successional habitat, too many clearcuts, DOF management of state forests, the high cost of protecting seedlings, no concern with diversity of forests, and lack of uneven-aged management.

\section{Environmental impacts of timber harvesting}

Ten percent (10\%) of respondents who were concerned about forest management had concerns about the environmental impacts from timber harvesting. Most were concerned about soil compaction caused by mechanized logging equipment; two were concerned about poor reclamation of skid trails and landings or strip mines. 
Other forest management concerns

Six percent (6\%) of respondents had forest management concerns other than those already mentioned. Three of these were concerned about reforestation with pine species; one each was concerned about DOF mulching requirements, lack of DOF interaction on private land, and the lack of artificial regeneration.

Table 10. Distribution of respondents' concerns related to forest management.

\section{Management Concern (n $=97,37 \%$ of respondents)}

Cutting practices

High-grading

Diameter limit cutting

Poor cutting practices

Partial cuts

Selective cutting

Logging driven by economic interests

Silvicultural practices

Lack of regeneration harvests

Lack of appropriate silviculture

Lack of Timber Stand Improvement

Lack of active management

Lack of prescribed fire

Harvesting without sufficient advanced regeneration

Not enough early successional habitat

DOF mgmt on state lands

Other silvicultural concerns

Environmental impacts of timber harvesting

Other forest management concerns
Percent of respondents within main category

60

\% within subcategory

53

40

16

7

5

3

52

\% within subcategory

28

20

20

18

12

10

4

4

8

10

6 
Each respondent could associate a concern about forest management with up to four counties. The total number of coded concerns related to forest management was 232. This comprised 19\% of all concerns. Jackson and Pocahontas counties had the largest proportion of concerns related to forest management (33\% each) followed by Nicholas (31.6\%), Wirt (30.8\%), Summers (28.6\%), and Greenbrier (28\%). Figure 13 displays the distribution of the relative importance of forest management concerns. Figure 14 displays the same information about forest management concerns using the Inverse Distance Weighted interpolation tool to emphasize broad areas of concern within the state.

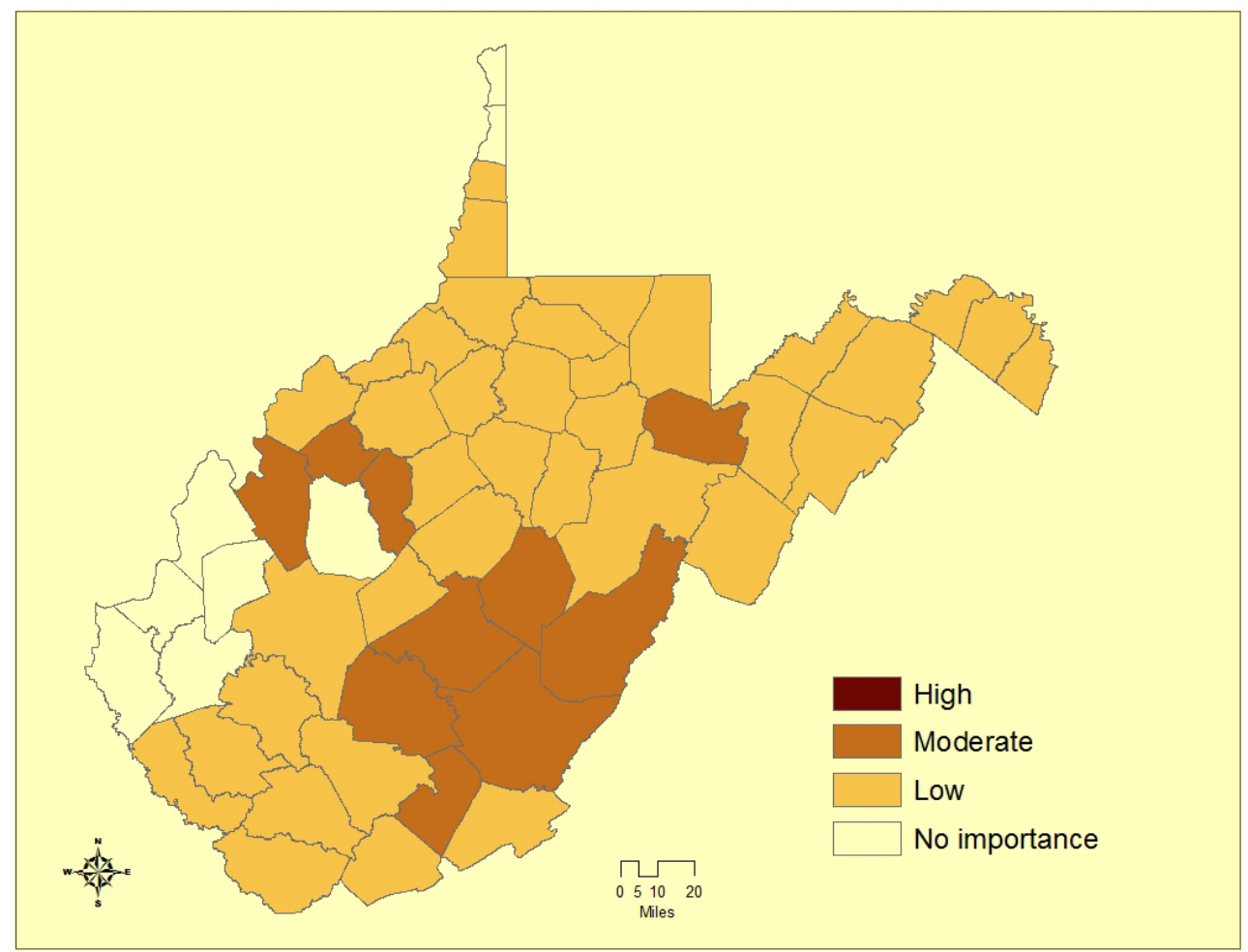

Figure 13. Relative importance of forest management concerns. 


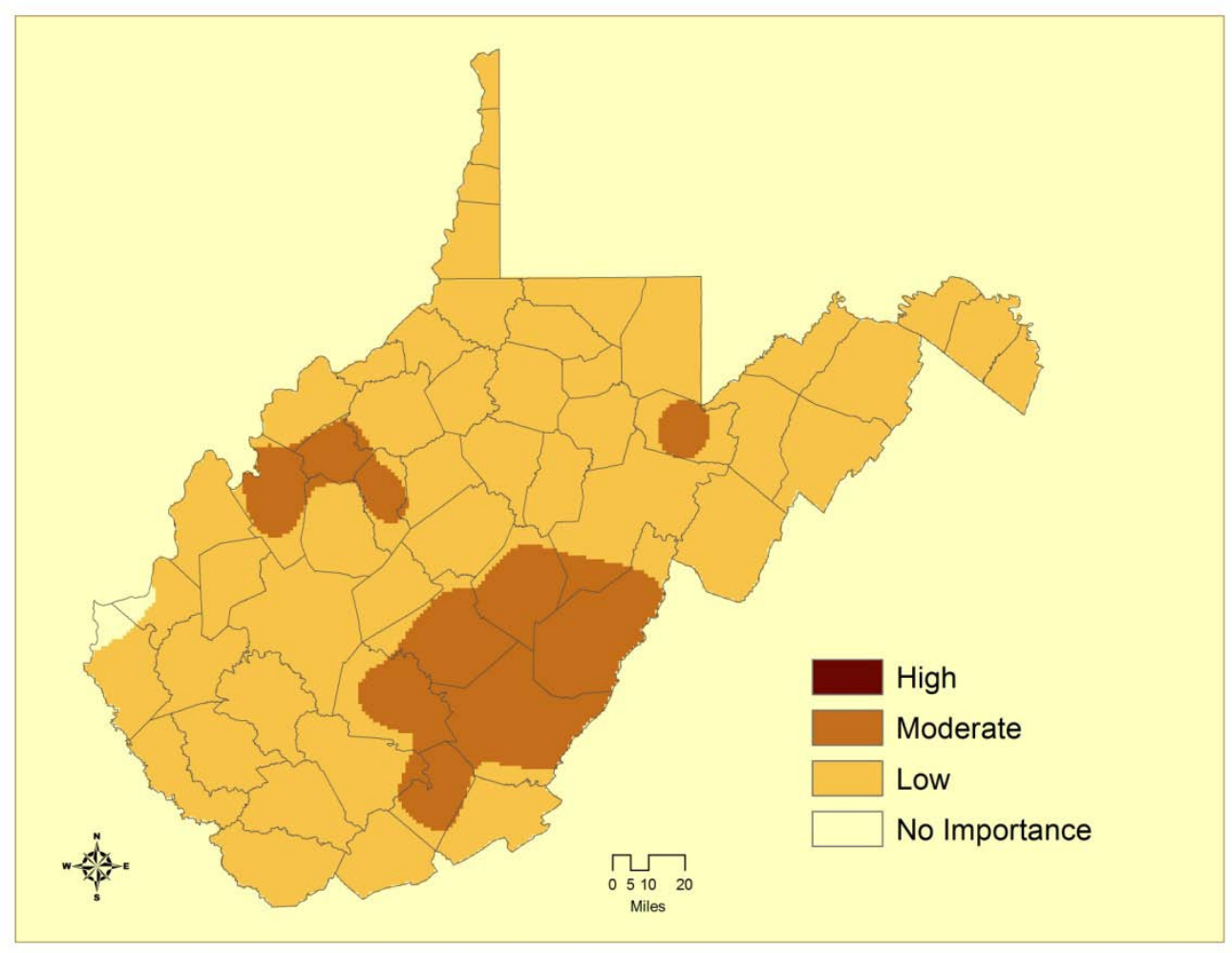

Figure 14. Forest management concerns mapped using an interpolation tool to emphasize broad areas of concern within the state.

\section{Invasive Plants}

Thirty-three percent (33\%) of all respondents (86 respondents) had concerns related to invasive plants. This was the third most prevalent concern expressed by survey respondents. Respondents' concerns were placed into one of two subcategories in order to obtain more information.

Forty-seven percent (47\%) of respondents had concerns about the negative impacts of invasive species in general. Respondents expressed the concepts that invasive species are impacting forest regeneration in a negative manner and that they are dominating forest regeneration. There is no mention of any particular invasive species. 
Fifty-three percent (53\%) of respondents had concerns about the negative impacts of specific invasive species. Respondents expressed the concern that one or more invasive species are negatively impacting forest regeneration and are increasing and are dominating regeneration. The majority of respondents mentioned tree-of-heaven (65\%), followed by Japanese stiltgrass (63\%). Other species mentioned, in order of frequency, were multiflora rose (13\%), autumn olive (13\%), exotic honeysuckles (11\%), oriental bittersweet (11\%), kudzu (9\%), and garlic mustard (9\%). Four percent (4\%) of respondents mentioned Japanese barberry, mile-a-minute, and Japanese knotweed, and one percent (1\%) mentioned Paulownia. See Table 11 for the distribution of respondents' concerns related to invasive plants.

Table 11. Distribution of respondents' concerns related to invasive plants.

\begin{tabular}{lc}
\hline $\begin{array}{l}\text { Invasive plants concern } \\
\text { (n= 86, 33\% of respondents) }\end{array}$ & $\begin{array}{c}\text { Percent of } \\
\text { respondents within } \\
\text { main category }\end{array}$ \\
\hline Concerned about negative impacts of & 47 \\
invasive plants in general & 53 \\
Concerned about negative impacts of & \\
specific invasive plants & Percent within \\
Invasive species of & subcategory \\
concern & 65 \\
Tree-of-heaven & 63 \\
Japanese stiltgrass & 13 \\
Multiflora rose & 13 \\
Autumn olive & 11 \\
Exotic honeysuckles & 11 \\
Oriental bittersweet & 9 \\
Kudzu & 9 \\
Garlic mustard & \\
\hline
\end{tabular}

Each respondent could associate a concern about invasive plants with up to four counties. The total number of coded concerns related to invasive plants was 201. This comprised $16.6 \%$ of 
all concerns. Hancock and Wayne counties had the largest proportion of concerns related to invasive plants (67\% each) followed by Brooke (50\%), Putnam (50\%), Calhoun (36.4\%), and Jefferson (36.4\%). Figure 15 displays the distribution the relative importance of invasive plant concerns. Figure 16 displays the same information about invasive plant concerns using the Inverse Distance Weighted interpolation tool to emphasize broad areas of concern within the state.

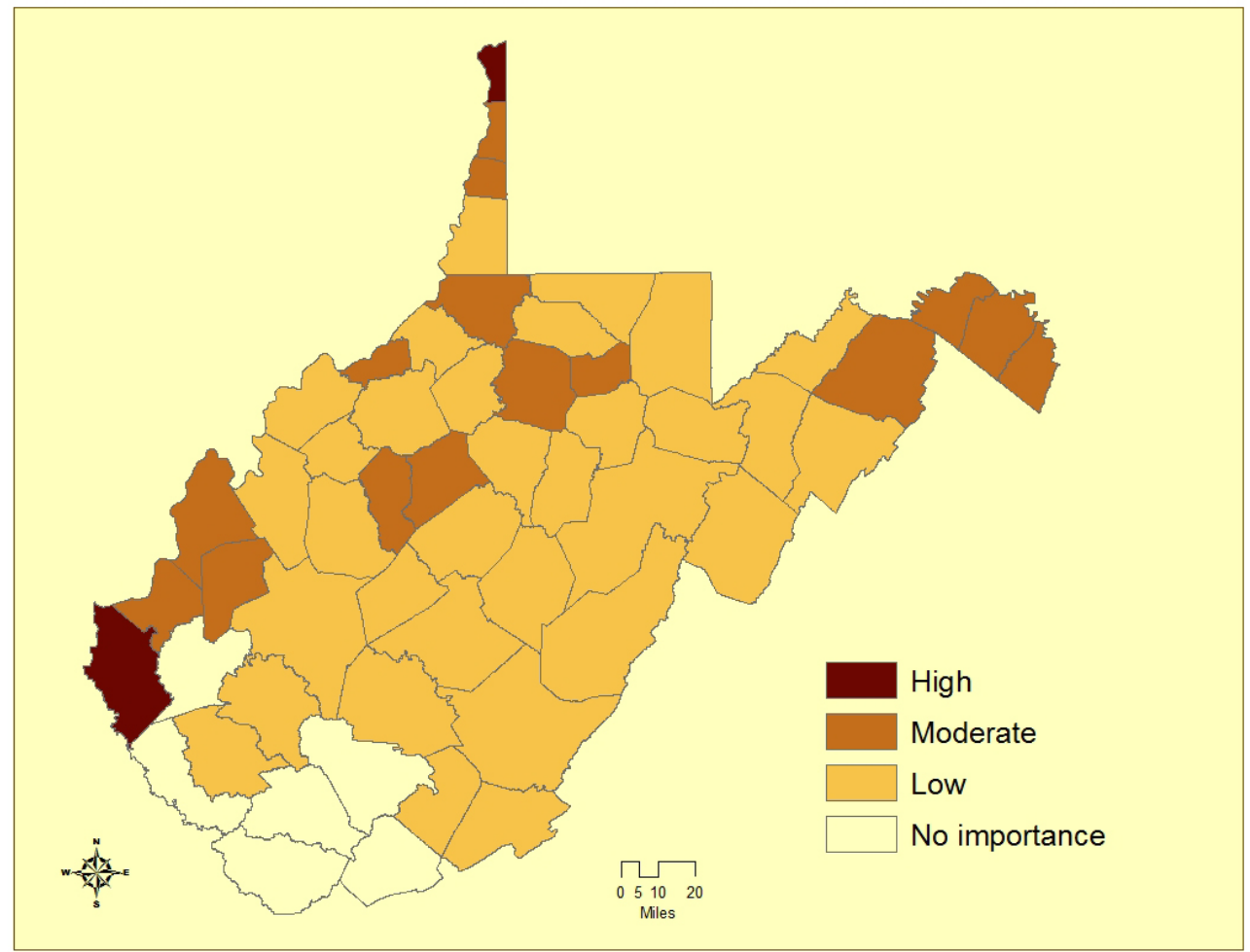

Figure 15. Relative importance of invasive plants. 


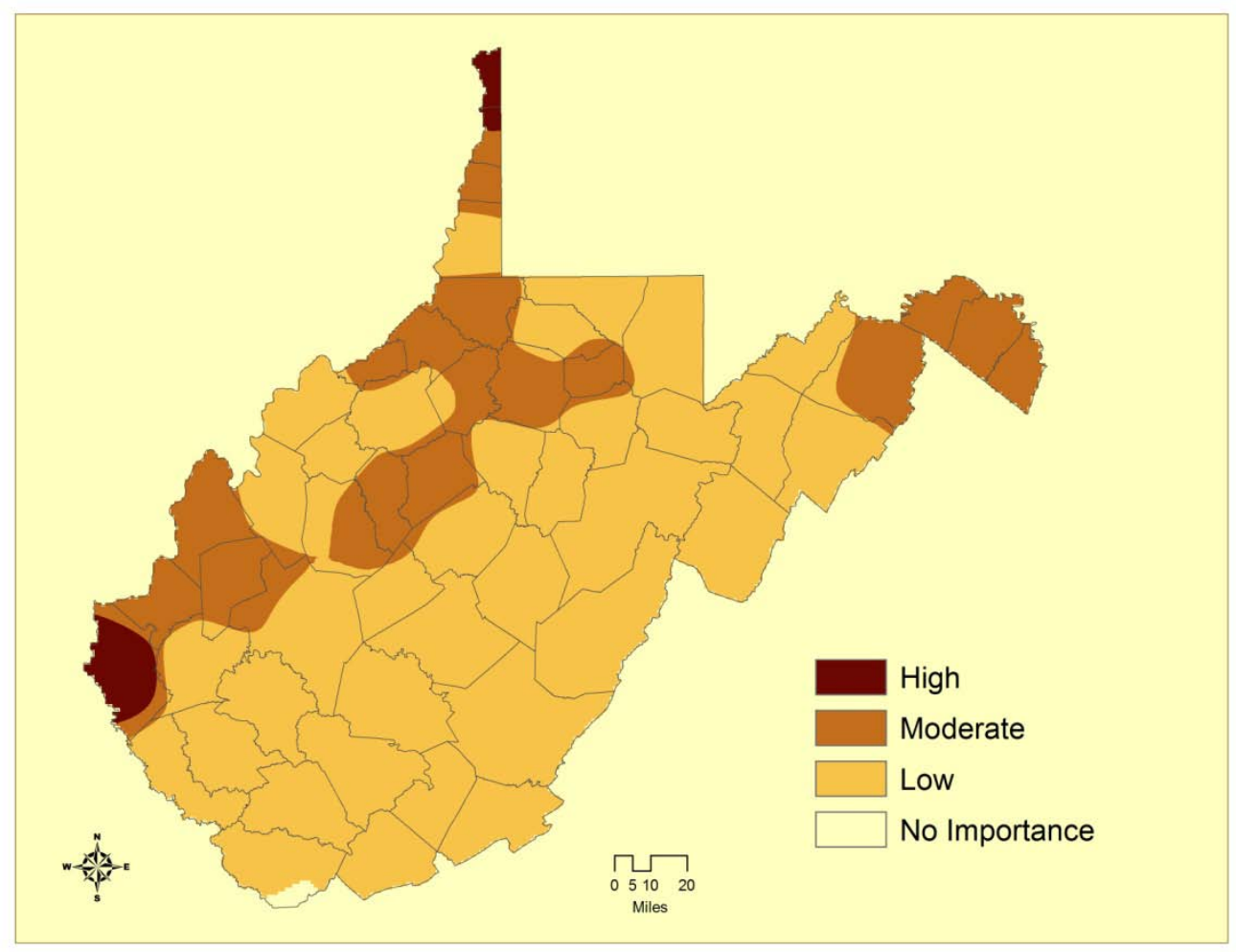

Figure 16. Invasive plant concerns mapped using an interpolation tool to emphasize broad areas of concern within the state.

\section{Composition of Regeneration}

Twenty-eight percent (28\%) of all respondents had concerns related to the composition of regeneration. This was the fourth most prevalent concern expressed by survey respondents. Concerns were placed into four subcategories in order to obtain more information. It was possible for a response to be coded with more than one subcategory code. Seventy-three respondents' concerns were coded into four subcategories to yield 99 subcategory codes. See Table 12 for the distribution of respondents’ concerns related to composition of regeneration.

\section{Lack of adequate desirable regeneration}

Seventy-four percent (74\%) of respondents who expressed concerns related to the composition of regeneration believe that there is a lack of adequate desirable regeneration. Some 
concern was with the lack of desirable regeneration in general, but most (93\%) respondents pointed out one or more particular species that are not regenerating adequately. Of specific tree species, oak was mentioned by $67 \%$ of respondents and red oak was mentioned by $30 \%$. Other species mentioned were black cherry (7\%), hickory (6\%), and white oak (4\%). Sugar maple, walnut, white ash, and yellow poplar were each named by $2 \%$ of respondents. Two percent (2\%) of respondents did not name a species, but stated a concern with lack of regeneration of "shade intolerants.” Seven percent of respondents did not name a particular species or type of tree.

Less desirable species are increasing in importance

Fifty-three percent (53\%) of respondents who expressed concerns related to the composition of regeneration believe that less desirable species are increasing in importance. Their concern was either that in general less desirable species are increasing in importance, or more often the respondent pointed out one or more particular species that are increasing and dominating regeneration. When a species was named, red maple was mentioned by 33\% of respondents followed by fire cherry (21\%), and beech (18\%). Other species mentioned were birch (13\%), striped maple (10\%), yellow poplar (8\%), and unspecified maple (5\%). White pine, sourwood, post oak, paw paw, ironwood, and aspen were each mentioned by 3\% of respondents. Eighteen (18\%) percent did not name any species but stated a concern with the increase in importance of "shade tolerants.” Thirteen percent (13\%) of respondents with concerns in this subcategory did not name any particular species or type of trees.

The third subcategory expresses the concern that the species diversity of regeneration is decreasing; three percent (3\%) of responses were coded into this subcategory.

The fourth category expresses the concern that in general, the species composition of regeneration is changing. There is no mention of "desirable species" as opposed to "less 
desirable” species as in the first and second subcategories. No particular tree species are mentioned. Five percent (5\%) of respondents' concerns were placed into this category.

Table 12. Distribution of respondents' concerns related to composition of regeneration.

\begin{tabular}{cc}
\hline $\begin{array}{l}\text { Composition of Regeneration } \\
\text { (n= 73, 28\% of respondents) }\end{array}$ & $\begin{array}{l}\text { Percent of respondents within } \\
\text { main category }\end{array}$ \\
\hline Lack of adequate desirable regeneration & 74 \\
Oaks (general) & 67 \\
Red oak & 30 \\
Black cherry & 7 \\
Hickory & 6 \\
White oak & 4 \\
No species named & 7
\end{tabular}

Less desirable species increasing in importance 53

Red maple 33

Fire cherry $\quad 21$

Beech 18

Shade intolerants 18

Birch 13

Striped maple $\quad 10$

Yellow-poplar $\quad 8$

Unspecified maple $\quad 5$

No species named 13

Species diversity of regeneration is decreasing 3

Composition of regeneration is changing (no mention of desirable vs. less desirable species)

Each respondent could associate a concern about composition of regeneration with up to four counties. The total number of coded concerns related to composition of regeneration was 171. This comprised $14 \%$ of all concerns. Raleigh County had the largest proportion of concerns 
related to composition of regeneration (37.5\%) followed by Mercer (33\%), Fayette (28.6\%), Summers (28.6\%), and Nicholas (26.3\%). Figure 17 displays the relative importance of concerns about composition of regeneration across West Virginia. Figure 18 displays the same information using the Inverse Distance Weighted interpolation tool to emphasize broad areas of concern within the state.

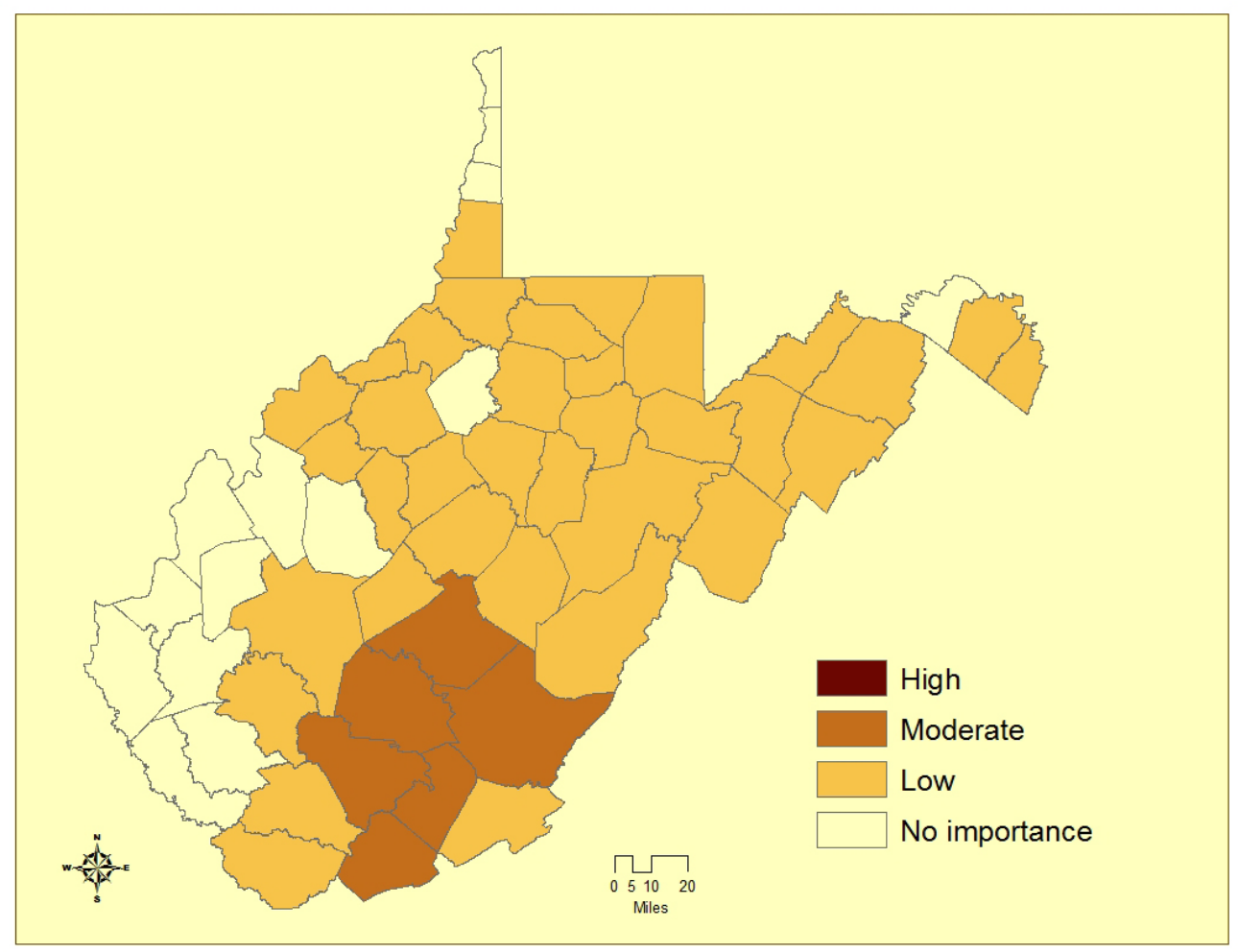

Figure 17. Relative importance of concerns about composition of regeneration. 


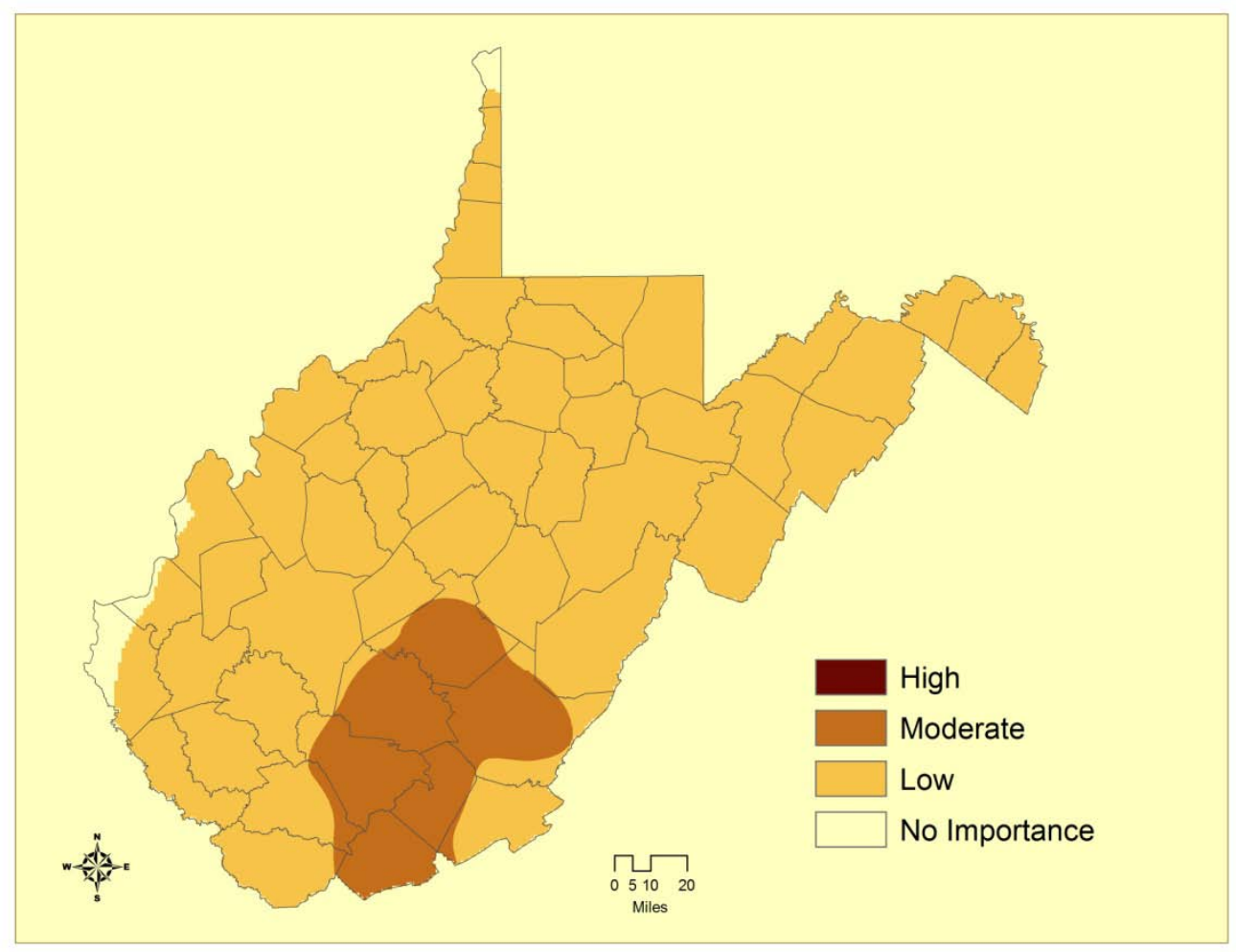

Figure 18. Concerns about composition of regeneration mapped using an interpolation tool to emphasize broad areas of concern within the state.

\section{Interfering vegetation}

For the purposes of this project, the term "invasive species" refers to non-native plant species. However, some respondents refer to native plants (such as beech and striped maple) that can invade an area as "invasive species." If the term "invasive plants” is used, but the concern explicitly mentions a native tree or other plant, this is considered "interfering vegetation."

Thirty two respondents (12\% of total) had concerns about vegetation that interferes with and negatively impacts desirable forest regeneration. See Table 13 for the distribution of respondents' concerns related to composition of regeneration. One respondent mentioned “undesirable plants that cause poor regeneration”, but all other respondents specified one or more particular types of plants. Three plants were of most concern: beech ( $44 \%$ of respondents in this 
concern group named beech), fern (named by $41 \%$ of respondents in this group), and striped maple (28\% of respondents). Other plants named were grasses (13\%), fire cherry and grapevine (9\%) each, and birch (6\%). Several other plants were mentioned by one respondent each:

greenbrier, red maple, hornbeam, mountain maple, spicebush, and paw paw.

Table 13. Distribution of respondents’ concerns related to interfering vegetation.

\begin{tabular}{lc}
\hline $\begin{array}{l}\text { Interfering vegetation } \\
\text { (n= 32, 12\% of respondents) }\end{array}$ & Percent \\
\hline Beech & 44 \\
Ferns & 41 \\
Striped maple & 28 \\
Grasses & 13 \\
Fire cherry & 9 \\
Grapevine & 9 \\
Birch & 6 \\
\hline
\end{tabular}

Each respondent could associate a concern about composition of interfering vegetation with up to four counties. The total number of coded concerns related to interfering vegetation was 82 . This comprised $6.8 \%$ of all concerns. Lincoln County had the largest proportion of concerns related to interfering vegetation (100\%) followed by Logan (20\%), Webster (18.2\%), Mingo (17.6\%), and Clay (16.7\%). Figure 19 displays the relative importance of concerns about interfering vegetation across West Virginia. 


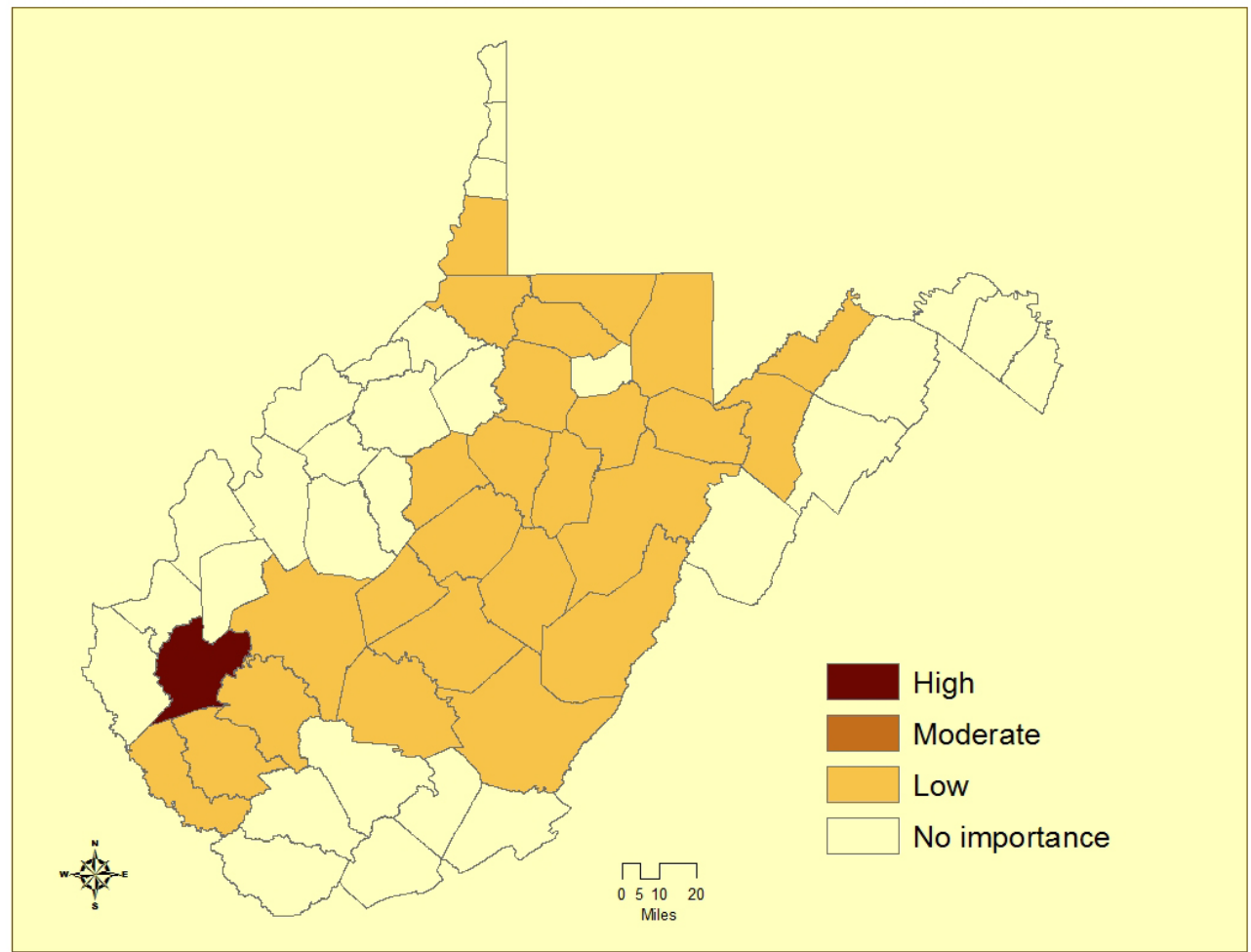

Figure 19. Relative importance of concerns about interfering vegetation.

\section{Forest Health}

Eight percent (8\%) of all respondents expressed concerns related to forest health.

Respondents' concerns were placed into four subcategories in order to obtain more information. See Table 14 for the distribution of respondents’ concerns related to forest health. Fifty-nine percent (59\%) of respondents who were concerned about forest health stated that one or more specific insects are having a negative impact on forest regeneration. The majority of respondents mentioned emerald ash borer (62\%), followed by gypsy moth (46\%) and hemlock wooly adelgid (38\%). Other species mentioned were balsam wooly adelgid and southern pine beetle (8\% each).

Thirty-two percent of respondents who were concerned about forest health stated that one or more specific diseases are having a negative impact on forest regeneration. Four respondents 
mentioned beech bark disease, and white pine blister rust, chestnut blight, oak wilt, black knot, and thousand canker diseases were mentioned by one respondent each.

Twenty-three percent of respondents who were concerned about forest health mentioned that insects and/or disease in general are having a negative impact on regeneration, without mentioned any specific insects or diseases. Fourteen percent of respondents mentioned other forest health issues such as white oak die-off.

Table 14. Distribution of concerns related to forest health.

\begin{tabular}{ll}
\hline $\begin{array}{l}\text { Forest Health } \\
\text { (n= 22, 8\% of respondents) }\end{array}$ & $\begin{array}{l}\text { Percent of respondents within } \\
\text { main category }\end{array}$ \\
\hline
\end{tabular}

Specific insect has negative impact

Emerald ash borer

sy moth

Hemlock wooly adelgid

Balsam wooly adelgid

Southern pine beetle

Specific disease has negative impact

Beech bark disease

White pine blister rust

Chestnut blight

Oak wilt

Black knot

Thousand canker disease
59

$\%$ within subcategory

62

46

38

8

8

32

\% within subcategory

57

14

14

14

14

14

23

14

Other forest health issue

Each respondent could associate a concern about forest health with up to four counties.

The total number of coded concerns related to forest health was 46 . This comprised $3.8 \%$ of all concerns. Brooke County had the largest proportion of concerns related to forest health (50\%) 
followed by Hancock (33\%), Ohio (33\%), Monroe (18.2\%), and Mercer (11.1\%). Figure 20 displays the relative importance of concerns about forest health across West Virginia.

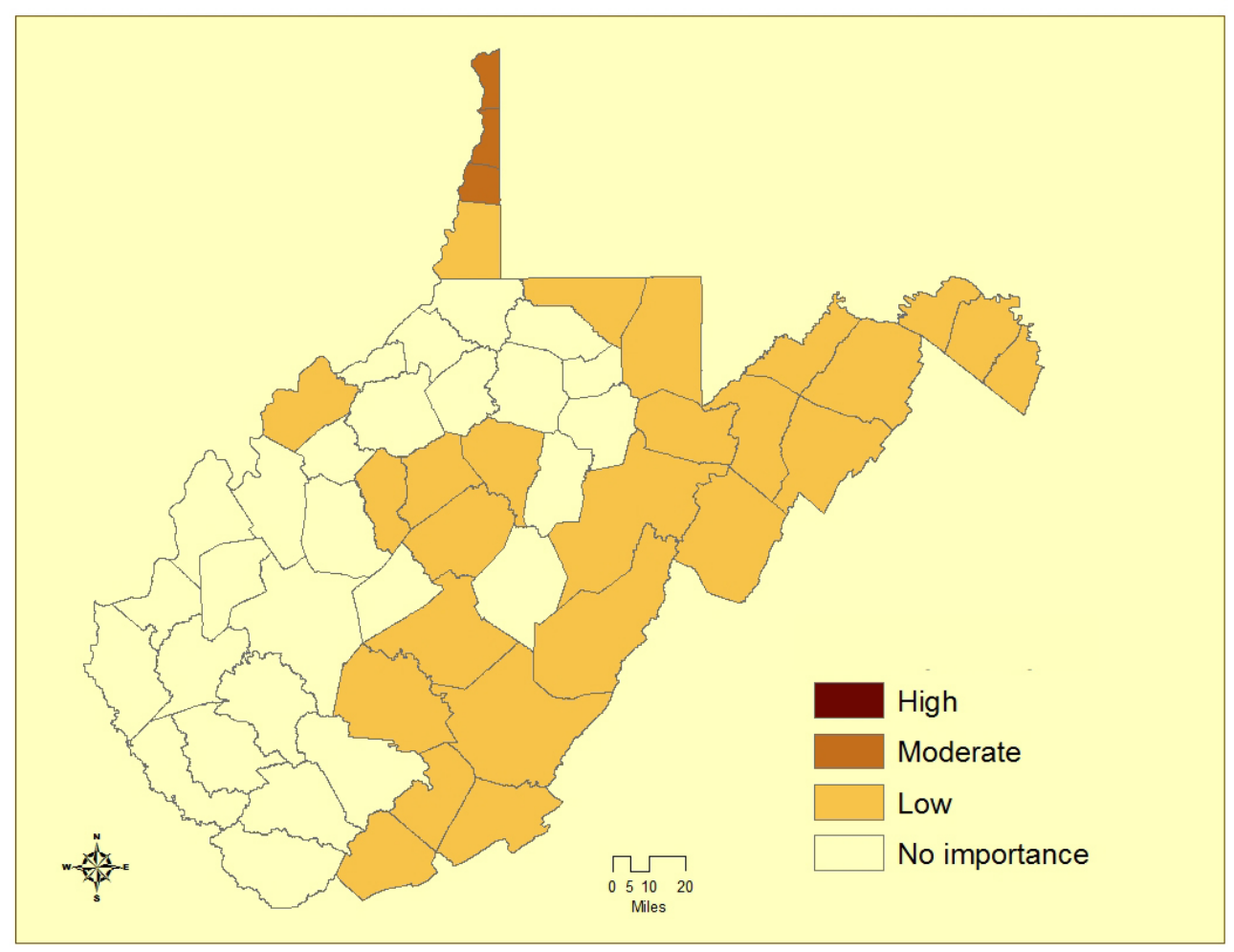

Figure 20. Relative importance of concerns about forest health.

\section{Awareness and Attitudes}

Nineteen respondents (7\% of all respondents) expressed concerns related to the attitudes and awareness of both landowners and the public. The major concern of respondents in this category (68\% of respondents) is the idea that landowners lack awareness about the importance of regeneration and the importance of spending time and money to ensure adequate regeneration. Related to this concern is the idea that the profession of forestry is undervalued by landowners (2 respondents) and that there is a lack of assistance from the DOF to landowners to encourage the importance of regeneration (2 respondents). Other concerns were that public attitudes toward 
clearcuts and prescribed fire were an obstacle to use of these methods to encourage adequate regeneration (1 respondent each).

Each respondent could associate a concern about awareness and attitudes with up to four counties. The total number of coded concerns related to awareness and attitudes was 44 . This comprised 3.8\% of all concerns. Cabell County had the largest proportion of concerns related to awareness and attitudes (33\%) followed by Jackson (16.7\%), Summers (14.3\%), Raleigh (12.5\%), and Mercer (11.1\%). Figure 21 displays the relative importance of concerns about attitudes across West Virginia.

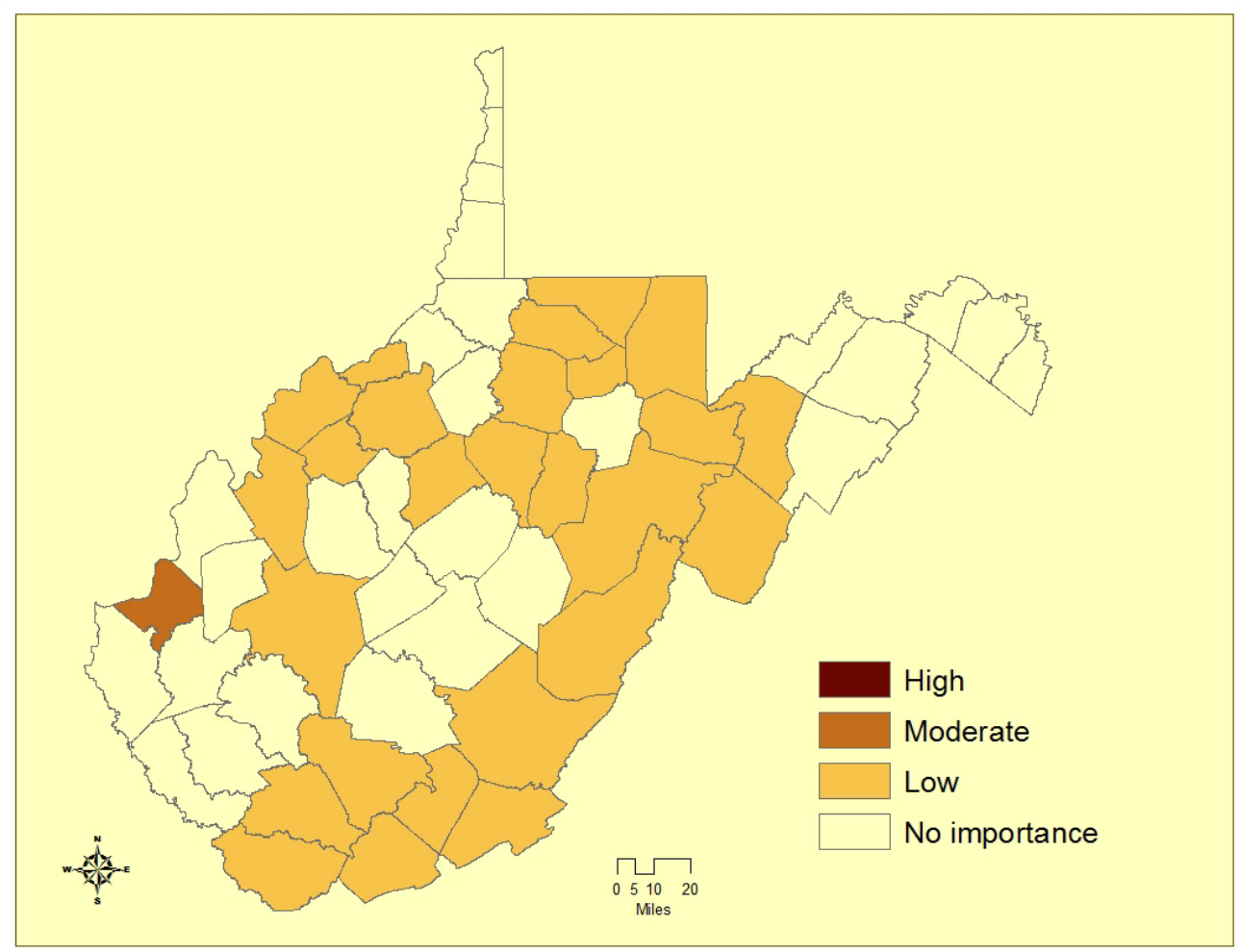

Figure 21. Relative importance of concerns about attitudes. 


\section{Mining and Mineral Development}

Fifteen respondents ( $6 \%$ of total) were concerned about mining and other mineral development. Eighty percent (80\%) of respondents in this group have observed a lack of regeneration on former surface mines and are concerned that surface mines negatively impact forest regeneration. The lack of regeneration on former surface mines was attributed to erosion or soil compaction. Twenty percent (20\%) of respondents in this group mentioned that oil and gas development is fragmenting forest land. Each respondent could associate a concern about mineral development with up to four counties. The total number of coded concerns related to mineral development was 33. This comprised $2.7 \%$ of all concerns. Boone County had the largest proportion of concerns related to mineral development (35.3\%) followed by Wayne (33.3\%), Mingo (29.4\%), McDowell (28.6\%), and Logan (25\%). Figure 22 displays the relative importance of concerns about mineral development across West Virginia.

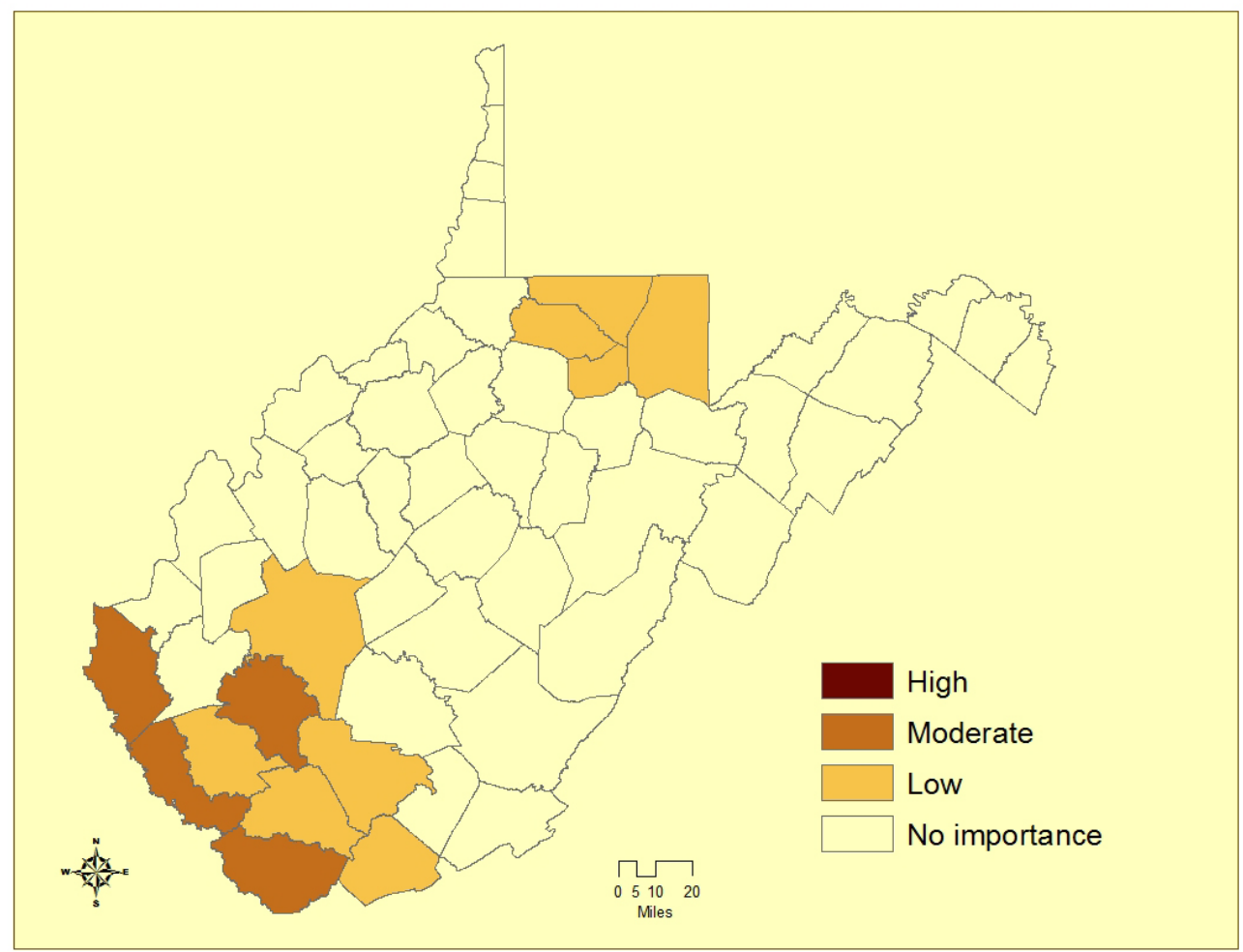

Figure 22. Relative importance of concerns about mineral development. 


\section{Density of Regeneration}

Four percent (4\%) of all respondents had concerns related to the density of forest regeneration. Most respondents (80\%) stated they are observing either no advanced regeneration of desirable tree species or little advanced regeneration of desirable tree species. Two respondents expressed the concern that regeneration is too dense, and that there are too many stems per acre. Each respondent could associate a concern about density of regeneration with up to four counties. The total number of coded concerns related to density of regeneration was 20 . This comprised $1.6 \%$ of all concerns. Wood County had the largest proportion of concerns related to density of regeneration (6.3\%) followed by Fayette (5.7\%), Upshur (5.7\%), Hardy (5.3\%), and Nicholas (5.3\%). Figure 23 displays the relative importance of concerns about regeneration density across West Virginia.

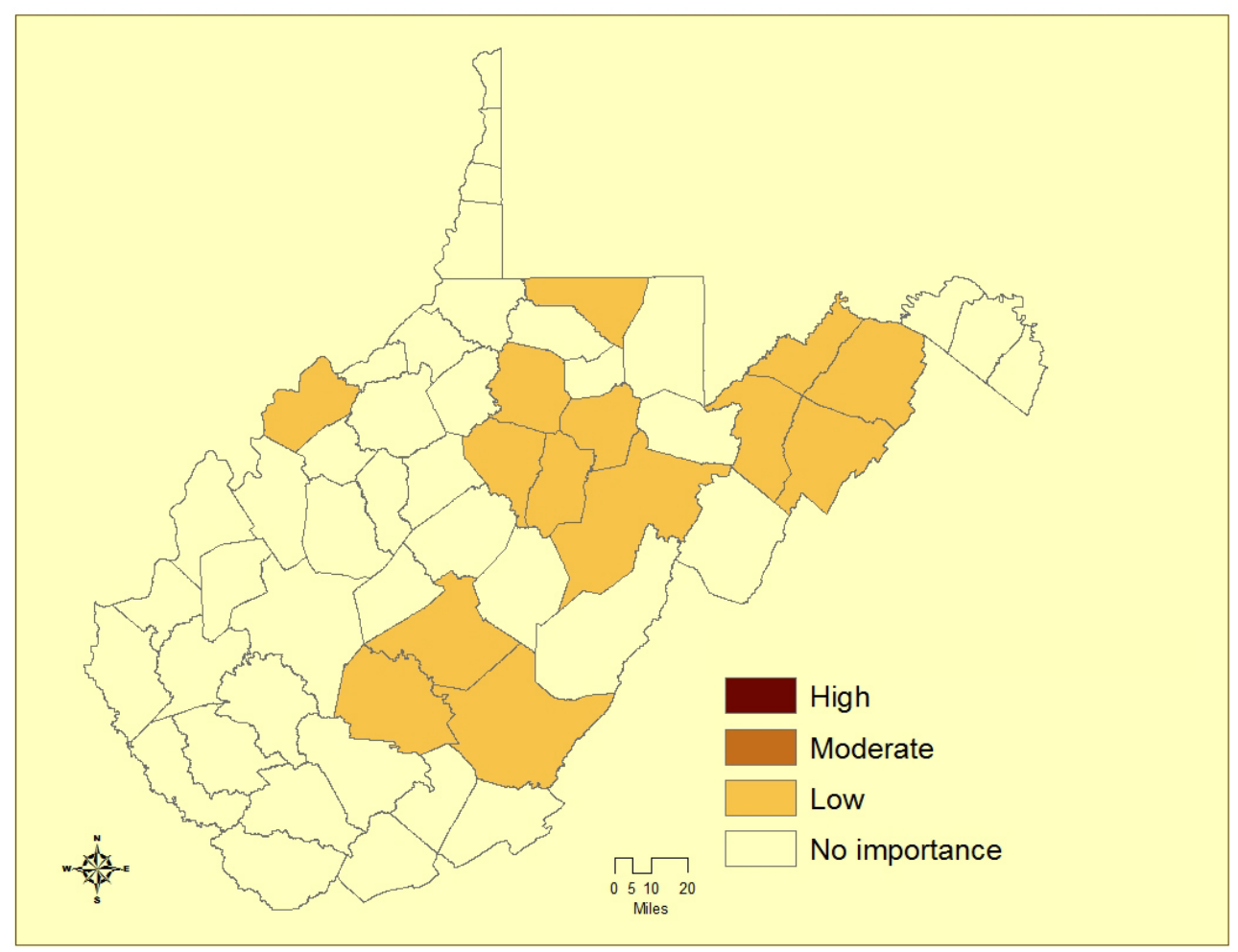

Figure 23. Relative importance of concerns about regeneration density. 


\section{Wildfire}

Four percent (4\%) of all respondents expressed concerns related to the negative impacts of wildfires on forest regeneration. Wildfires concerned respondents because of fire scars and timber defects, soil damage, and an increase in undesirable species. Respondents were concerned about recurring fires in southern West Virginia that destroy any oaks that are regenerating.

Each respondent could associate a concern about wildfire with up to four counties. The total number of coded concerns related to wildfire was 24 . This comprised $2 \%$ of all concerns. Wyoming County had the largest proportion of concerns related to wildfire (30.8\%) followed by Logan (25\%), Mingo (23.5\%), McDowell (21.4\%), and Boone (17.6\%). Figure 24 displays the relative importance of concerns about wildfire across West Virginia.

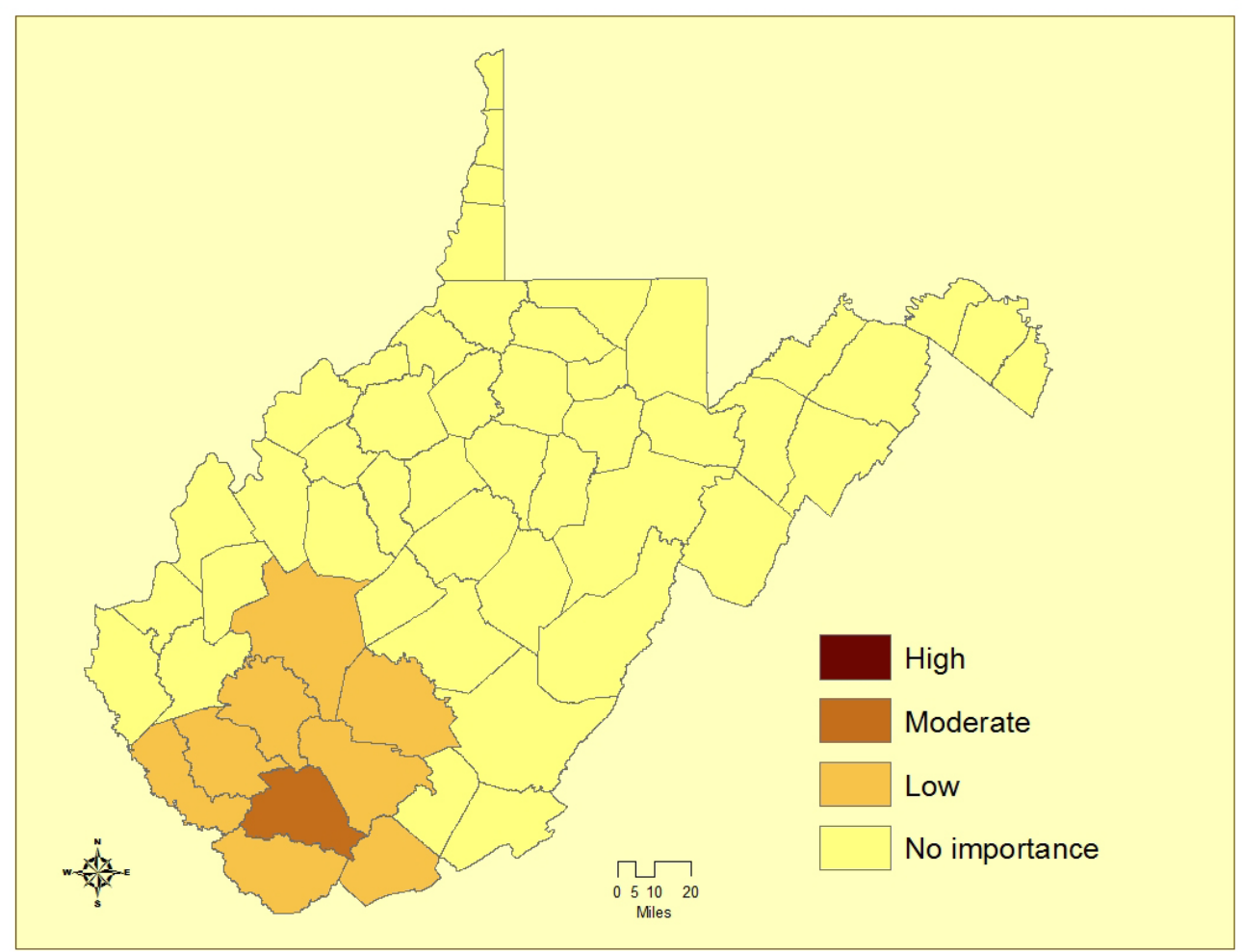

Figure 24. Relative importance of concerns about wildfire. 


\section{Fragmentation}

Four percent (4\%) of all respondents had concerns related to the negative impact of forest fragmentation on regeneration. Respondents mentioned a variety of factors. The majority (80\%) are concerned that residential, commercial, and industrial development is converting forest land to non-forest uses. The remaining $20 \%$ are concerned in a more general sense that forest land is being fragmented and that fragmentation is negatively impacting forest regeneration.

Each respondent could associate a concern about fragmentation with up to four counties. The total number of coded concerns related to fragmentation was 35 . This comprised $2.9 \%$ of all concerns. Hampshire County had the largest proportion of concerns related to fragmentation (14.3\%) followed by Marion (14.3\%), Monongalia (14.3\%), Preston (9.5\%), and Randolph (9.5\%). Figure 25 displays the relative importance of concerns about fragmentation across West Virginia.

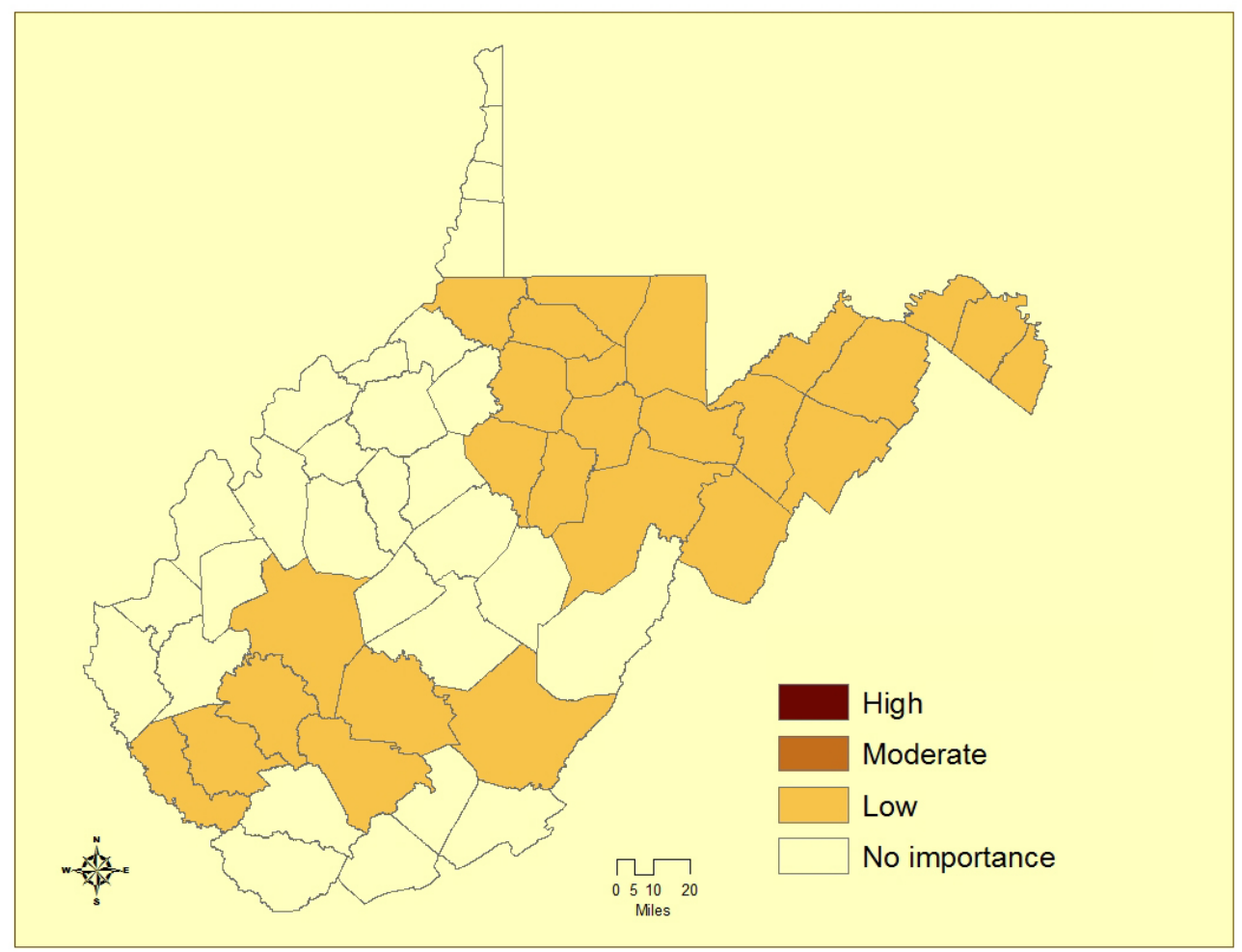

Figure 25. Relative importance of concerns about fragmentation. 


\section{Other concerns}

Five percent of respondents had concerns that were placed into an "Other” category. This was a diverse mix of concerns. Four of these responses were worded such that the actual concern could not be determined due to insufficient explanation on the part of the respondent. Other concerns were a poor timber market (2 respondents), damage to regeneration from weather, pollution, exposed topsoil leading to erosion and poor regeneration, no market for cull logs and tops, poor regeneration on sandstone, and modified water levels and hydrologic regimes along rivers that impacted riparian forests (one respondent each).

Each respondent could associate a concern about other issues with up to four counties. The total number of coded concerns related to other issues was 17 . This comprised $1.4 \%$ of all concerns. Marshall County had the largest proportion of concerns related to other issues (18.2\%) followed by Tyler (12.5\%), Pleasants (9.1\%), McDowell (7.1\%), and Wood (6.3\%). Figure 26 displays the relative importance of other concerns about regeneration across West Virginia. 


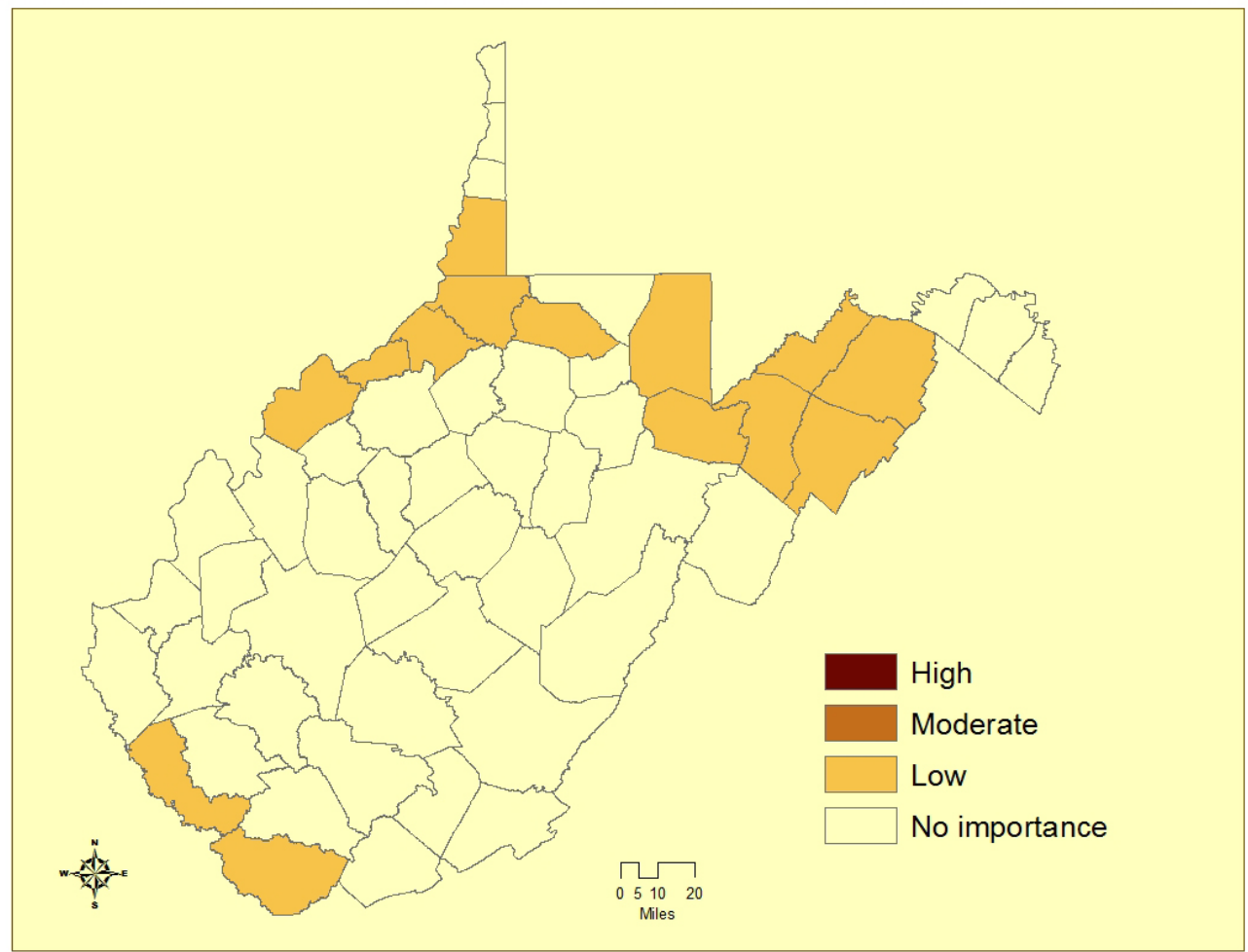

Figure 26. Relative importance of other concerns about regeneration. 


\section{CHAPTER V}

\section{Discussion}

The objectives of this research were to determine how natural resource professionals perceive the quality of regeneration, their level of satisfaction with regeneration, the types of concerns they have, and the locations and spatial variability of their regeneration concerns.

When asked about their satisfaction with the forest regeneration they have seen in West Virginia during the past 10 years, almost half (49\%) of 261 natural resource professionals (NRPs) reported they were dissatisfied. Eighty-nine percent had at least one concern about regeneration, while $30 \%$ had three concerns. For two-thirds (66\%) of respondents, the trees they would like to see regenerate most abundantly did not correspond to the trees they actually observed to regenerate most abundantly. In general, satisfaction with regeneration was highest in the southwestern, southern, and southeastern parts of the state. Satisfaction was lowest in the northern half of the state, including the northwest, north-central, and eastern panhandle counties (see Figure 5 and Figure 8). Although there are no field measurements that assess the adequacy of forest regeneration on a statewide basis, the opinions of professionals who have a stake in the successful regeneration of forests and who have spent a collective total of over 5,300 years practicing forest-related work in West Virginia can be helpful in determining the possible causes and spatial distribution of regeneration problems.

What are some of the factors that are associated with whether or not a natural resource professional is satisfied with regeneration? Several attributes were examined using logistic regression to evaluate the relationship between each attribute and whether or not respondents 
were satisfied. The odds ratio at the 90 percent confidence level was determined for each of these relationships and three were found to be statistically significant.

Involvement with at least one timber harvest, seeing their desired trees regenerating, and not reporting any specific concerns all significantly increased the odds that respondents were satisfied with regeneration. Another attribute that was not statistically significant but that might be interesting to examine more closely is employment sector. Respondents who worked for the private sector had more than twice the odds of being satisfied with regeneration than those who worked for the public sector. In fact, Table 27 shows that the majority of those in the private sector were satisfied (60\%) while the majority of those in the public sector were dissatisfied (59\%). This discrepancy between NRPs in the public and private sectors could be a good question to explore with further research.

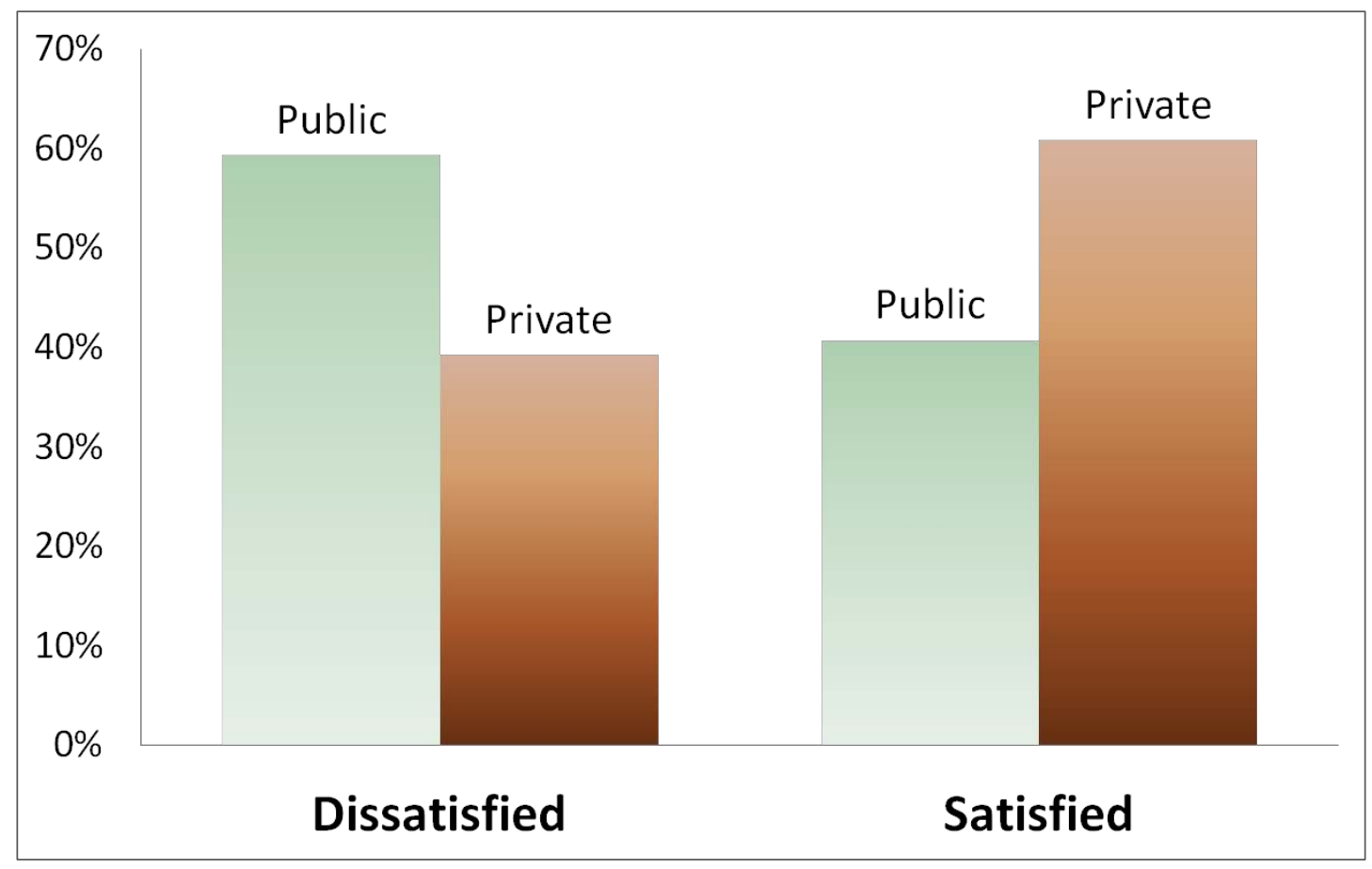

Figure 27: Percent of public and private employees who were dissatisfied and satisfied with regeneration. 
Other studies in the central Appalachian region that have addressed regeneration have come to similar conclusions. A statewide mail survey was conducted in New York by Cornell University in order to obtain a better understanding of barriers to forest regeneration (Connelly et al. 2010). The approach of the survey was similar to this one in that it gathered the expert opinions of professionals who observed regeneration in the field. Regeneration in New York was evaluated to be marginally successful or to have completely failed in $70 \%$ of stands statewide. Spatial variation was also found in that study, with regeneration judged to be more successful in the Adirondacks region and less successful in the southern and southeastern regions. Interestingly, deer were also reported to be less of a concern in the Adirondacks (Connelly et al. 2010).

An analysis of FIA plot data from 2002-2006 done by The Nature Conservancy found that 57 percent of FIA plots in New York had poor or fair regeneration of desirable timber species and that inadequate regeneration was of greatest concern in the southern and southeastern parts of the state (Shirer and Zimmerman 2010), corroborating the results of the New York forester survey (Connelly et al. 2010).

In 2001, because of concerns in Pennsylvania, the Pennsylvania Bureau of Forestry cooperated with the Forest Service's FIA program to begin an intensive landscape-scale study of regeneration. The range of results for successful regeneration of commercial species was from 50 percent to 64 percent (McWilliams et al. 2004). There were no significant regional differences in the quality of regeneration. All of the above studies agree with the current study that in general, there is a lack of satisfactory regeneration in the central Appalachian region.

What types of concerns do natural resource professionals have about regeneration in West Virginia? Twelve broad categories of concerns were identified (see Figure 9). Four of these 
were most important: deer, forest management, invasive species, and the species composition of regeneration. The negative impact of deer on forest regeneration was foremost; $48 \%$ of all respondents expressed this concern at least once. The relative importance of concerns related to deer was not evenly distributed across all counties. It was highest in the northern half of the state, including the northwestern and north-central counties and the Eastern panhandle (see Figure 10). What accounts for the higher level of concern in the northern part of the state? A suggestion for further research is to study the distribution of deer populations across West Virginia in relation to regeneration concerns. Deer population densities can be estimated from deer harvest numbers and other data and are not evenly distributed across the state. When an informal comparison is made of maps that depict the average annual buck harvest per square mile between 1993-2008 for each West Virginia county (Crum 2009) and the relative importance of regeneration concerns related to deer for each county (see Figure 11), there appears to be a similarity in distributions. Again, moderate to high deer densities were found in the northern half of the state, while lower densities were found in the southern half. Interestingly, one southern county (Monroe) had relatively high deer densities; it also had a relatively high relative importance value for deer/regeneration concerns. Thus, many of the counties where concerns about deer and regeneration were high are the same counties where estimates of deer densities were high.

Other surveys of professionals have also found that deer was the preeminent factor impacting regeneration. Connelly et al. (2010) surveyed New York foresters, who reported that regeneration would be impeded on $65 \%$ of forest stands if no action was taken to reduce deer browsing, and that deer browsing was the leading barrier to successful regeneration. A 2007 statewide mail survey assessed the perceptions of Michigan foresters regarding deer depredation (Cook 2008). Ninety-five percent of respondents believed that deer have had a significant 
negative impact on forests in Michigan; 40\% have observed significant deer damage across at least half of their service area. Most (66\%) foresters saw deer damage as patchy or with clear geographical trends, and not uniformly widespread. In a 2006 mail survey of foresters in Wisconsin, more respondents (80\%) identified deer as a strong to very strong contributor to oak regeneration failure than any other factor (Wisconsin Council on Forestry 2006). In another study, natural resource professionals working in Wisconsin were interviewed to explore the factors that inhibit oak regeneration; they mentioned deer herbivory more often than anything else (Knoot et al. 2010).

Forest management was another important concern for natural resource professionals in West Virginia: most were concerned about high-grading, diameter-limit cutting, and the lack of active management of forest land using appropriate silvicultural principles and timber stand improvement. Concerns about forest management were widespread, although there was a cluster of counties in the southeastern part of the state where the level of concern was greater (see Figure 11). Fajvan et al. (1998) found that most timber harvests in West Virginia are diameter limit cuts; it is a prevalent region-wide practice (Nyland 1992). In 2006, only 5 percent of nonindustrial private forest landowners in West Virginia sought forest management advice from a professional (Butler 2008). West Virginia state foresters were surveyed in 2001 and reported that "harvesting with little regard for desired future conditions," "overuse of diameter-limit cutting," and "lack of silvicultural prescriptions on private property," were three of the highest-ranked concerns (McGill et al. 2004). Because of their age and stand size, it can be assumed that many poorly stocked stands in West Virginia have originated from poor harvesting practices (Widmann et al. 2012). 
Invasive plants were also an important concern for NRPs in West Virginia; most notably, tree-of-heaven and Japanese stiltgrass. The highest levels of concern about invasive plants were in the northern half of the state, including the eastern panhandle (see Figure 12); this coverage corresponded to areas with the highest levels of concern about deer. Researchers have hypothesized that deer facilitate the success of invasive plants and create conditions for their establishment (Knight et al. 2009).

Foresters in New York (Connelly et al. 2010) also considered invasive species an important factor in regeneration. In that survey, exotic species were grouped with native species into one predetermined category called “interfering vegetation;” foresters ranked this category as second in importance only to deer as having a moderate or severe impact on regeneration across all regions of the state.

The importance of invasive plants is already being addressed in West Virginia. The Potomac Highlands Cooperative Weed and Pest Management Area in Grant and Pendleton counties is raising awareness about this issue on public and private lands; cooperative management areas are planned for other regions of the state. Cost-share programs are available through the Natural Resource Conservation Service (NRCS) to help landowners eliminate invasive plants on private land. Applications for cost-share funds are competitively ranked; as part of the rankings process, higher priority should be given to areas with more severe impacts. The species composition of regeneration was a prominent and widespread concern of NRPs in West Virginia, especially the lack of adequate oak regeneration. Closely related to this was the increasing importance of less desirable species, particularly red maple, fire cherry and birch, beech and striped maple, and shade-tolerant species in general that are displacing oak. Regeneration of oaks has been recognized as a problem in the central Appalachians for many 
years (Carvell and Tryon 1961, Loftis 2004). The latest FIA inventory data show that oaks represent more than 45 percent of trees 20 inches and above in diameter, but only eight percent of trees less than ten inches in diameter (Widmann et al. 2012). At the same time, there have been large increases in the numbers of red maple, beech, and other low-value shade-tolerant saplings such as blackgum. Nonindustrial private landowners own $80 \%$ of oak forests in the eastern United States (McWilliams et al. 2004). Thus concerns about oak regeneration are intricately related to concerns about forest management, since regeneration harvests and other silvicultural prescriptions necessary to perpetuate oaks are unlikely to be implemented given the low level of interest and investment in forest management that has been evidenced in West Virginia (Butler 2008, Fajvan et al. 1998, McGill et al. 2004, Perkey and Powell 1988, Egan et al. 1997).

Frustration with a lack of forest management and a lack of regard for stand condition is shared by natural resource professionals in other states. In response to interviews investigating the causes underlying the potential loss of oak forests in Wisconsin, over $80 \%$ of interviewees viewed private landowner management decisions as a driving factor in regional forest change (Knoot et al. 2010). Interviewees mentioned specific decisions including high-grading, unwillingness to use clearcutting to regenerate oaks, and unwillingness to invest in timber stand improvement as obstacles to oak regeneration.

Most NRPs in West Virginia reported that they did regeneration assessments of some kind; most (93\%) did assessments in areas where timber had been or will be harvested. However, most assessments were done by visual observation. Plot-based surveys were done by $40 \%$ of those who did pre-harvest regeneration assessments. A number of decision tools have been developed for use in predicting the success of natural hardwood regeneration after a timber 
harvest (Marquis et al. 1992, Brose et al. 2008, Steiner et al. 2008). In West Virginia, Carvell (1988) developed guidelines for making pre-harvest assessments and he stresses their importance. Carvell cautions that "too often regeneration surveys have taken the form of casual observations” (Carvell 1988). He advises that regeneration surveys must be well-planned and should examine the entire stand.

Finally, one of the limitations of this study was the uneven distribution of observations about regeneration around the state. Although observations were made in all 55 West Virginia counties, most were made in the mountain counties of Randolph, Tucker, Nicholas, and Greenbrier. Generally, counties in the western part of the state, especially Mason and Lincoln, and counties in the northern panhandle, especially Brooke and Hancock, had the fewest observations and were underrepresented in this study (see Figure 2). However, it does not appear that counties were under-represented because the survey population in those counties had a lower response rate. A Spearman rank correlation between the total number of questionnaires sent to a county and the percent response from that county was significant and there was an inverse correlation ( $r=-0.27287 ; \mathrm{p}=0.0665)$. So in counties where a greater number of questionnaires were sent, there is evidence of a lower response rate. In actuality, underrepresented counties had fewer questionnaires sent and had a slightly higher response rate (on average) than where counties where a higher number of questionnaires were sent.

The unevenness of survey observations could be due to the fact that timber harvesting activity varies between counties. It is logical that counties with more timber harvests should have more observations of regeneration. A suggestion for further research is to compare the distribution of timber harvests in West Virginia in relation to the frequency of observations and of regeneration concerns. Timber harvest acreage between 2006 and 2009 was highest in 
Randolph, Nicholas, Greenbrier, and many of the other counties where a relatively high number of observations about regeneration were made (WV Division of Forestry 2010). There may have been few timber harvests in counties where there were few observations of regeneration. In addition, there was a high concentration of observations in Randolph and surrounding counties due to the fact that Elkins (Randolph County) is a hub of operations for the Monongahela National Forest, the West Virginia Division of Natural Resources, and the U.S. Fish and Wildlife Service, among other agencies and organizations. Thus there is a high concentration of natural resource professionals in this region. Although the data in this study was normalized to account for this uneven distribution of observations, it still remains a limitation.

However, this survey was useful in pointing out areas of the state about which much less is known than about other areas that have been assigned a high-priority status for conservation and research. The relative importance of concerns about deer and invasive species was high in many of the underrepresented counties in this survey. Although the sample size of observations for these counties was small and it is hard to draw conclusions, it would be helpful to look more closely at perceptions about regeneration in these counties in a targeted study, perhaps consisting of a focus group. 


\section{LITERATURE CITED}

Abrams, M.D. 1992. Fire and the development of oak forests. BioScience. 42 (5):346-353.

Allison, P.D. 1999. Logistic Regression Using the SAS System: Theory and Application. SAS Institute, Inc., Cary, NC, 288 p.

The American Association for Public Opinion Research. 2008. Standard Definitions: Final Dispositions of Case Codes and Outcome Rates for Surveys. Fifth edition. Lenexa, Kansas: AAPOR.

Bailey, R.G. 1995. Description of the ecoregions of the United States. Second edition. Misc. Publ. 1391. Washington, DC: US Department of Agriculture, Forest Service, 108 p.

Beck, D.E. 1988. Regenerating cove hardwood stands.P. 156-166 in Guidelines for regenerating Appalachian hardwood stands, Smith, H.C., Perkey, A.W., and W.E. Kidd, eds. SAF Publ. 88-03. Morgantown, WV: West Virginia University Books.

Birch, T.W., and N.P. Kingsley. 1978. The forest-land owners of West Virginia. Resour. Bull. NE-58. Broomall, PA: U.S. Department of Agriculture, Forest Service, Northeastern Forest Experiment Station. 76 p.

Brewer, C.A. 2006. Basic Mapping Principles for Visualizing Cancer Data Using Geographic Information Systems (GIS). American Journal of Preventive Medicine. 30 (2) Supplement, p. S25-S36.

Brose, P.H., Gottschalk, K.W., Horsley, S.B., Knopp, P.D., Kochenderfer, J.N., McGuinness, B.J., Miller, G.W., Ristau, T.E., Stoleson, S.H., and S.L. Stout. 2008. Prescribing regeneration treatments for mixed-oak forests in the Mid-Atlantic region. Gen. Tech. Rep. NRS-33. Newtown Square, PA: U.S. Department of Agriculture, Forest Service, Northern Research Station. 100 p.

Butler, B.J. 2008. Family forest owners of the United States, 2006. Gen. Tech. Rep. NRS-27. USDA Forest Service, Northern Research Station, Newtown Square, PA.

Campbell, T.A., B.R. Laseter, W.M. Ford, R.H. Odom, K.V. Miller. 2006. Abiotic factors influencing deer browsing in West Virginia. Northern Journal of Applied Forestry 23 (1):20-26.

Carvell, K.L., and E.H. Tryon. 1961. The effect of environmental factors on the abundance of oak regeneration beneath mature oak stands. Forest Science. 7 (2):98-10.

Carvell, K.L. 1988. Field guide for analyzing potential hardwood stand regeneration. P. 148-155 in Guidelines for regenerating Appalachian hardwood stands, Smith, H.C., Perkey, A.W., and W.E. Kidd, eds. SAF Publ. 88-03. Morgantown, WV: West Virginia University Books. 
Clark, F.B. 1992. A historical perspective of oak regeneration. P. 3-13 in Oak regeneration: Serious problems, practical recommendations (Symposium Proceedings), Loftis, D.L., and C.E. McGee, eds. 1993 Gen. Tech. Rep. SE-84. Asheville, NC: U.S. Department of Agriculture, Forest Service, Southeastern Forest Experiment Station GTR-SE-084.

Collins, R.J. and W.P. Carson. 2004. The effects of environment and life stage on Quercus abundance in the eastern deciduous forest, USA: are sapling densities most responsive to environmental gradients? Forest Ecology and Management. 201 (2-3): 241-258.

Connelly, N.A., P.J. Smallidge, G.R. Goff, and P.D. Curtis. Forester's perceptions of forest regeneration and possible barriers to regeneration in New York State. 2010. HDRU Series No. 10-2, Cornell University Department of Natural Resources.

Cook, B. 2008. Forester perceptions of deer depredation on the forests of Michigan. Michigan Society of American Foresters.

Crum, J. 2009. Sixteen year average of antlered bucks harvested per square mile during the November two-week firearms deer season by West Virginia county map, 1993-2008. West Virginia Division of Natural Resources (WVDNR), Wildlife Section.

Cubbage, F.W. 1991. Public regulation of private forestry. Journal of Forestry. 89 (12):31-35.

Davidson, W.H. 1988. Potential for planting hardwoods in the Appalachians. P. 255-268 in Guidelines for regenerating Appalachian hardwood stands. Smith, H.C., Perkey, A.W., and W.E. Kidd, eds. SAF Publ. 88-03. Morgantown, WV: West Virginia University Books.

Dillman, D. 2000. Mail and internet surveys, the tailored design method. John Wiley \& Sons, Inc., New York.

Donovan, G. 2005. Chronic regeneration failure in northern hardwood stands: a liability to certified forest landowners. Michigan Society of American Foresters conference.

Egan, A.F., J. Rowe, D. Peterson, and G. Phillipi. 1997. West Virginia tree farmers and consulting foresters: a comparison of views on timber harvesting. Northern Journal of Applied Forestry. 14 (1):16-19.

Ellefson, P.V.; M.A. Kilgore, C.M. Hibbard and J.E. Granskog. 2004. Regulation of forestry practices on private land in the United States: Assessment of state agency responsibilities and program effectiveness. Staff Paper Series Number 176. Department of Forest Resources, University of Minnesota.

Emerson, P., Skousen, J., and P. Ziemkiewicz. 2009. Survival and growth of hardwoods in brown versus gray Sandstone on a surface mine in West Virginia. Journal of Environmental Quality. 38 (5):1821-1829.

Fajvan, M.A., Grushecky, S.T. and C.C. Hassler.1998. Effects of harvesting practices on West Virginia’s wood supply. Journal of Forestry. 96 (5):33-39. 
Flory, S.L. 2010. Community and ecosystem consequences of Microstegium vimineum invasions in eastern forests. P. 14-15 in Proceedings, 21st U.S. Department of Agriculture interagency research forum on invasive species: January 12-15, 2010; Annapolis, MD. McManus, K.A, and K.W. Gottschalk, eds. Gen. Tech. Rep. NRS-P-75. Newtown Square, PA: U.S. Department of Agriculture, Forest Service, Northern Research Station.

Galford, J., Auchmoody, L.R., Smith, H.C., and R.S. Walters. 1991. Insects affecting establishment of northern red oak seedlings in central Pennsylvania. P. 271-280 in Proceedings, 8th Central Hardwood Forest Conference; 1991 March 4-6; University Park, PA. McCormick, L. H., and K.W. Gottschalk, eds. Gen. Tech. Rep. NE-148. Radnor, PA: U.S. Department of Agriculture, Forest Service, Northeastern Forest Experiment Station.

Gilliam, F.S. 2007. The ecological significance of the herbaceous layer in temperate forest ecosystems. BioScience. 57 (10):845-858.

Gould, P.J., K.C. Stiner, M.E. McDill,, and J.C. Finley. 2006. Modeling seedling-origin oak regeneration in the central Appalachians. Canadian Journal of Forest Research. 36: 833844.

Hicks, R.R. 1998. Ecology and management of central hardwood forests. John Wiley and Sons. New York, NY. 412 p.

Horsley, S.B. 1988. How vegetation can influence regeneration. P. 38-55 in Guidelines for regenerating Appalachian hardwood stands. Smith, H.C., Perkey, A.W., and W.E. Kidd, eds. SAF Publ. 88-03. Morgantown, WV: West Virginia University Books.

Horsley, S.B. 1993. Mechanisms of interference between hayscented fern and black cherry. Canadian Journal of Forest Research 23: 2059-2069.

Horsley, S.B., Stout, S.L. Stout, and D.S. DeCalesta. 2003. White-tailed deer impact on the vegetation dynamics of a northern hardwood forest. Ecological Applications. 13 (1):98118.

Hosmer, D.W., and S. Lemeshow. 2000. Applied Logistic Regression. New York: Wiley, 375 p.

Huebner, C.D. and P.C. Tobin. 2006. Invasibility of mature and 15-year-old deciduous forests by exotic plants. Plant Ecology. 186:57-68.

Jenks, G.F. 1977. Optimal data classification for choropleth maps: Occasional Paper No. 2. Lawrence, Kansas: University of Kansas, Department of Geography.

Johnson, J.E., Miller, G.W.; Baumgras, J.E., and C.D. West. 1998. Assessment of residual stand quality and regeneration following shelterwood cutting in Central Appalachian hardwoods. Northern Journal of Applied Forestry. 15 (4):203-218.

Kenefic, L.S. and R.D. Nyland. 2005. Diameter-limit cutting and silviculture in northeastern forests. USDA Forest Service Publication NA-TP-02-05.

Knight, T.M., Dunn, J. L., Smith, L.A., Davis, J. and S. Kalisz. 2009. Deer facilitate invasive plant success in a Pennsylvania forest understory. Natural Areas Journal. 29 (2):110-116. 
Knoot, T.G., L.A. Schulte, and M. Rickenbach. 2010. Oak conservation and restoration on private forestlands: Negotiating a social-ecological landscape. Environmental Management 45:155-164.

Kochenderfer, J.N., Adams, M.B., Miller, G.W., and F. Wood. 2006. Growth and development of planted northern red oak on bulldozed skid roads after clearcutting in Appalachian hardwoods. Res. Pap. NE-730. Newtown Square, PA: U.S. Department of Agriculture, Forest Service, Northeastern Research Station. 16 p.

Lindner, J.R., Murphy, T.H., and G.E. Briers. 2001. Handling nonresponse in social science research. Journal of Agricultural Education. 42 (4):43-53.

Loftis, D.L. 1990. Predicting post-harvest performance of advance red oak reproduction in the Southern Appalachians. Forest Science. 36 (4):908-916.

Loftis, D.L. Predicting oak regeneration: State of the art. 1993. P. 134-137 in Oak regeneration: Serious problems, practical recommendations (Symposium Proceedings), Loftis, D. L., and C.E. McGee, eds. 1993 Gen. Tech. Rep. SE-84. Asheville, NC: U.S. Department of Agriculture, Forest Service, Southeastern Forest Experiment Station.

Loftis. D.L. 2004. Upland oak regeneration and management. P. 163-167 in Upland oak ecology symposium: history, current conditions, and sustainability, M.A. Spetich, ed. Gen. Tech. Rep. SRS-73. Asheville, NC: U.S. Department of Agriculture, Forest Service, Southern Research Station.

Lorimer, C.G. 1993. Causes of the oak regeneration problem. P. 14-39 in Oak regeneration: Serious problems, practical recommendations (Symposium Proceedings), Loftis, D.L., and C.E. McGee, eds. Gen. Tech. Rep. SE-84. Asheville, NC: U.S. Department of Agriculture, Forest Service, Southeastern Forest Experiment Station.

Lorimer, C.G. 1984. Development of the red maple understory in northeastern oak forests. Forest Science 30:3-22.

Lyon, J. and W.E. Sharpe. 2003. Impacts of hay-scented fern on nutrition of northern red oak seedlings. Journal of Plant Nutrition. 26: 487-502.

Marquis, D.A. 1981. The effect of deer browsing on timber production in Allegheny hardwood forests of northwestern Pennsylvania. USDA For. Serv. Res. Pap. NE-475. 10 p.

Marquis, D.A. and R. Brenneman. 1981. The impact of deer on forest vegetation in Pennsylvania. USDA Forest Service, Northeaster For. Exp Station General Technical Report NE-65. Broomhall, PA. 7 p.

Marquis, D.A., Ernst, R.L, and S.L. Stout. 1992. Prescribing silvicultural treatments in hardwood stands of the Alleghenies (revised). Gen. Tech. Rep. NE-96. Radnor, PA: U.S. Department of Agriculture, Forest Service, Northeastern Forest Experiment Station. 101 p.

Marquis, D.A. and M.J. Twery. 1993. Decision-making for natural regeneration in the northern forest ecosystem. P. 156-173 in Oak Regeneration: Serious problems, practical 
recommendations (Symposium Proceedings), Loftis, D.L., and C.E. McGee, eds. Gen. Tech. Rep. SE-84. Asheville, NC: U.S. Department of Agriculture, Forest Service, Southeastern Forest Experiment Station.

McEwan, R.W., Dyer, J.M., and N. Pederson. 2011. Multiple interacting ecosystem drivers: toward an encompassing hypothesis of oak forest dynamics across eastern North America. Ecography 34: 244-256.

McGill, D.W., Westfall, M.A., Gartin, S.A., O'Dell, K.S., and H.N. Boone. 2004. Identifying priority forest management issues in West Virginia: A survey of state service foresters. P. 282-286 in Proceedings, 14th Central Hardwood Forest Conference; 2004 March 16-19; Wooster, OH, Yaussy, D.A., Hix, D.M., Long, R.P.; and P.C. Goebel, eds. Gen. Tech. Rep. NE-316. Newtown Square, PA: U.S. Department of Agriculture, Forest Service.

McWilliams, W.H., Stout, S.L., Bowersox, T.W., and L.H. McCormick. 1995a. Adequacy of advance tree-seedling regeneration in Pennsylvania's forests. Northern Journal of Applied Forestry. 12 (4):187-195.

McWilliams, W.H., Bowersox, T.W., Gansner, D.A., McCormick, L.H., and S.L. Stout. 1995b. Landscape-level regeneration capacity for native hardwood forests of Pennsylvania. P. 196-203 in Proceedings, 10th Central Hardwood Forest Conference; 1995 March 5-8; Morgantown, WV, Gottschalk, K.W., and S.L. Fosbroke, eds. Gen. Tech. Rep. NE-197. Radnor, PA: U.S. Department of Agriculture, Forest Service, Northeastern Forest Experiment Station.

McWilliams, W.H., O’Brien, R.A., Reese, G.C. and K.L. Waddell. 2002. Distribution and abundance of oaks in North America. P. 13-33 in W.J. McShea and W.M. Healy, eds. Oak forest ecosystems: ecology and management for wildlife. Johns Hopkins University Press, Baltimore, Maryland, USA.

McWilliams, W.H., Bowersox, T.W., Brose, P.H., Devlin, D.A., Finley, J.C., Horsley, S., Gottschalk, K.W., Lister, T.W., McCormick, L.H., Miller, G.W., Steiner, K.C., Stout, S.L., Westfall, J.A., and R.L. White. 2004. Indicators of regenerative capacity for eastern hardwood forests. P. 136-140 in Proceedings of Society of American Foresters 2003 National Convention. SAF Publication 04-01.

Michael, E.D. 1988. Effects of whitetail eeer on Appalachian hardwood regeneration. P. 89-96 in Guidelines for regenerating Appalachian hardwood stands, Smith, H.C., Perkey, A.W., and W.E. Kidd, eds. SAF Publ. 88-03. Morgantown, WV: West Virginia University Books.

Miller, G.W. and J.N. Kochenderfer. 1998. Maintaining species diversity in the Central Appalachians. Journal of Forestry. 96 (7):28-33.

Miller, G.W., Kochenderfer, J.N., Knibbs, J., and J.E. Baumgras. 2001. Vegetative conditions and management options in even-age stands on the Monongahela National Forest. In Proceedings: National Silvicultural Workshop; 1999 Oct. 5-7; Kalispell, MT, Baras, S.J., ed. Proc. RNRS-P-00. Ogden, UT; USDA Forest Service, Rocky Mountain Research Station. 
Nowacki, G.J. and M.D. Abrams. 1992. Community, edaphic, and historical analysis of mixed oak forests of the Ridge and Valley Province in central Pennsylvania. Canadian Journal of Forest Research. 22 (6):790-800.

Nyland, R.D. 1992. Exploitation and greed in eastern hardwood forests. Journal of Forestry. 90 (1):33-37.

Office of Legislative Auditor, Performance Evaluation and Review Division. 1995. The negative effects of deer on West Virginia.

Oswalt, C.M., Oswalt, S.N., and W.K. Clatterbuck. 2007. Effects of Microstegium vimineum (Trin.) A. Camus on native woody species density and diversity in a productive mixedhardwood forest in Tennessee. Forest Ecology and Management. 242 (2-3):727-732.

Perkey, A.W. and D.S. Powell, 1988. Regenerating Appalachian hardwoods: the current situation. P. 5-16 in Guidelines for regenerating Appalachian hardwood stands, Smith, H. C., Perkey, A. W., and W.E. Kidd, eds. SAF Publ. 88-03. Morgantown, WV: West Virginia University Books.

Rawinski, T.J. 2008. Impacts of white-tailed deer overabundance in forest ecosystems: an overview. Northeastern Area State and Private Forestry Forest Service, U.S. Department of Agriculture, Newtown Square, PA.

Sander, I.L. 1972. Size of oak advance reproduction: key to growth following harvest cutting. Res. Pap. NC-79. St. Paul, MN: U.S. Department of Agriculture, Forest Service, North Central Forest Experiment Station. 6 p.

Sander, I.L., Johnson, P.S., and R. Rogers. 1984. Evaluating oak advance reproduction in the Missouri Ozarks. Res. Pap. NC-251. St. Paul, MN: U.S. Department of Agriculture, Forest Service, North Central Forest Experiment Station. 16 p.

Schuler, T.M., and G.W. Miller. 1996. Guidelines for using tree shelters to regenerate northern red oak. P. 37-45 in Proceedings - tree shelter conference; 1995 June 20-22; Harrisburg, PA, J. Brisette, ed. Gen. Tech. Rep. NE-221. Radnor, PA: U.S. Department of Agriculture, Forest Service, Northeastern Forest Experiment Station.

Schuler, T.M. 2004. Fifty years of partial harvesting in a mixed mesophytic forest: composition and productivity. Canadian Journal of Forest Research. 34: 985-1007.

Schuler, T.M., and G.W. Miller. 1995. Shelterwood treatments fail to establish oak reproduction on mesic forest sites in West Virginia: 10-year results. P. 375-387 in Proceedings, 10th Central Hardwood Forest Conference; 1995 March 5-8; Morgantown, WV, Gottschalk, K.W. and S.L. Fosbroke (eds.). Gen. Tech. Rep. NE-197. Radnor, PA: U.S. Department of Agriculture, Forest Service, Northeastern Forest Experiment Station.

Shirer, R. and C. Zimmerman. 2010. Forest regeneration in New York State. The Nature Conservancy, Albany, NY. 
Smith, H.C., and G.W. Miller. 1987. Managing Appalachian hardwood stands using four regeneration practices: 34-year results. Northern Journal of Applied Forestry. 4 (4):180186.

Smith, H.C. 1993. Development of red oak seedlings using plastic shelters on good-to-excellent hardwood sites in West Virginia. Res. Pap. NE-672. Radnor, PA: U.S. Department of Agriculture, Forest Service, Northeastern Forest Experiment Station. 7 p.

Steiner, K.C., Finley, J.C., Gould, P.J., Fei, S., and M. McDill. 2008. Oak regeneration guidelines for the Central Appalachians. Northern Journal of Applied Forestry. Vol. 25 (1):5-16.

Stinson, K.A.; Campbell, S.A.; Powell, J.R.; Wolfe, B.E.; Calloway, R.M.; Thelan, G.C.; Hallett, S.G.; Prati, D.; and J.N. Klironomos. 2006. Invasive plant suppresses the growth of native tree seedlings by disrupting belowground mutualisms. PLoS. 4(5): e140.

Tift, B.D. and M.A. Fajvan. 1999. Red maple dynamics in Appalachian hardwood stands in West Virginia. Can. J. For. Res. 29:157-165.

U.S. Department of Agriculture, Forest Service. 2003. Sustainability assessment highlights for the northern United States. NA-TP-05-03. Newtown Square, PA: Northeastern Area State and Private Forestry. 99 p.

U.S. Department of Agriculture, Forest Service. 2010. Forest inventory and analysis national core field guide: field data collection procedures for phase 2 plots. Version 5.0.

Vickers, L.A., Fox, T.R., Loftis, D.L., and D.A. Boucugnani. 2011. Predicting forest regeneration in the Central Appalachians using the REGEN expert system. Journal of Sustainable Forestry. 30 (8):790-822.

Weitzman, S., and G.R. Trimble, Jr. 1957. Some natural factors that govern the management of oaks. Pap. No. 88. Upper Darby, PA: U. S. Department of Agriculture, Forest Service, Northeastern Forest Experiment Station. 40 p.

West Virginia Division of Forestry. 2010. West Virginia Statewide Forest Resource Assessment and Strategy. Charleston, WV.

West Virginia Forest Practice Standards Committee. 1972. West Virginia Forest Practice Standards.

West Virginia Legislative Auditor, Performance Evaluation and Research Division. 2011. Agency Review: Department of Commerce, Division of Natural Resources. Charleston, WV, January 2011. Report No. PE 10-19-486.

Widmann, R.H., Cook, G.W., Barnett, C.J., Butler, B.J., Griffith, D.M., Kurtz, C.M., Morin, R.S.; Moser, W.K., Perry, C.H., Piva, R.J., Riemann, R., and C.W. Woodall. 2012. West Virginia’s Forests 2008. Resour. Bull. NRS-61. Newtown Square, PA: U.S. Department of Agriculture, Forest Service, Northern Research Station, 64 p. 
Widmann, R.H., Dye, C.R., and G.W. Cook. 2007. Forests of the mountain state. Resour. Bull. NRS-17. Newtown Square, PA: U.S. Department of Agriculture, Forest Service, Northern Research Station. 28 p.

Wisconsin Council on Forestry. 2006. Natural oak regeneration survey. Survey completed by the Wisconsin Department of Natural Resources.

Yuska, A.M., Steiner, K.C., and J.C. Finley. 2008. Effects of deer exclosures on oak regeneration in closed-canopy stands. P. 91-99 in Proceedings, 16th Central Hardwood Forest Conference; 2008 April 8-9; West Lafayette, IN, Jacobs, D.F., and C.H. Michler, eds. 2008. Gen. Tech. Rep. NRS-P-24. Newtown Square, PA: U.S. Department of Agriculture, Forest Service, Northern Research Station. 


\section{APPENDIX}

Survey Notifications and Questionnaire 


\section{Notice of Upcoming Survey West Virginia Forest Regeneration Dear WV Natural Resources Professional:}

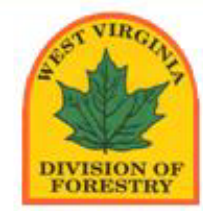

In a few days you will receive a survey designed to collect information about forest regeneration issues. The survey is part of a research project sponsored by the West Virginia Division of Forestry and conducted by West Virginia University. West Virginia University's Institutional Review Board has acknowledgement of this study on file.

I am writing to notify you about the survey and ask for your participation. Your on-the-ground experience will provide us with valuable information about the current state of forest regeneration and the range of concerns that are facing foresters and other natural resource professionals.

The Division of Forestry and its partners are working to identify, understand, and resolve forest regeneration issues in the state. With your generous help, our research can be successful. Thank you in advance for your participation.

\section{Dave McGill}

Forestry Extension Specialist

West Virginia University

(304) $293-5930$

dmcgill@wvu.edu

Extension Service

WestVirginiaUniversity.

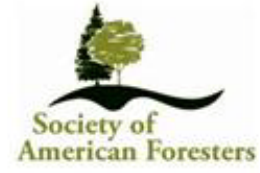

Division of Forestry and Natural Resources

WestVirginiaUniversity 


\section{Survey Cover Letter: Initial Mailing}

February 28, 2011

Dear West Virginia Natural Resource Professional:

The enclosed survey is sponsored by the West Virginia Division of Forestry.

It is being conducted by West Virginia University. This research project is part of a larger effort by the Division of Forestry and its partners to identify, understand, and resolve forest regeneration issues.

We are sending this survey to foresters and other natural resource professionals across the state. Your on-the-ground experience can provide valuable information about the current state of forest regeneration, the types of regeneration problems that may be occurring, where they may be occurring, and some of the factors that may be affecting regeneration.

Your participation in this survey is voluntary and you can quit at any time without any penalty. Please consider contributing your experience and knowledge to this research effort. You do not have to answer all of the questions, but any information you provide will contribute to the project's success. You must be over 18 years of age to participate.

If you do not wish to participate, please let us know by returning the enclosed questionnaire, blank or with a note, in the self-addressed, stamped envelope provided.

Information you provide is anonymous; only summaries will be reported in which no individual's answers can be identified. West Virginia University's Institutional Review Board acknowledgment of this study is on file.

We will be conducting follow-up focus groups based on the results of this initial survey. If you are willing to participate in a focus group, please check the appropriate box on the enclosed survey. We will contact you at a later time with more details.

If you have any further questions, please feel free to contact us at the phone numbers below.

Sincerely,

Dr. Dave McGill, Principal Investigator

Professor and Extension Specialist

Forest Resources Management

(304) 293-5930
Ellen Voss

Graduate Research Assistant

Forest Resources Management

(304) 293-5741 


\title{
Reminder Postcard
}

\section{Reminder about Important Survey West Virginia Forest Regeneration}

\author{
Dear WV Natural Resources Professional:
}

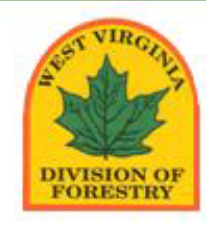

Two weeks ago, we mailed a survey designed to collect information about forest regeneration issues. The survey is part of a research project sponsored by the West Virginia Division of Forestry and conducted by West Virginia University. West Virginia University's Institutional Review Board has acknowledgement of this study on file.

If you have already completed and returned the survey, please accept our sincere thanks. If not, please take a few minutes to do so today.

If you did not receive a survey or have misplaced it, please call me and I will mail another one immediately. Your on-the-ground experience will provide us with valuable information about the current state of forest regeneration and the types of regeneration problems that are facing foresters and other natural resource professionals.

Dave McGill

Forestry Extension Specialist

West Virginia University

(304) 293-5930

dmcgill@wvu.edu

Extension Service

WestVirginiaUniversity.

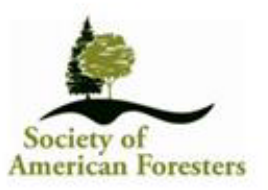

Division of Forestry and Natural Resources

WestVirginiaUniversity 


\section{Cover Letter: Second Mailing of Survey}

April 4, 2011

Dear West Virginia Natural Resource Professional:

Last month we mailed you a survey concerning forest regeneration in West Virginia. The survey is part of a research project by the Division of Forestry and its partners to identify, understand, and resolve forest regeneration issues. According to our records, you have not yet returned the survey.

We sent this survey to foresters and other natural resource professionals across the state. Your on-the-ground experience will provide valuable information about the current state of forest regeneration, the types of regeneration problems that may be occurring, where they may be occurring, and some of the factors that may be affecting regeneration.

Your participation in this survey is voluntary and you can quit at any time without any penalty. Please consider contributing your experience and knowledge to this research effort. You do not have to answer all of the questions, but any information you provide will contribute to the project's success. You must be over 18 years of age to participate.

If you do not wish to participate, please let us know by returning the enclosed questionnaire, blank or with a note, in the self-addressed, stamped envelope provided.

Information you provide is anonymous; only summaries will be reported in which no individual's answers can be identified. West Virginia University's Institutional Review Board acknowledgment of this study is on file.

We will be conducting follow-up focus groups based on the results of this initial survey. If you are willing to participate in a focus group, please check the appropriate box. We will contact you at a later time with more details.

If you have any further questions, please feel free to contact us at the phone numbers below.

Sincerely,

Dr. Dave McGill, Principal Investigator

Professor and Extension Specialist

Forest Resources Management

(304) 293-5930
Ellen Voss

Graduate Research Assistant

Forest Resources Management

(304) 293-5741 


\section{Survey}

\section{Forest Regeneration in West Virginia Issues facing natural resource professionals}

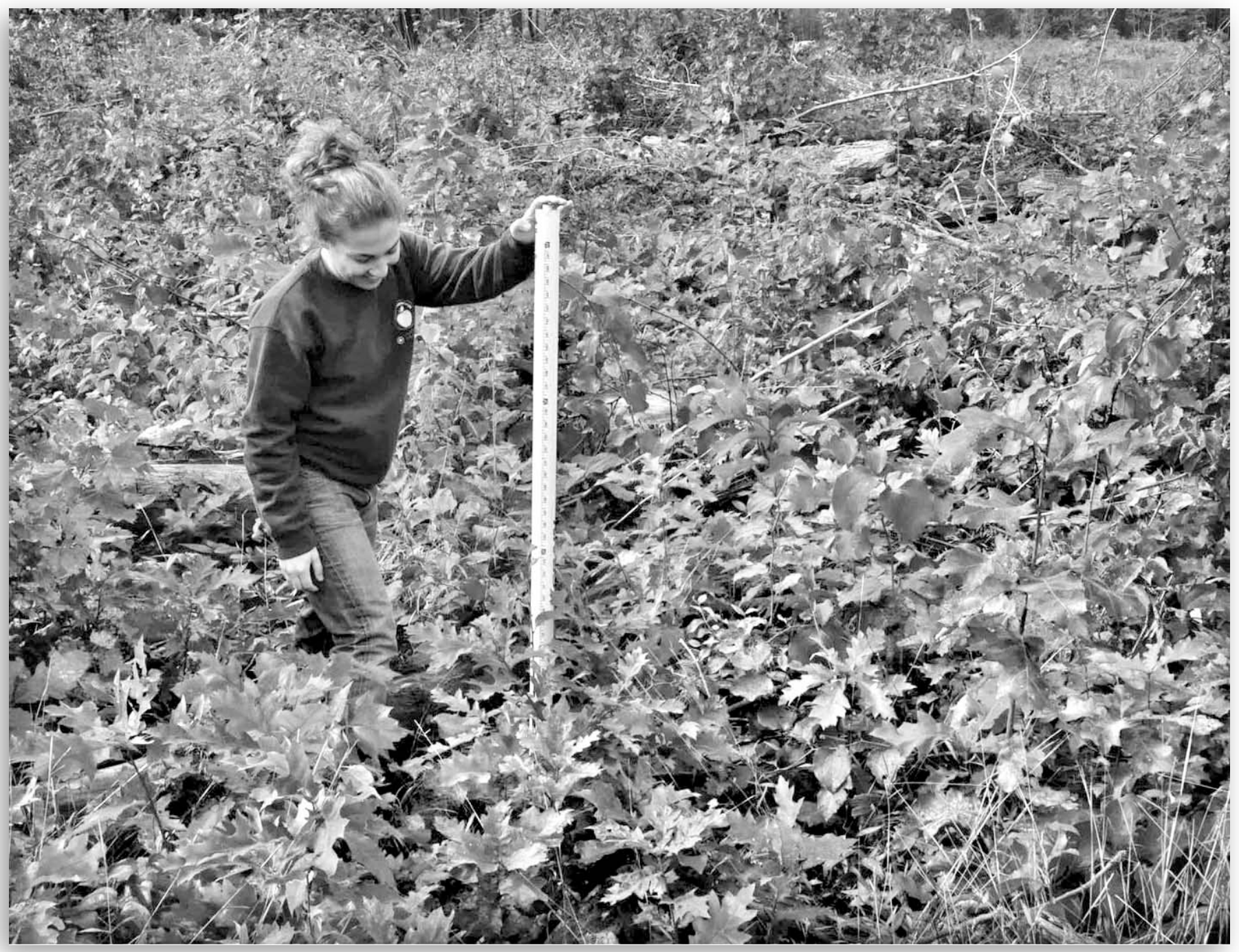

March 2011

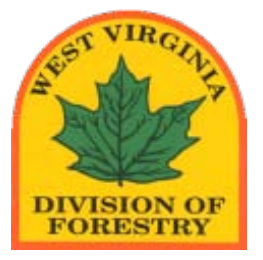

Division of Forestry and

Natural Resources

W WestVhriginiaUniversity.

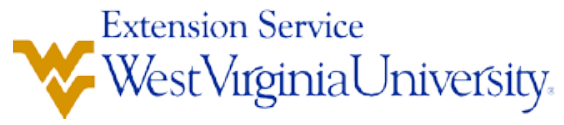

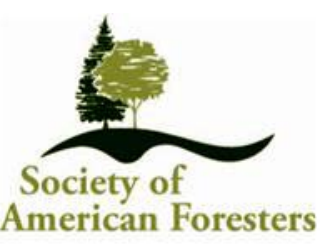




\section{Forest Regeneration in West Virginia: Successes and Challenges}

\section{About this survey}

West Virginia University is conducting this survey on behalf of the West Virginia Division of Forestry. We are contacting foresters, wildlife biologists, and other natural resource professionals in order to learn about their perceptions of forest regeneration in West Virginia.

Your experience and education in the natural resources field are important to the success of this project. The information you provide about your first-hand observations of forest regeneration will help us to better understand the issues that may exist and how they vary in different areas.

Your participation is voluntary and you have the right to refrain from answering any questions. Please feel free to answer only those questions you are comfortable with. If you choose to participate, your answers will be kept confidential.

Thank you for participating in this survey.

\section{Instructions}

- $\quad$ Either a pen or pencil can be used.

- When marking a check box, please use an "X."

- If you need to change an answer, please erase or clearly cross out your old answer.

- All questionnaires will remain confidential at all times.

Please return your completed questionnaire in the enclosed postage-paid envelope to:

Ellen Voss

West Virginia University

Division of Forestry \& Natural Resources

P.O. Box 6125

Morgantown, WV 26506-6125

Please contact Ellen Voss at evoss@mix.wvu.edu or (304) 293-5741 if you have any questions.

\section{START SURVEY HERE}

\section{Please check all that apply:}

Send me a summary of the results of this survey.

I would like to participate in a follow-up focus group based on the results of this survey. We will contact you with more information about the focus group.

I prefer not to participate in this survey (please return blank questionnaire). 


\section{CONTINUE SURVEY HERE:}

The Dictionary of Forestry (SAF 2008) defines forest regeneration as

"The act of renewing tree cover by establishing young trees naturally or artificially.

Regeneration usually maintains the same forest type and is done promptly after the previous stand or forest was removed. Regeneration may be natural (natural seeding, coppice, or root suckers) or artificial (direct seeding or planting)."

In this survey, it is assumed that your answers about "regeneration" refer to natural regeneration. If your answers refer to artificial regeneration, please be specific (use terms like planted, seeded, or artificial).

\section{Please tell us about your professional natural resources experience.}

1. How would you best describe your natural resource specialty?

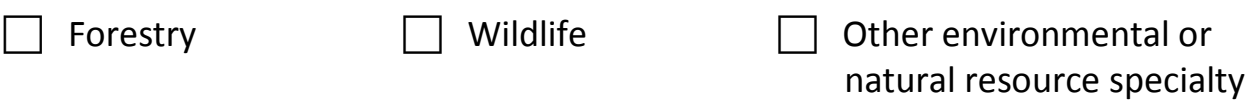

2. What type of forest-related work do you do? (Check all that apply)

Forest Management

$\square$ Forest management plan writing

$\square$ Grapevine control

$\square$ Tree planting

Other regeneration activities

$\square$ Invasive species control

Other:

Timber-related

$\square$ Timber inventory/cruising

$\square$ Timber procurement

Timber sale administration

Logging compliance

Certification/auditing

Timber harvesting, logging

Other

Wildlife management

Wildfire control

Education/Outreach

Wildlife management plan

Research

writing

Other: 
3. How would you best describe your employment category?

$\begin{array}{lll}\square \text { Corporation/TIMO/REIT } & \square \text { State Government } \\ \square \text { Other private company } & \square \text { Federal Government } & \square \text { Retired } \\ \square \text { Self-employed } & \square \text { College/University } & \square \text { Other }\end{array}$

4. How long have you been practicing forest-related work? Years

5. How long have you been practicing in West Virginia? Years

6. In your professional capacity, how frequently are you able to observe forest regeneration? (Check one)
$\square$ Never
$\square$ Rarely
Occasionally
Frequently

7. List up to four counties in West Virginia where most of your observations of regeneration take place.

1.

2.

8. How many timber harvests have you been involved with in West Virginia over the past 10 years? (If zero, write 0) Timber harvests (If zero, skip to Question 13)

9. What was the approximate average acreage of these harvests? Acres

10. Of the total harvests, what percent have you revisited after harvest to assess regeneration? Percent of total

11. In general, when did you revisit these sites?

Years following harvest

12. Please list up to four counties in West Virginia where most of these timber harvests have occurred during the past 10 years.

1.

2.

.
3.

4. 


\section{How do you assess forest regeneration?}

13. Do you do any assessments of forest regeneration of any kind?
(If yes, continue to the next question)
$\square$ No
(If no, skip to Question 19)

14. Do you perform these assessments in areas where timber has been or will be harvested?
$\square$ Yes
(If yes, continue to the next question)
(If no, skip to Question 17)

15. What kinds of pre-harvest assessments do you perform related to the quantity and quality of forest regeneration? (Please check all that apply)

Visual observation

Plot-based surveys: Standard plot size Plot density (Plots per acre)

Other type of assessment (please describe)

None

16. What kinds of post-harvest assessments do you perform related to the quantity and quality of forest regeneration? (Please check all that apply)

Visual observation

Plot-based surveys: Standard plot size Plot density (Plots per acre)

Other type of assessment (please describe)

None

17. In areas not associated with timber harvests, do you do any kind of assessment related to the quantity and quality of forest regeneration? (Please check all that apply)

Visual observation

Plot-based surveys: Standard plot size

Plot density (Plots per acre)

Other type of assessment (please describe)

$\square$ None

18. How do you record your assessments of forest regeneration? (Please check all that apply)

Handwritten notes $\quad \square$ Paper data sheets $\quad \square$ Electronic data recorder

Other method (Please describe)

Do not record assessments

What are your successes and challenges with forest regeneration? 
19. How do you define successful forest regeneration?

20. What are some of the signs, indicators, or factors you use to judge successful regeneration?

21. In general, how satisfied have you been with the regeneration you have seen in West Virginia during the past 10 years?
Completely satisfied
Mostly satisfied
Mostly dissatisfied
Completely dissatisfied

22. Of the counties in WV you are familiar with, in which have you seen the most successful forest regeneration? (Please list up to four counties)

1.

2.

23. In the counties in WV where you make most of your observations of regeneration, and in terms of your specific profession, which tree species would you like to see regenerate most abundantly? (Please list up to 3 species)

1.

2.

3.

24. In the counties in WV where you make most of your observations of regeneration, which tree species actually do regenerate most abundantly? (Please list up to 3 species)

1.

2.

3.

25. Have you had any concerns about forest regeneration in West Virginia during the past 10 years?

No (If no, skip to Question 43) $\square$ Yes (If yes, please continue to the next question)

26. Please list your top concern related to forest regeneration in West Virginia. 
27. How strong is this concern?
$\square$ Minor
Moderate
Somewhat serious
$\square$ Very serious

28. What are some of the signs, indicators, or factors that form the basis for this concern?

29. How long have you had this concern? Years

30. In your experience, in which counties is this concern the greatest? (Please list up to four)

1.

2.

3.

4.

31. Do you have another concern related to forest regeneration in West Virginia?

Yes (If yes, please continue) $\square$ No (If no, skip to Question 43)

32. What is your second major concern?

33. How strong is this concern?
$\square$ Minor
Moderate
Somewhat serious
$\square$ Very serious

34. What are some of the signs, indicators, or factors that form the basis for this concern?

35. How long have you had this concern? Years

36. In your experience, in which counties is this concern the greatest? (Please list up to four)

1.

2.

37. Do you have another concern related to forest regeneration in West Virginia?
3.

4 
38. What is your third major concern?

39. How strong is this concern?
$\square$ Minor
Moderate
Somewhat serious
Very serious

40. What are some of the signs, indicators, or factors that form the basis for this concern?

41. How long have you had this concern?

Years

42. In your experience, in which counties is this concern the greatest? (Please list up to four)

1.

2.
3.

4.

43. Please give specific examples of successes or specific examples of concerns related to forest regeneration. Please describe actual species, actual location, site type, forest type, etc.

44. Please use the space below to share any other comments you have related to forest regeneration in West Virginia.

Thank you for participating in this survey. Your responses will be very helpful.

Please return your completed survey in the enclosed postage-paid return envelope.

If you would like a summary of the results from this survey, please check the box at the start of the survey on Page One. Please also indicate if you would like to participate in a follow-up focus group. 